\title{
TOWARD THE SYNTHESIS OF NOVEL BENZISOSELENAZOLONES
}

\author{
by Vassilios Kanellis \\ Bachelor of Science Chemistry, \\ Ryerson University Toronto, ON, Canada, 2012
}

\begin{abstract}
A thesis presented to Ryerson University in partial fulfillment of the requirements for the degree of Master of Science in the Program of Molecular Science
\end{abstract}

Toronto, Ontario, Canada, 2016

CV Vassili Kanellis 2016 
Author's Declaration

I hereby declare that I am the sole author of this thesis. This is a true copy of the thesis, including any required final revisions, as accepted by my examiners.

I authorize Ryerson University to lend this thesis to other institutions or individuals for the purpose of scholarly research

I further authorize Ryerson University to reproduce this thesis by photocopying or by other means, in total or in part, at the request of other institutions or individuals for the purpose of scholarly research.

I understand that my thesis may be made electronically available to the public. 


\begin{abstract}
Ebselen is a synthetic selenium-containing organic compound that has been studied as a potential treatment for a number of conditions. Ebselen is an antioxidant, capable of scavenging peroxide and other reactive oxygen species. This research is focused on the preparation of novel ebselen derivatives towards biologically active compounds with tunable redox properties and pharmacokinetics. Currently we are exploring different synthetic routes towards ebselen, which are compatible with desired modifications to the ebselen scaffold including replacement of the phenyl group with different aryl or heteroaryl moieties, as well as functional group substitution on the benzisoselenazolone ring. The pathways investigated include a recently published transition metal-mediated method as well as a novel approach using isocyanates.
\end{abstract}




\section{Acknowledgements}

I would like to thank my supervisor, Dr. Viirre, for his unwavering support. I'd also like to thank my committee members, Dr. Robert Gossage and Dr. Stephen Wylie, for their feedback and assistance; Nande Wright for her assistance, patience and friendship; and my former and current lab mates, Bashar Alkhouri, Robert Denning, Daniyl Oleynik and Kevin Paul for helping make the lab a pleasant place to work. I would also like to thank my grandparents, Katina and Vasili Kanellis and Daphne Edmunds; my mother, Monica; my father, Steve; and my brother, Demetri. Lastly I would like to mention my friends Glen-Thomas Totton, Hardeep Bhachhoo, Zahraa Kerawala and all my friends in East York who made life a little more enjoyable with their good humour and support. 


\section{Table of Contents}

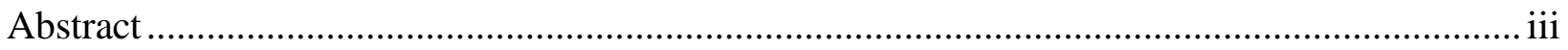

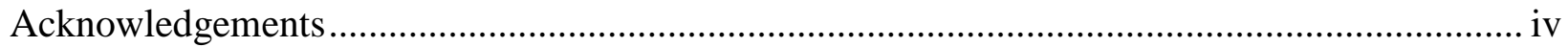

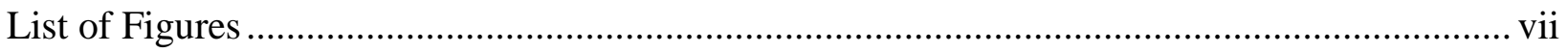

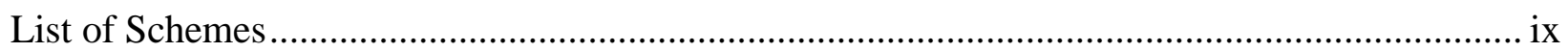

List of Tables ..................................................................................................................

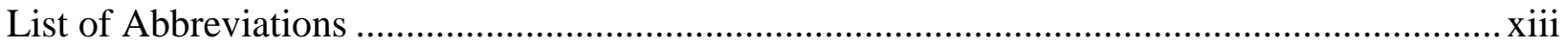

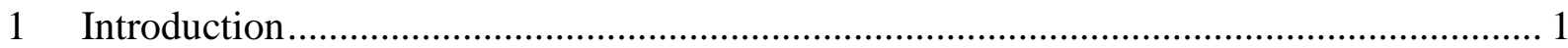

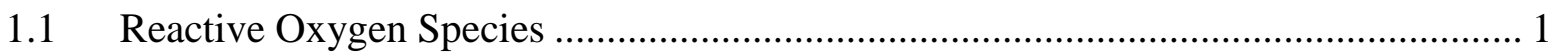

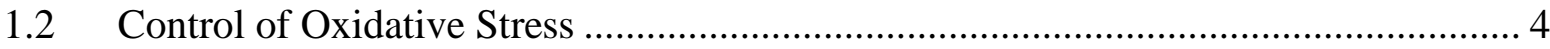

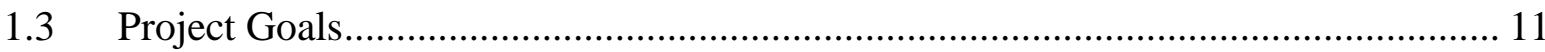

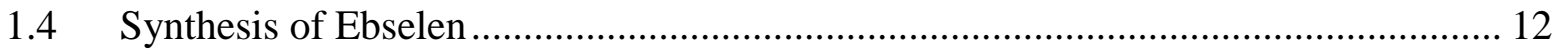

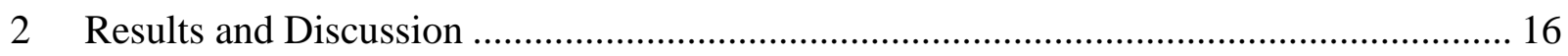

2.1 Attempting the Cross-Coupling Procedure …….......................................................... 16

2.2 Attempts at Ebselen via Directed Lithiation............................................................. 22

2.3 Attempts at Ebselen via Diazonium Displacement ..................................................... 30

2.4 Possible Route From $o$-lithiation of Protected Selenol ........................................... 34

2.5 Possible Route via C-H Bond Activation ..................................................................... 41

2.6 Generation of Selenium Nucleophiles .................................................................. 43

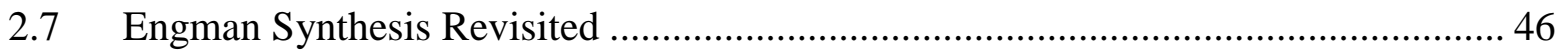




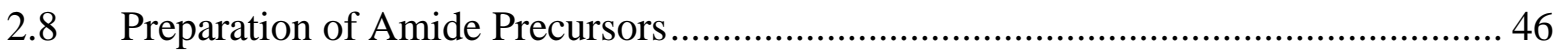

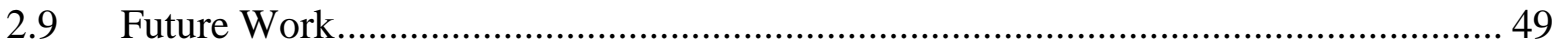

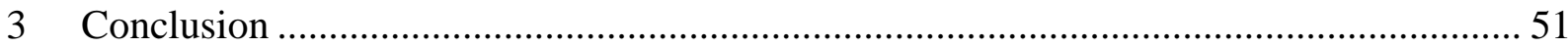

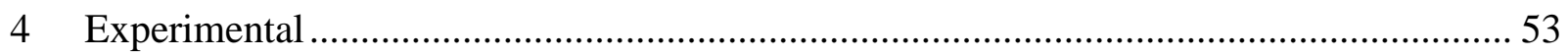

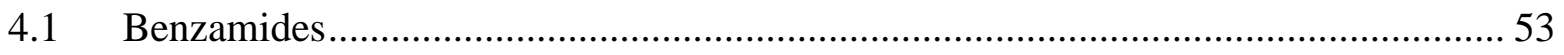

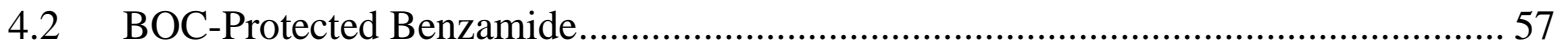

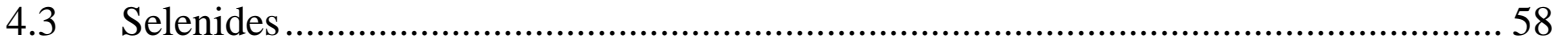

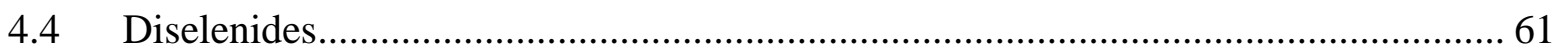

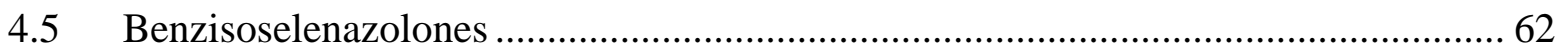

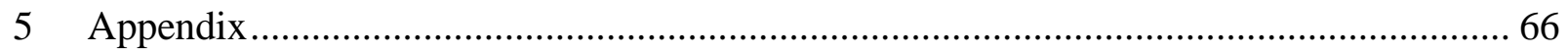

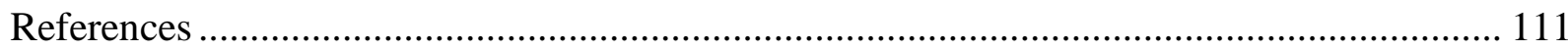




\section{List of Figures}

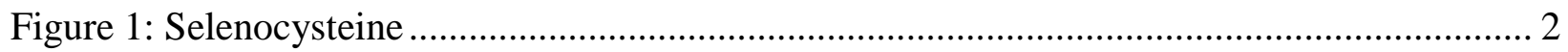

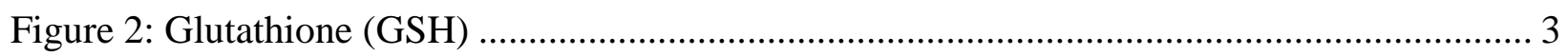

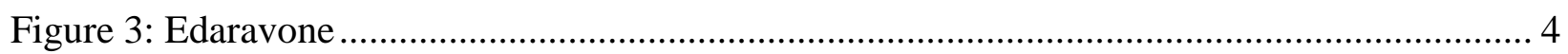

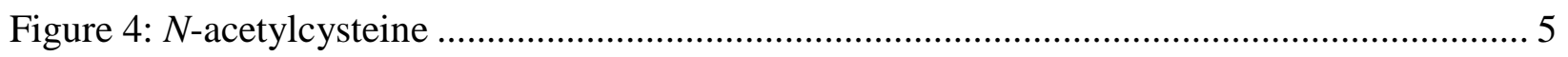

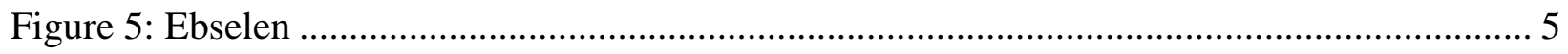

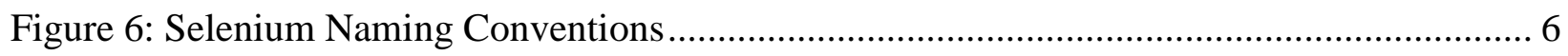

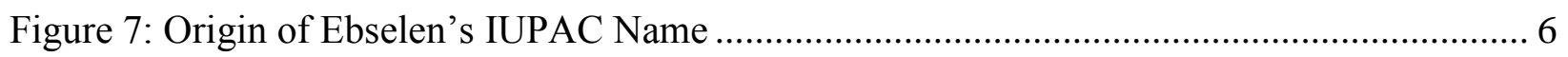

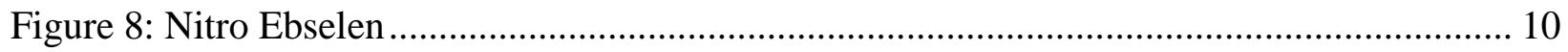

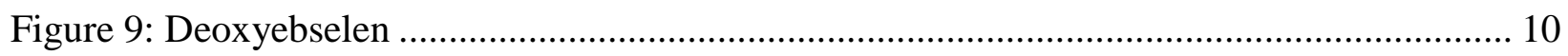

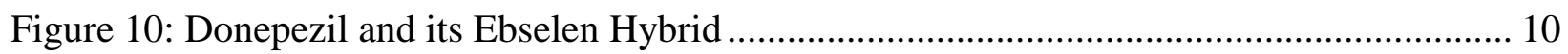

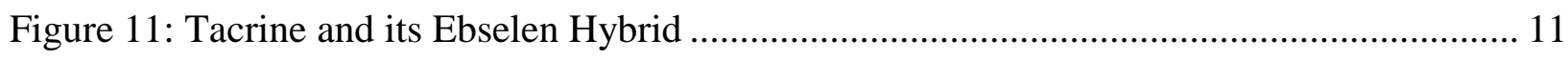

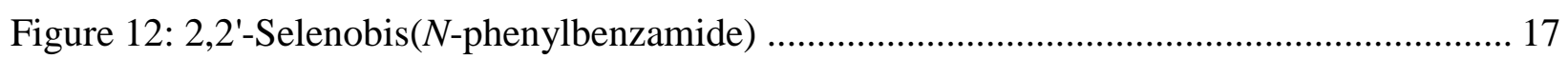

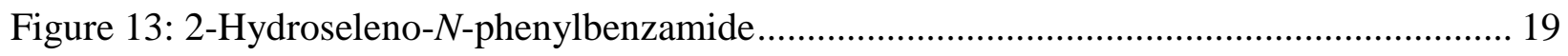

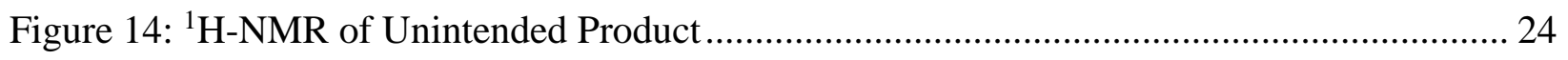

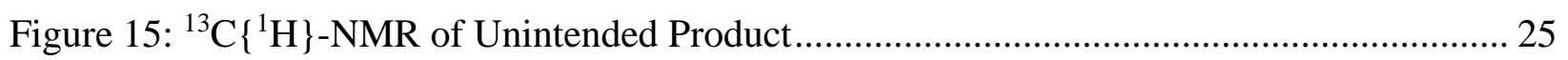

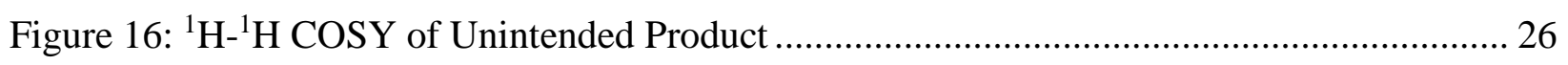

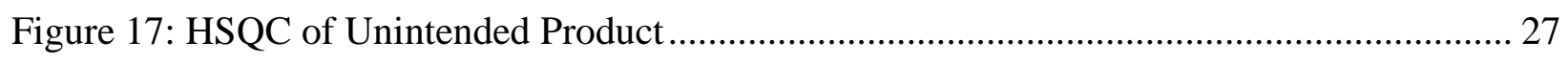

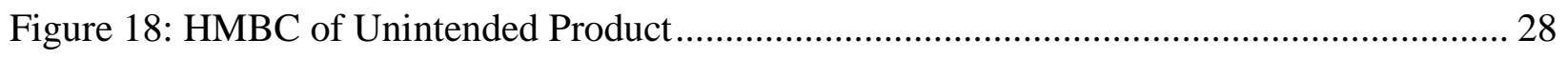

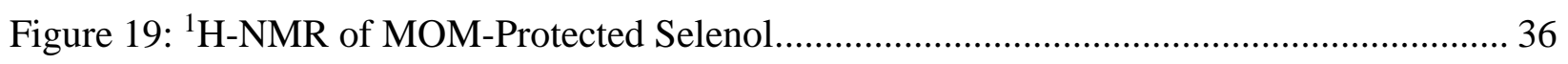

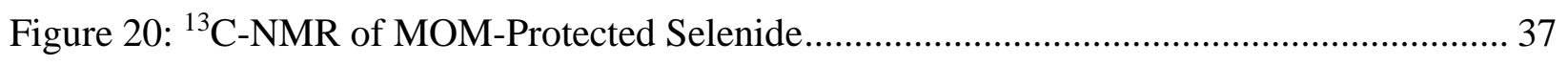

Figure 21: Expansion of 1H-NMR Spectrum for 4-t-butylphenyl MOM Selenide....................... 38

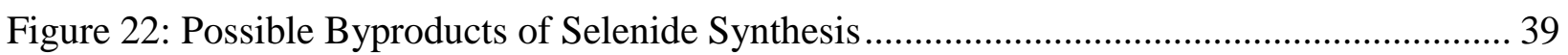


Figure 23: ${ }^{1} \mathrm{H}-\mathrm{NMR}$ of Crude Product in DMSO

Figure 24: ${ }^{1} \mathrm{H}-\mathrm{NMR}$ of Crude Amide in DMSO $+\mathrm{D}_{2} \mathrm{O}$

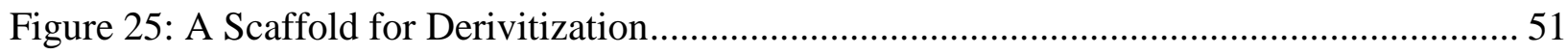




\section{List of Schemes}

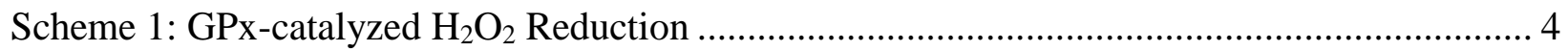

Scheme 2: The Relationship Between Ebselen and its Corresponding Selenol ............................. 7

Scheme 3: Proposed Mechanism of Ebselen's Activity ……....................................................... 7

Scheme 4: Proposed Mechanism of Diselenide GPx Mimicry .................................................... 8

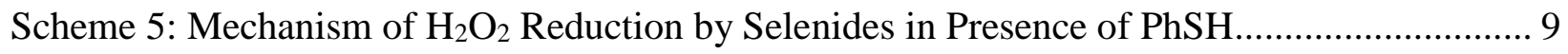

Scheme 6: Original Ebselen Synthesis from Anthranilic Acid.................................................. 12

Scheme 7: Synthesis of Ebselen from Benzanilide...................................................................... 12

Scheme 8: A Cross-Coupling Route Toward Ebselen ............................................................ 13

Scheme 9: Synthesis of an Aryl Sulfide via C-H Bond Activation .............................................. 14

Scheme 10: Synthesis of an Aryl Amide via Directed $o$-Lithation ........................................... 14

Scheme 11: Proposed Route to Benzisoselenazolones ……………......................................... 15

Scheme 12: A Cross-Coupling Route Toward Ebselen ............................................................... 16

Scheme 13: First Generation Buchwald-Hartwig Precatalysts Used in Cross-Coupling ............. 17

Scheme 14: Balkrishna's Unintended Selenide Synthesis............................................................ 19

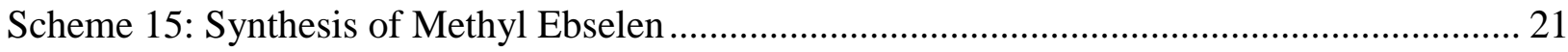

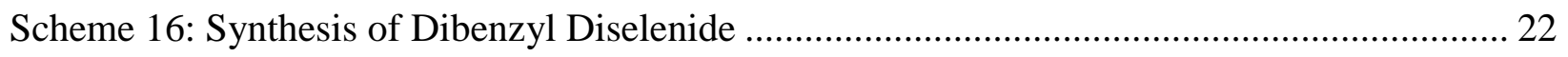

Scheme 17: Synthesis of Ebselen from Benzanilide............................................................. 22

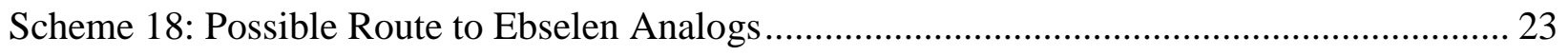

Scheme 19: Unexpected Result of Benzamide Cyclization Attempt in THF ............................... 24

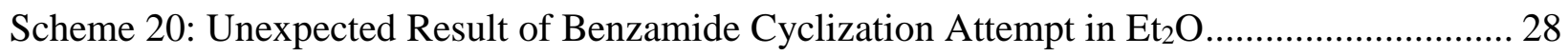

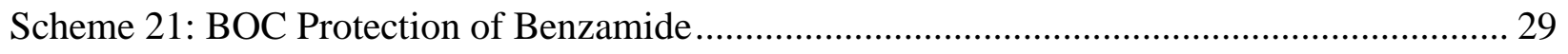

Scheme 22: Attempted Cyclization of $N$-BOC Benzamide ......................................................... 29 
Scheme 23: Synthesis of a Methyl Derivative of Ebselen ...................................................... 30

Scheme 24: Original Ebselen Synthesis from Anthranilic Acid................................................ 31

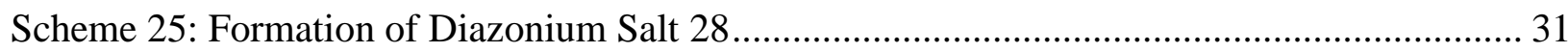

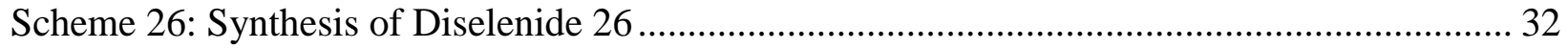

Scheme 27: Attempt at Organic Diazonium Formation ........................................................... 32

Scheme 28: Mechanism of the Reduction of Selenium by Rongalite ........................................ 33

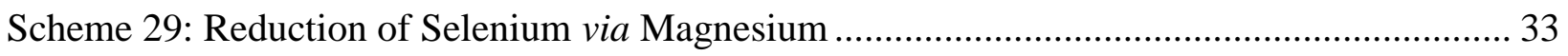

Scheme 30: Synthetic Route Toward MOM-Protected Phenyl Selenols......................................... 34

Scheme 31: Literature Synthesis of Phenyl Selenol via Selenyl Grignard Formation .................. 34

Scheme 32: Proposed Benzisoselenazolone Synthesis from Protected Selenol 37 ....................... 35

Scheme 33: Literature Procedure for Directed Lithiation Followed by Isocyanate Quench ........ 39

Scheme 34: Attempted ortho-lithiation/Aromatic Substitution..................................................... 40

Scheme 35: Test to Indicate Whether or not $o$-Lithiation Occurred.............................................. 41

Scheme 36: Published Reaction Between MOM-protected Selenol and BuLi.............................. 41

Scheme 37: Sulfenylation of a Carbazole via C-H Activation ..................................................... 42

Scheme 38: C-H Activation Experiment on a Pyrimidinyl Benzamide …................................... 42

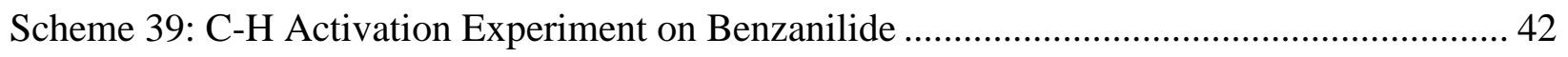

Scheme 40: CuI/phen-Free Literature Benzisoselenazolone Synthesis......................................... 44

Scheme 41: Synthesis of Ebselen via Selenium Reduced by Hydrazine ...................................... 46

Scheme 42: Proposed Synthetic Pathway Toward Novel Ebselen Derivatives............................. 46

Scheme 43: Cyclization of Target Diamide to Yield a Novel Ebselen Derivative........................ 47

Scheme 44: Synthesis of 4-(4-methylbenzamido)benzoic acid .................................................... 47

Scheme 45: Analysis of Substituent Effect on Selenide Formation ........................................... 50 
Scheme 46: Possible Route to Ebselen Analogs via CuI and Pd-Catalyzed Cross-Coupling ...... 50

Scheme 47: Palladium Catalyzed Ebselen Synthesis............................................................ 51 


\section{List of Tables}

Table 1: The Effects of Solvents and Ligands on the CuI Catalyzed Ebselen Synthesis ............ 20

Table 2: The Effects of Bases on the CuI Catalyzed Ebselen Synthesis ................................. 21

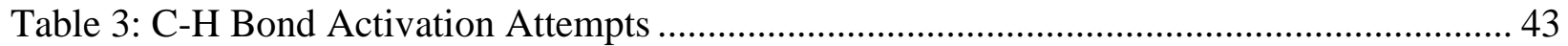

Table 4: Attempts at Synthesizing Ebselen via Generation of Selenium Nucleophiles .............. 45 


\section{List of Abbreviations}

bipy: 2,2'-bipyridine

BOC: $t$-butyloxycarbonyl

DACH: 1,2-diaminocyclohexane

DCM: dichloromethane

DMF: dimethylformamide

DMG: Directed Metalating Group

DMAP: $N, N$-dimethylaminopyridine

DoM: Directed ortho Metalation

GPx: Glutathione Peroxidase

GSH: Glutathione

HMDS: bis(trimethylsilyl)amine

MOM: methoxymethyl ether

NAC: $N$-acetylcysteine

NADPH: Nicotinamide adenine dinucleotide phosphate

PABA: $p$-aminobenzoic acid

PEG: Polyethylene glycol

phen: 1.10-phenanthroline

ROS: Reactive Oxygen Species 
SOD: Superoxide Dismutase

TLC: thin layer chromatography

tmeda: tetramethylethylenediamine

Trx: Thioredoxin 


\section{Introduction}

\subsection{Reactive Oxygen Species}

Reactive oxygen species (ROS) are highly reactive oxygen containing chemical species that are known to react destructively with various essential cell components such as lipids, proteins and DNA. ${ }^{1}$ Excessive levels of ROS such as superoxide $\left(\mathrm{O}_{2}{ }^{-1}\right)$, peroxynitrite $\left(\mathrm{ONOO}^{-1}\right)$ and hydrogen peroxide $\left(\mathrm{H}_{2} \mathrm{O}_{2}\right)$ are implicated in various age-related diseases, such as cancer, Parkinson's and diabetes. $^{2,3}$ These ROS are naturally produced by aerobic organisms during essential cellular processes such as metabolism. ${ }^{3,4}$ Mitochondria process oxygen and as a result they are responsible for the production of a large percentage of a cell's ROS. Oxidative damage to the mitochondria, as well as to DNA, is associated with aging. The production of ROS and the damage associated with them is also known to increase with age. ${ }^{3}$ The rapid aging of small animals compared to large ones is often attributed to their higher rate of metabolic activity, and therefore greater production of ROS. ${ }^{4}$ Due to the damage they are associated with causing, ROS were initially assumed to be unwanted yet unavoidable byproducts of vital biological reactions. However, more recent research shows that ROS production is necessary for various cell signalling pathways as well as for proper immune system function. ${ }^{5}$ The hydroxyl radicals $(\mathrm{OH} \bullet)$ formed by the decomposition of intracellular hydrogen peroxide cause oxidative damage and cell signalling issues which lead to disease, but if the concentration of hydrogen peroxide is too low, problems arise with cell signalling and homeostasis is lost. ${ }^{1}$ Reactive oxygen species are also necessary for the destruction of bacteria by macrophages and to control the release of insulin by

pancreatic cells. ${ }^{3}$ Antioxidants, which act as ROS scavengers, have been promoted heavily as a method of protecting against oxidative stress. The role of ROS in an organism is complex, and studies of lower organisms such as flies and worms have shown an increase in lifespan when 
their internal ROS levels are increased. ${ }^{1,3}$ In order to keep ROS at a healthy concentration, all organisms contain antioxidant systems to neutralize excess ROS. ${ }^{6}$

\subsubsection{Endogenous Antioxidants}

The production of ROS in cells is ubiquitous and several antioxidant enzymes exist to neutralize them before they can react with essential cell components. The superoxide dismutase (SOD) family of proteins catalyzes the conversion of superoxide to hydrogen peroxide. ${ }^{1}$ This hydrogen peroxide then goes on to be converted to water through the action of intracellular peroxidases. These intracellular peroxidases have a redox active functionality in their active site which facilitates their oxidation. Some examples include catalase, which contains an iron in its active site, peroxiredoxins which contain cysteines in their active sites and glutathione peroxidases (GPx) which contain selenocysteines in their active sites. A related enzyme, thioredoxin (Trx), has the role of reducing (thus regenerating) active site disulfides/diselenides of peroxidases, allowing them to react once again with ROS. By disabling these enzymes, biochemists can cause a buildup of hydrogen peroxide in order to study the effect of ROS. ${ }^{3}$

\subsubsection{Glutathione Peroxidase and Selenoproteins}

Selenium was not known to be an essential trace element until the first isolation of a selenoprotein in the 1970's where it was discovered as part of the active site of GPx in the form of selenocysteine (Figure 1).<smiles>N[C@@H](C[SeH])C(=O)O</smiles>

Figure 1: Selenocysteine 
Selenocysteine is the selenium analog of the sulfur containing amino acid cysteine. It is considered the $21^{\text {st }}$ amino acid yet it is not coded for directly in DNA. Sulfur and selenium are both chalcogens with similar chemical properties, and thus many cysteine containing enyzmes will behave the same way if cysteine is replaced by selenocysteine. However, selenocysteine has a lower reduction potential than cysteine, and the selenol functionality has a lower $\mathrm{p} K_{\mathrm{a}}$ than thiols, These properties are crucial for the antioxidant activity of selenoenzymes and selenoproteins and distinguishes them from their sulfur counterparts. ${ }^{7}$ For these reasons, elemental selenium, a precursor for the biosynthesis of selenoenzymes and selenoproteins, has been linked to various health benefits such as a decreased risk of cancer. ${ }^{8}$

The glutathione peroxidases, using glutathione (GSH, Figure 2) as a substrate, act as a natural defense against ROS. ${ }^{9}$<smiles>N[C@@H](CCC(=O)N[C@@H](CS)C(=O)NCC(=O)O)C(=O)O</smiles>

Figure 2: Glutathione (GSH)

All four of the unique GPx that have been identified in mammals contain selenocysteine in their active site. ${ }^{10}$ This selenium atom is essential for its activity; exchanging it for sulfur has been shown to cause a drop in activity by $2-3$ orders of magnitude. ${ }^{11}$ Scheme 1 illustrates the catalytic cycle of GPx. The active site selenol of GPx reduces a hydroperoxide, being itself oxidized to the corresponding selenenic acid. The selenenic acid then reacts with glutathione creating a selenylsulfide which can be reduced back to a selenol by reaction with another molecule of glutathione, creating the disulfide dimer. This dimer can then go on to be reduced by 
nicotinamide adenine dinucleotide phosphate (NADPH) into two units of GSH via an enzyme catalyzed reaction.

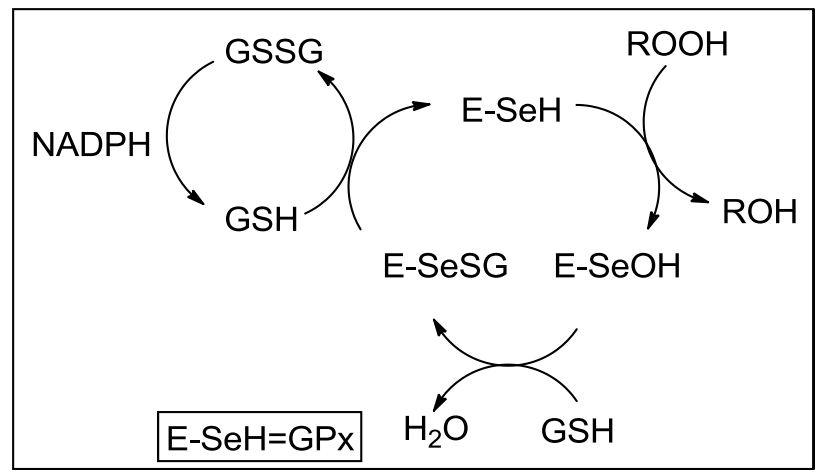

\section{Scheme 1: GPx-catalyzed $\mathrm{H}_{2} \mathrm{O}_{2}$ Reduction}

\subsection{Control of Oxidative Stress}

Since ROS are present to some extent in healthy cells, and since organisms have a variety of ways to neutralize these species, it is difficult to obtain statistically relevant data when testing the efficacy of an antioxidant drug. Nevertheless, various antioxidants are being used as treatments for the damage caused by excess ROS. $^{2}$ Experiments have been performed where the enzyme SOD was administered to patients. Esters of glutathione have also been synthesized, the ester group improving membrane transport. One of the first drugs approved as an ROS scavenger was edaravone (Figure 3$)^{2}$

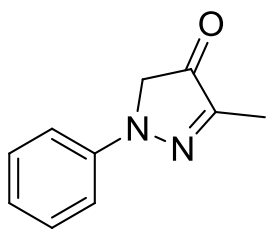

Figure 3: Edaravone

Another well-known antioxidant is $\mathrm{N}$-acetylcysteine (NAC) (Figure 4). ${ }^{2}$ 
<smiles>CC(=O)NC(CS)C(=O)O</smiles>

\section{Figure 4: $N$-acetylcysteine}

The synthesis of GSH within cells relies on cysteine as a limiting precursor and as such administration of NAC raises intracellular GSH. $\mathrm{N}$-acetylcysteine also behaves as an antioxidant on its own. Its antioxidant ability is aided by the nucleophilicity of its thiol functionality and by redox interactions with other chalcogens. ${ }^{12}$ A promising and rapidly growing class of antioxidants are the organochalcogen enzyme mimetics. Ebselen (Figure 5) was the first such compound shown to exhibit GPx mimicry but since its discovery a variety of different GPx mimics have been synthesized.

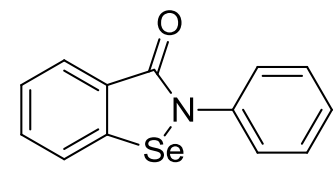

Figure 5: Ebselen

\subsubsection{A Brief Overview of Organoselenium Nomenclature}

Organoselenium nomenclature parallels that of organosulfur. Figure 6 shows some common bonding arrangements of selenium and the names attributed to them. 


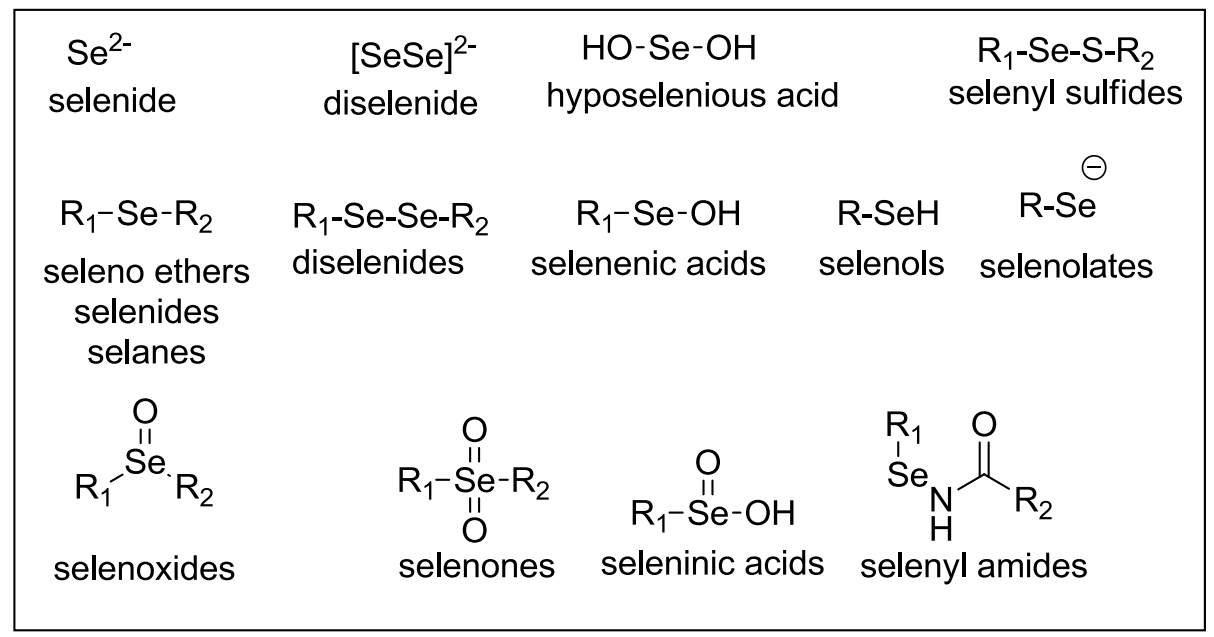

\section{Figure 6: Selenium Naming Conventions}

Ebselen is a benzisoselenazolone and therefore a selenyl amide. The name benzisoselenazolone is derived from oxazole. Substituting oxygen for the heavier chalcogen selenium gives a selenazole. The addition of a carbonyl oxygen would make a selenazolone and the fusion of a benzene ring gives a benzisoselenazolone (Figure 7).

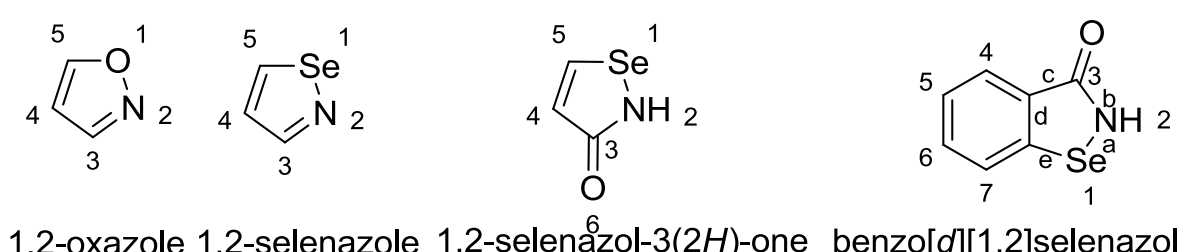

1,2-oxazole 1,2-selenazole 1,2-selenázol-3(2H)-one benzo[d][1,2]selenazol-3(2H)-one

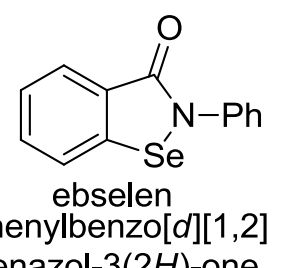

\section{Figure 7: Origin of Ebselen's IUPAC Name}

\subsubsection{Ebselen and Other Selenyl Amides}

Ebselen is the first selenium compound shown to exhibit minimal toxicity in rats LD $_{50} 110$ $\mathrm{mg} / \mathrm{kg}) .{ }^{13}$ It is a lipid soluble benzisoselenazolone/selenyl amide that is an antioxidant and a GPX mimic. ${ }^{12}$ It also has been found to have antioxidant, anti-inflammatory and anti-cancer 
properties. ${ }^{11}$ Originally, researchers were hesitant about its potential as a medicine due to the toxicity associated with organoselenium compounds. It was first assumed that it functioned by providing a bioavailable source of selenium to aid cells in GPx synthesis, however tests on cells with depleted GPx did not show restored GPx activity upon administration of ebselen. ${ }^{14}$ Many mechanisms have been proposed to explain the pharmacology of ebselen, usually showing ebselen being reduced to the corresponding selenol (Scheme 2), and then going through a variety of transformations until being regenerated.<smiles>O=c1c2ccccc2[se]n1-c1ccccc1</smiles><smiles>C</smiles><smiles>O=C(Nc1ccccc1)c1ccccc1S(=O)(=O)c1ccccc1</smiles>

\section{Scheme 2: The Relationship Between Ebselen and its Corresponding Selenol}

Recent DFT calculations however suggest that ebselen is never reformed and instead cycles between a selenol, selenyl sulfide, and selenenic acid form. ${ }^{11}$

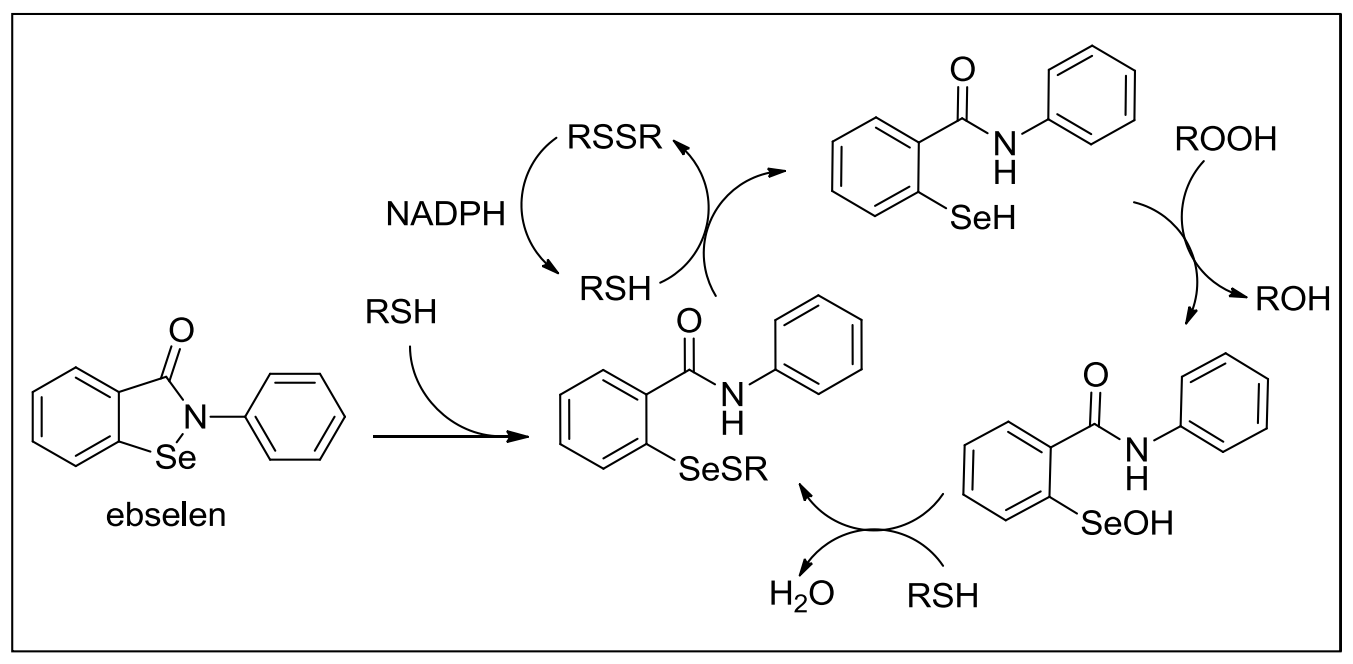

Scheme 3: Proposed Mechanism of Ebselen's Activity 
As shown in Scheme 3, ebselen reacts with an endogenous thiol (RSH) to form the open ring selenyl sulfide. This can react with another thiol, generating a selenol and disulfide (RSSR). The selenol is the active antioxidant and reduces a molecule of hydrogen peroxide (or another ROS), generating water and a selenenic acid. The cycle then continues when the selenenic acid reacts with another thiol, generating water and another selenyl sulfide. ${ }^{11}$

\subsubsection{Diselenides}

Diaryl diselenides also function as GPx mimics. It was originally thought that the Se-N bond was necessary for ebselen's effect due to its low bond strength, but in $1989 \mathrm{~N}, \mathrm{~N}$-dimethylbenzyl amine diselenide (see Scheme 4), which lacks a Se-N covalent bond, was found to have peroxidase activity an order of magnitude greater than that of ebselen. ${ }^{11,15}$

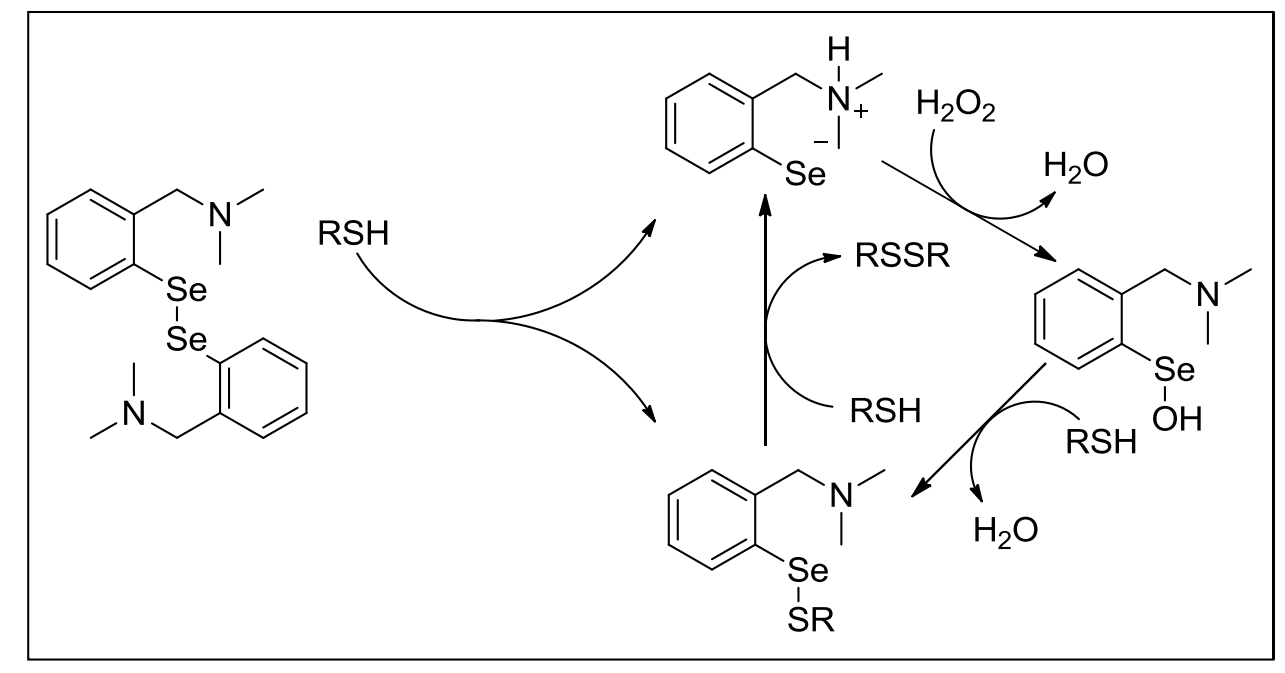

Scheme 4: Proposed Mechanism of Diselenide GPx Mimicry

Scheme 4 is an example of a mechanism proposed for the GPx activity of diselenides. As with ebselen, the active antioxidant is in the form of a selenol/selenolate. As diaryl diselenides are easier to synthesize than benzisoselenazolones, it would be useful to develop their potential as antioxidants. 


\subsubsection{Selenides}

Dialkyl and diaryl diselenides have also been shown to exhibit peroxidase activity. Interestingly, the proposed mechanism of their behaviour (Scheme 5) does not involve a selenol/selenolate. ${ }^{11}$

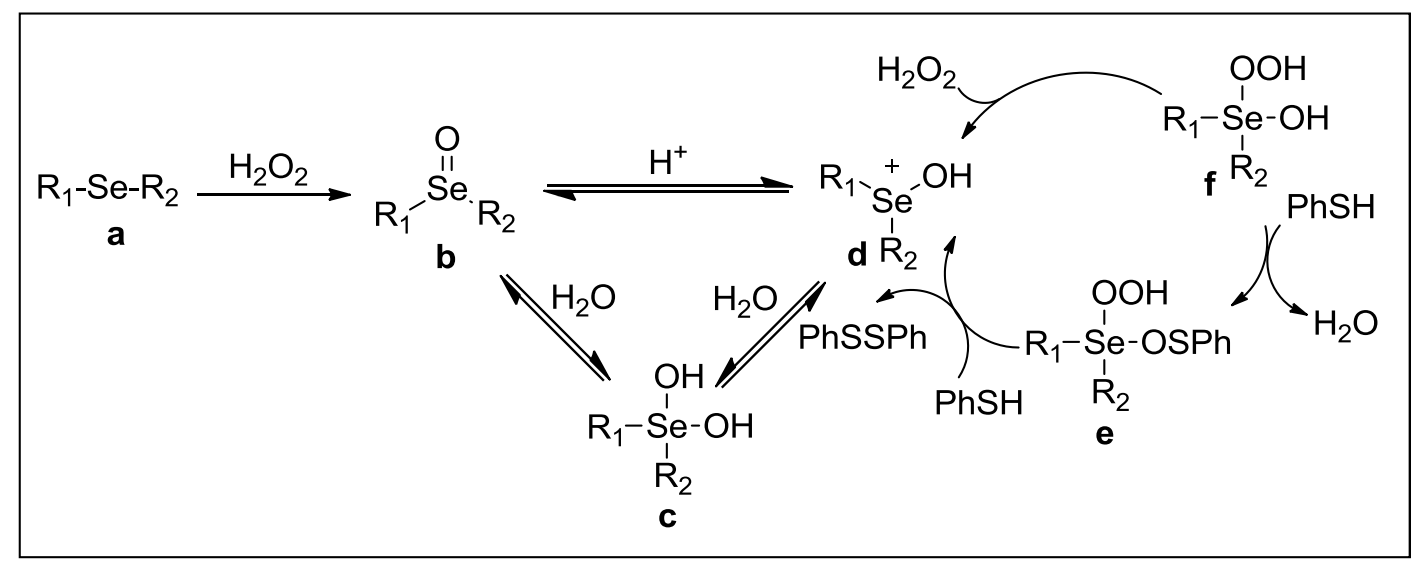

\section{Scheme 5: Mechanism of $\mathrm{H}_{2} \mathrm{O}_{2}$ Reduction by Selenides in Presence of PhSH}

As shown in Scheme 5, the active antioxidant is thought to be a hydroxyl perhydroxy selane (i.e,

f). Unlike benzisoselenazolones and diselenides which need to be reduced before they can function as anti-oxidants, selenides (a) must first be oxidized to the corresponding selenoxide (b), a slow step which limits their catalytic activity.

\subsubsection{Existing derivatives}

A large variety of selenides, diselenides and selenyl amides have been synthesized in order to study their GPx mimicry. A $\mathrm{NO}_{2}$ group ortho to selenium (Figure 8) has been found to increase activity although it is uncertain whether it does this by electron withdrawing ability or by providing steric bulk around selenium. ${ }^{16}$ 
<smiles>O=c1c2cccc([N+](=O)[O-])c2[se]n1-c1ccccc1</smiles>

\section{Figure 8: Nitro Ebselen}

The replacement of the carbonyl group with a methylene unit (Figure 9) decreases the activity of benzisoselenazolones by an order of magnitude. ${ }^{16}$<smiles>c1ccc(PN2Cc3ccccc3[Se]2)cc1</smiles>

\section{Figure 9: Deoxyebselen}

Research is also being done into creating hybrid molecules, where the ebselen moiety is part of a larger medicinal compound. Due to Alzheimers being related to ROS, researchers have created hybrid molecules of the Alzheimers drug donepezil and ebselen (Figure 10). ${ }^{17}$
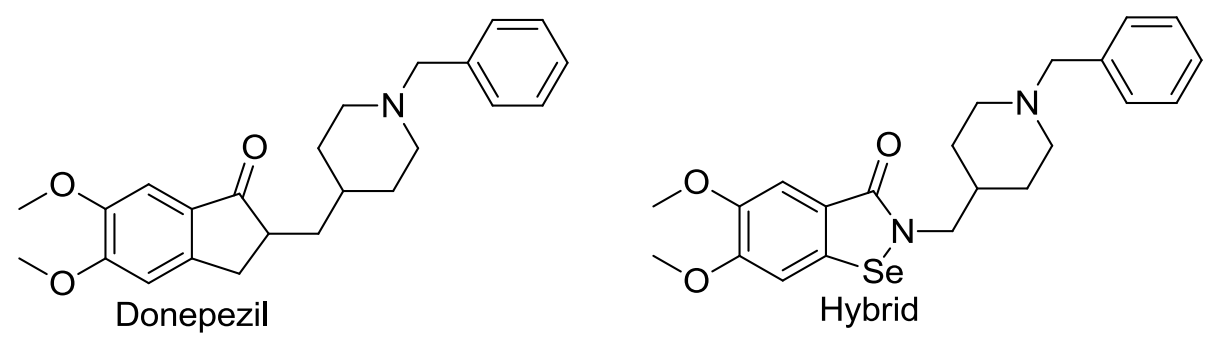

Figure 10: Donepezil and its Ebselen Hybrid

Hybrids of tacrine (Figure 11), a cholinesterase inhibitor also used for Alzheimers have also been reported. ${ }^{18}$ 

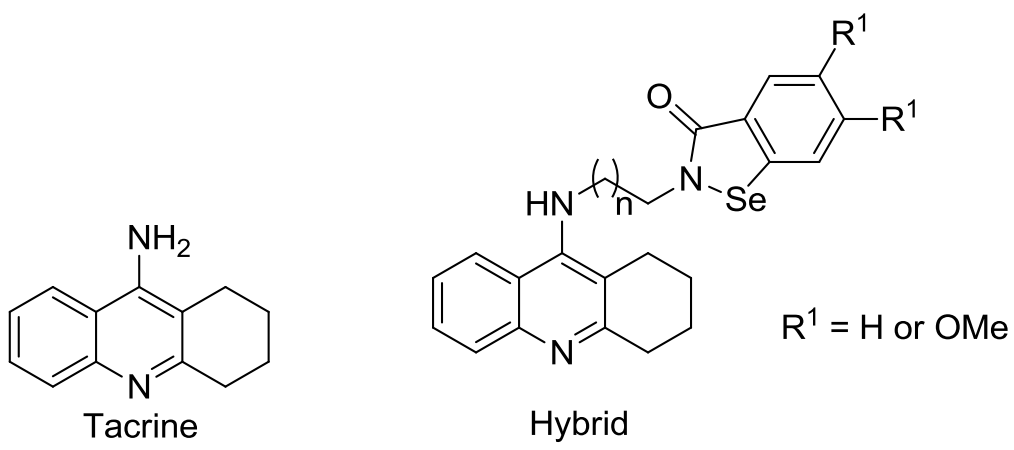

\section{Figure 11: Tacrine and its Ebselen Hybrid}

Ideally, these strategies would lead to the discovery of a single drug that could be administered to a patient that performs multiple unique functions inside the body.

\subsubsection{Limitations and Challenges}

While organoselenium compounds hold promise in the field of pharmacology, they are not substrate specific and because of this they can cause unpredictable biological effects. The exposed selenium atom allows for unintended reactions with thiols within the body. An excess of GPx mimics can also disrupt signalling pathways. Structural changes that increased the activity of ebselen type compounds were also shown to increase the toxicity. ${ }^{11}$ Until recently this class of compounds were considered to have no medicinal value and were known for being toxic, difficult to purify and extremely malodourous and hence progress in the field was slow. ${ }^{19}$ It is likely that the increasing interest in this field will lead to discoveries that will overcome these limitations.

\subsection{Project Goals}

The goal of this project is to synthesize a library of previously unreported analogs of ebselen, in addition to developing a reliable synthetic procedure, to provide tools towards the evaluation of their biological activity. 


\subsection{Synthesis of Ebselen}

\subsubsection{From Anthranilic acid}

Ebselen was first synthesized by Weiss in 1922 in 3 steps from anthranilic acid (Scheme 6). ${ }^{20}$

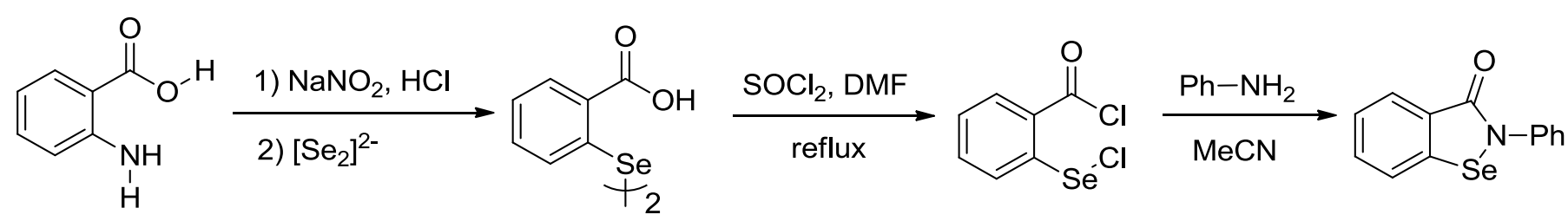

\section{Scheme 6: Original Ebselen Synthesis from Anthranilic Acid}

Despite being the most common method of synthesizing ebselen, it is known to produce the lowest yields compared to other literature methods. Due to the multistep nature of this protocol, it is less ideal for the synthesis of ebselen and its derivatives as it requires more time and resources than more elegant methods.

\subsubsection{From Benzanilide}

In 1989, Engman et al. published a one-pot synthesis of ebselen from benzanilide (Scheme 7). ${ }^{21}$

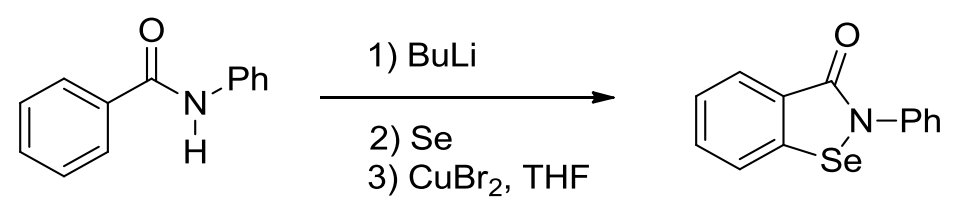

\section{Scheme 7: Synthesis of Ebselen from Benzanilide}

This procedure allows for a fast, simple synthesis of ebselen, however, benzanilide cannot be substituted with anything that is sensitive to butyl lithium. 


\subsubsection{From $o$-halobenzanilides}

A cross-coupling synthesis of ebselen was published in 2010 by Balkrishna et al. ${ }^{22}$

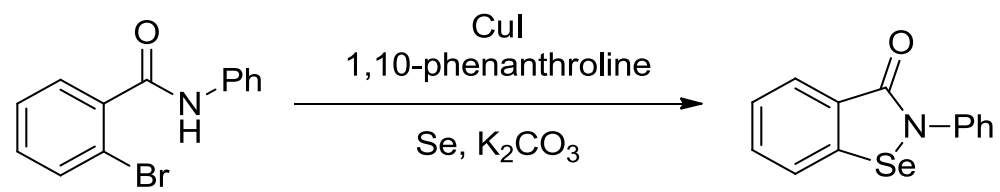

\section{Scheme 8: A Cross-Coupling Route Toward Ebselen}

This synthetic procedure holds a lot of promise for the synthesis of novel compounds. A variety of substitutions should be able to tolerate the reaction conditions, making it ideal for the synthesis of new ebselen derivatives.

\subsubsection{Novel Approaches}

During the course of research, several unpublished synthetic routes towards ebselen derivatives were pursued.

\subsubsection{C-H Bond Activation}

Carbon-hydrogen bond activation reactions are synthetically useful methods of functionalizing unsubstituted saturated and unsaturated organic compounds. Typically unreactive, an unsubstituted (C-H) aryl carbon can be functionalized after the generation of an organometallic species. A recent example of this class of reactions was reported by Qui et al. in 2015 and is shown in Scheme 9.23 


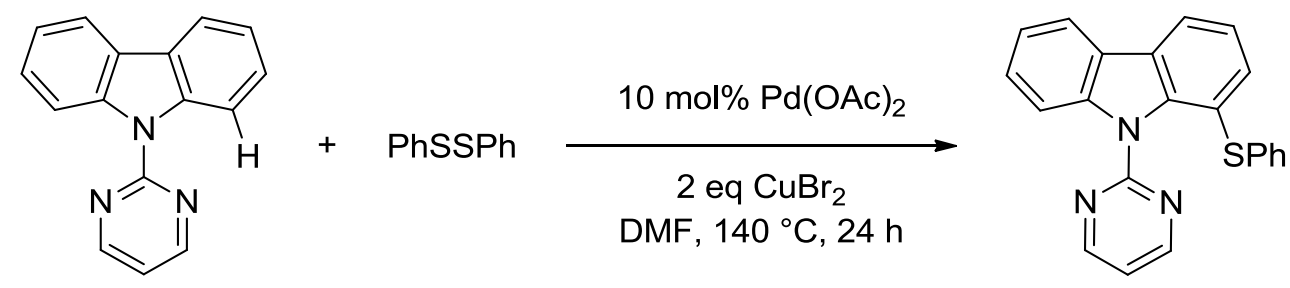

\section{Scheme 9: Synthesis of an Aryl Sulfide via C-H Bond Activation}

In our search for a reliable procedure to synthesize ebselen analogs, this type of methodology will be applied in an effort to substitute aromatic hydrogens with selenium.

\subsubsection{Directed ortho Metalation}

Directed ortho metalation (DoM) is a process by which a reaction can be regioselective for the ortho position. It involves the use of a strong alkyl lithium base as well as a directed metalating group (DMG) on the aromatic ring being substituted. The directed metalating group first coordinates with the alkyl lithium which deprotonates the ortho position. The o-lithiated intermediate is stabilized by coordination with the DMG. The addition of an electrophile leads to substitution at the desired (ortho) position. ${ }^{24}$ Alcohols protected with the MOM protecting group have been shown to ortho direct lithation (Scheme 10). ${ }^{25}$
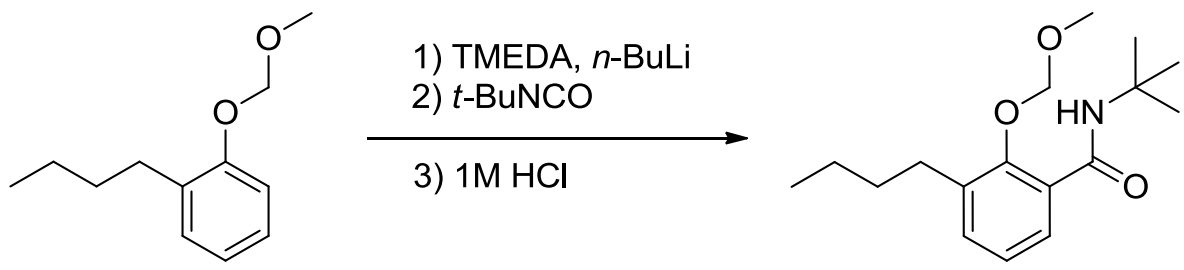

\section{Scheme 10: Synthesis of an Aryl Amide via Directed o-Lithation}

It was thought that a variety of $N$-substituted derivatives of ebselen could be synthesized through substitution of a phenyl selenide compound with different isocyanates (Scheme 11). 


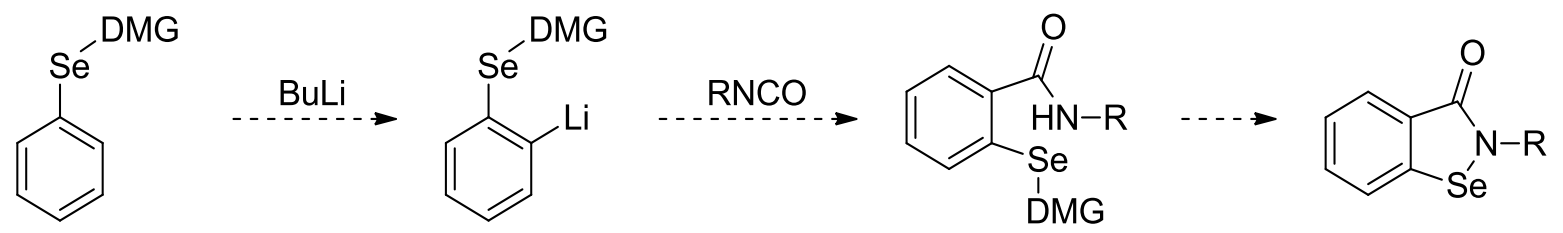

\section{Scheme 11: Proposed Route to Benzisoselenazolones}

This could potentially be achieved by starting with a phenyl selenide that contains an $o$ metalating group. Once the phenyl selenide is synthesized, it could be used as a precursor for various $N$-functionalized derivatives simply by reacting the $o$-lithiated compound with different isocyanates. 


\section{Results and Discussion}

\subsection{Attempting the Cross-Coupling Procedure}

In 2010, a copper-catalyzed cross coupling synthesis of benzisoselenazolones was reported by Balkrishna (Scheme 12). ${ }^{22}$

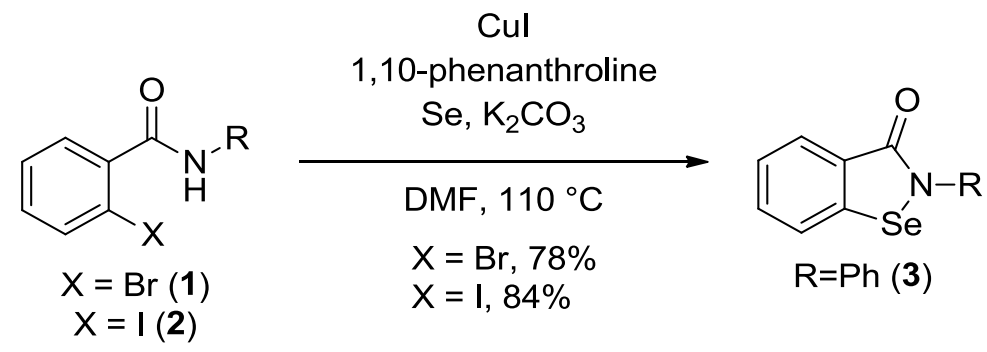

\section{Scheme 12: A Cross-Coupling Route Toward Ebselen}

Originally, our main objective was to apply this method to the synthesis of various analogs of ebselen in order to have them tested for their biological properties. The precursor amides were synthesized in good to moderate yield from their corresponding benzoyl chlorides (see section 4.1) Yields of over $80 \%$ are reported in the literature for the cross coupling reaction but attempts at reproducing these results led to substantially lower yields. A significant portion of the starting material was consumed to form a side-product that was difficult to separate from the synthesized ebselen and no reaction conditions were found that eliminated the production of the side-product. Even with a TLC rf separation of over 0.1 ( 0.27 and 0.13 for the side-product and ebselen in chloroform, respectively) it was difficult to obtain clean ebselen by column chromatography. This was apparent by the characteristic amido singlet at $10.43 \mathrm{ppm}$ in the ${ }^{1} \mathrm{H}-\mathrm{NMR}$ spectrum. ${ }^{26}$ This is possibly due to of the poor solubility of the side product in the column solvent. It was not until a method of purifying the side product was developed that the side-product was identified as 2,2'-selenobis( $N$-phenylbenzamide) (Figure 12) via ${ }^{1} \mathrm{H}-\mathrm{NMR} .{ }^{26}$ 


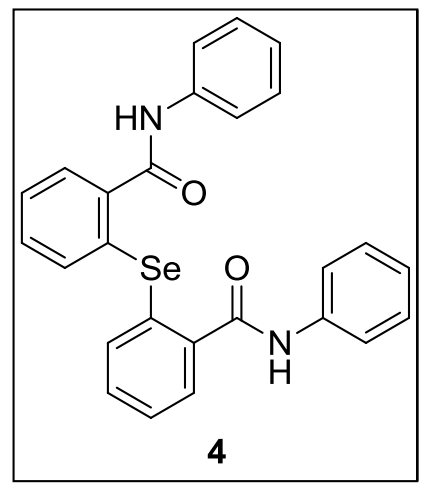

\section{Figure 12: 2,2'-Selenobis( $N$-phenylbenzamide)}

The palladacyclic precatalyst $\mathbf{5}$, comprised of palladium and the SPhos ligand (Scheme 13) was also used to synthesize ebselen (in $46 \%$ yield), however the side-product was still produced.
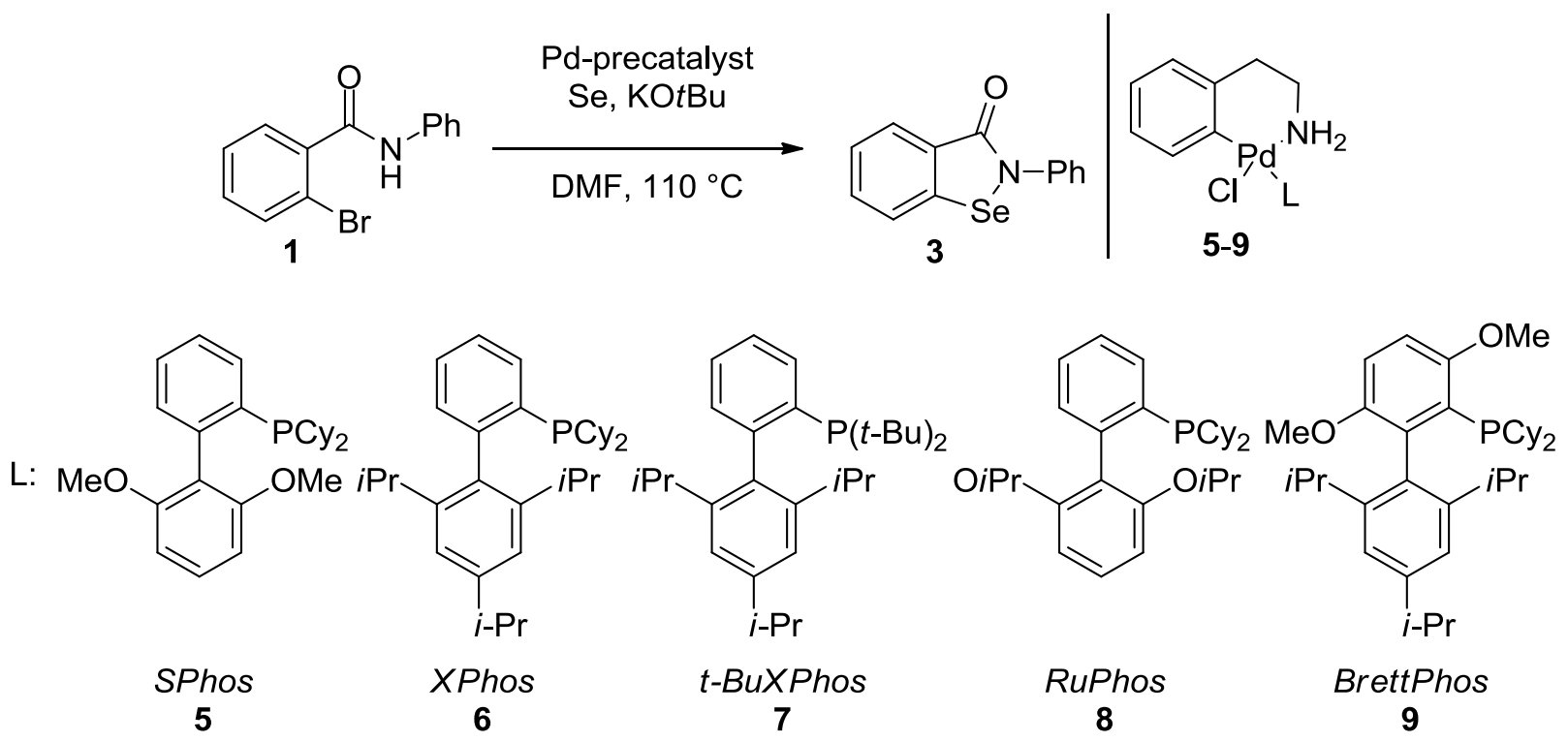

\section{Scheme 13: First Generation Buchwald-Hartwig Precatalysts Used in Cross-Coupling}

Palladium catalyzed syntheses of benzisoselenazolones have not yet been reported in the literature. Other palladium precatalysts (6-9) were applied to this methodology (Scheme 13) with reactions being monitored by TLC for the presence of ebselen but none were found to be more effective than Pd-SPhos (5). No catalyst system led to the complete consumption of starting material and TLC 
analysis of the reactions showed the presence of ebselen and the related monoselenide (4). The exception was Pd-XPhos (6) which led to no visible reaction as determined by TLC.

Various reaction conditions were applied toward the synthesis of ebselen. Initially, the work-up consisted of dissolving the reaction mixture in DMF and extracting it with $1 / 2$ saturated $\mathrm{NaCl}_{(\mathrm{aq})}$. This led to a yield of $4 \%$. The literature workup involves pouring the reaction mixture into a saturated $\mathrm{NaCl}_{(\mathrm{aq})}$ and collecting the precipitate. When following the literature procedure exactly on the same scale, a yield of $15 \%$ was obtained. The same conditions, except with $\mathrm{KO} t \mathrm{Bu}$ instead of $\mathrm{K}_{2} \mathrm{CO}_{3}$ as the base increased the yield to $30 \%$. Using $\mathrm{Cs}_{2} \mathrm{CO}_{2}$ as the base led to a crude product mixture, whose ${ }^{1} \mathrm{H}-\mathrm{NMR}$ spectrum did not contain the doublet signal characteristic of ebselen at $\delta$ $8.09 \mathrm{ppm}$. Performing the reaction in open air as opposed to under nitrogen atmosphere also did not lead to the production of ebselen. Employing $\mathrm{KO} t \mathrm{Bu}$ as the base and also changing the order of addition of reagents so that $\mathrm{CuI}$ was added last when the mixture was already hot, led to even higher yields (40\%). The highest yield obtained was 57\% from a microwave reaction in DMF for 5 minutes at $180{ }^{\circ} \mathrm{C}$ but this was not found to be reproducible.

The poor and inconsistent yields prompted a greater emphasis on keeping reactions free of air, light and water. Copper iodide was purified by dissolving in a boiling aqueous solution of sodium iodide and then inducing precipitation by dilution. DMF was transferred directly from a new Sure

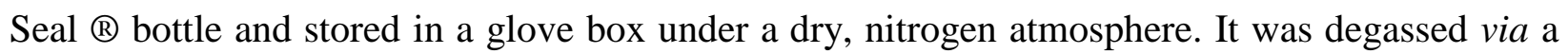
freeze pump thaw cycle immediately prior to use. The reaction was repeated, closely following the literature procedure and more consistent results were obtained than previously achieved. However, it appeared that a significant portion of the starting material was still being consumed to create the byproduct previously observed but not characterized. Column chromatography was attempted with various solvent conditions and consistently resulted in coelution of both ebselen and the side 
product. Experiments were done to see if the side product could perhaps be the corresponding selenol (Figure 13).<smiles>O=C(Nc1ccccc1)c1ccccc1O</smiles>

\section{Figure 13: 2-Hydroseleno- $N$-phenylbenzamide}

Samples of the side product were treated with the oxidant $\mathrm{CuBr}_{2}$, to see if it could be oxidized into ebselen but they were unsuccessful. By experimenting with different solvent systems it was found that the solubility of the side product in ethyl acetate and chloroform was noticeably lower than that of ebselen. Taking advantage of this, the side product was isolated from ebselen for the first time and its ${ }^{1} \mathrm{H}-\mathrm{NMR}$ data matched the literature spectrum for 2,2'-selenobis $(N$ phenylbenzamide). ${ }^{26}$

Interestingly, the authors of the original CuI mediated ebselen synthesis published a paper in 2015 showing that when using $N$-t-butyl benzamide (11), they obtained the corresponding monoselenide (12) as opposed to the desired benzisoselenazolone (Scheme 14). ${ }^{27}$

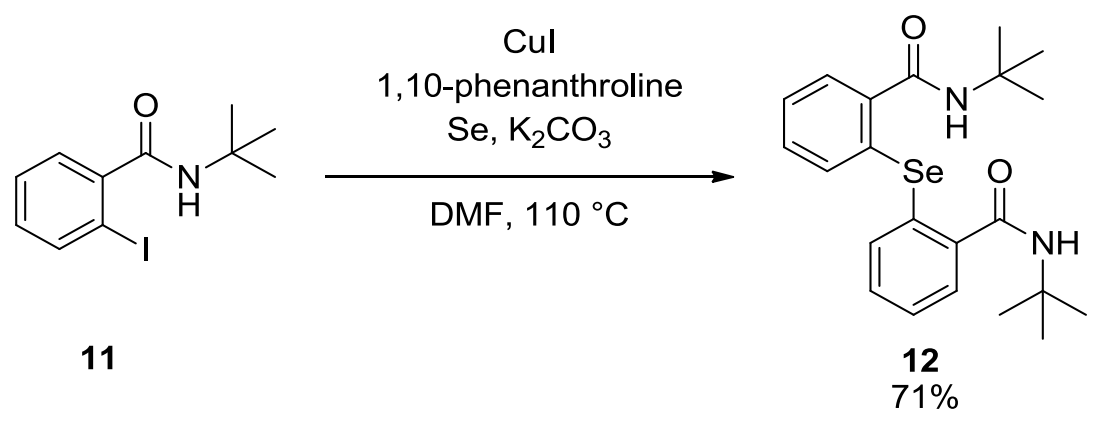

Scheme 14: Balkrishna's Unintended Selenide Synthesis 
They attribute this to the steric bulk of the $t$-butyl group and make no mention of this happening to any extent when starting from benzanilides. Some selected cross coupling experiments are shown in Table 1 and Table 2.

Table 1: The Effects of Solvents and Ligands on the CuI Catalyzed Ebselen Synthesis

\begin{tabular}{|c|c|c|c|c|c|}
\hline Entry & 1 (mmol) & Solvent & Catalyst & Se (eq) & $\begin{array}{c}\text { Compounds } \\
\text { Observed }\end{array}$ \\
\hline 1 & 0.36 & DMF & CuI, TMEDA & 1.2 & No reaction \\
\hline 2 & 0.36 & $\mathrm{DMF}$ & CuI,DACH & 1.2 & $1 / 4$ \\
\hline 3 & 0.36 & $\mathrm{DMF}$ & CuI,Proline & 1.2 & $1 / 4$ \\
\hline 4 & 0.36 & DMF & CuI,Bipy & 1.2 & No reaction \\
\hline 5 & 0.36 & 1,4-dioxane & CuI, phen & 1.2 & $1 / 3$ \\
\hline 6 & 0.36 & 1,4-dioxane & CuI, DACH & 1.2 & $1 / 4$ \\
\hline 7 & 0.36 & 1,4-dioxane & CuI, Proline & 1.2 & $1 / 3$ \\
\hline 8 & 0.36 & toluene & CuI, phen & 1.2 & $1 / 3 / 4$ \\
\hline 9 & 0.36 & toluene & CuI, DACH & 1.2 & $1 / 4$ \\
\hline 10 & 0.36 & toluene & CuI, proline & 1.2 & No reaction \\
\hline 11 & 0.36 & DMF & CuI, phen & 1.2 & No reaction \\
\hline 12 & 0.36 & DMF & $\mathrm{CuI}, \mathrm{DACH}$ & 1.2 & $1 / 4$ \\
\hline 13 & 0.36 & DMF & CuI, proline & 1.2 & $1 / 4$ \\
\hline 14 & 0.36 & DMF( air) & CuI, phen & 1.2 & $1 / 4$ \\
\hline 15 & 0.36 & 1,4-dioxane (open air) & $\mathrm{CuI}, \mathrm{DACH}$ & 1.2 & No reaction \\
\hline 16 & 0.36 & toluene (open air) & CuI, proline & 1.2 & $1 / 4$ \\
\hline
\end{tabular}


Table 2: The Effects of Bases on the CuI Catalyzed Ebselen Synthesis

\begin{tabular}{|c|c|c|c|c|c|}
\hline Entry & $1(\mathrm{mmol})$ & Solvent & Se (eq) & Base & $\begin{array}{c}\text { Compounds } \\
\text { Observed }\end{array}$ \\
\hline 1 & 0.36 & 1,4-dioxane & 1.2 & $\mathrm{~K}_{2} \mathrm{CO}_{3}$ & $1 / 3$ \\
\hline 2 & 0.36 & $t$-butanol & 1.2 & $\mathrm{~K}_{2} \mathrm{CO}_{3}$ & $1 / 3$ \\
\hline 3 & 0.36 & toluene & 1.2 & $\mathrm{~K}_{2} \mathrm{CO}_{3}$ & $1 / 3 / 4$ \\
\hline 4 & 0.36 & DMF & 1.2 & $\mathrm{~K}_{2} \mathrm{CO}_{3}$ & No rxn \\
\hline 5 & 0.36 & DMF & 1.2 & N/A & No rxn \\
\hline 6 & 0.36 & DMF & 1.2 & $\mathrm{NEt}_{3}$ & No rxn \\
\hline 7 & 0.36 & DMF & 1.2 & HMDS & No rxn \\
\hline 8 & 0.36 & DMF & 1.2 & Pyridine & No rxn \\
\hline
\end{tabular}

From these experiments, no conditions were found that led to complete consumption of the starting material. In every case where ebselen was formed, it appeared as a very faint spot by TLC analysis compared to the starting material. However, it is important to note that conditions were found that appeared to favour the formation of monoselenide over ebselen and vice-versa. Further experiments should be done in order to investigate selectivity and to find conditions that lead to greater conversion of the starting material. The cross-coupling methodology was also applied to the synthesis of a methyl analog of ebselen (Scheme 15).

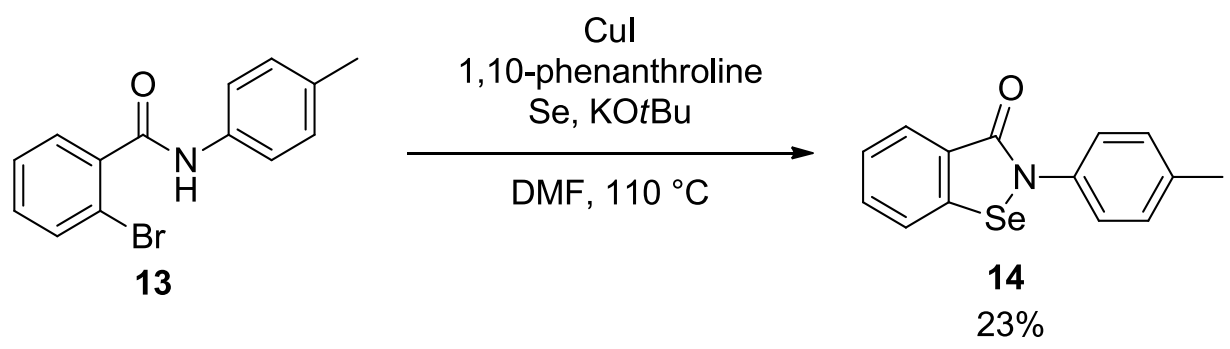

\section{Scheme 15: Synthesis of Methyl Ebselen}

Additional derivatives were not synthesized as efforts were directed towards reaction optimization. 


\subsubsection{Toward an Organic Selenium Source}

Dibenzyl diselenide was synthesized in order to see if it could be used as an organic source of selenium. The reaction was performed following a literature procedure for a phase-transfer synthesis of dibenzyl diselenides. ${ }^{28}$ PEG-200 was substituted for PEG-400 due to availability. The first trial yielded no product. A second trial was done with vigorous stirring and provided a poor yield of the desired diselenide (Scheme 16).

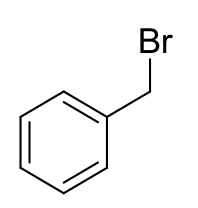

15

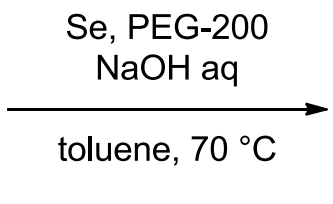

toluene, $70^{\circ} \mathrm{C}$<smiles>c1ccc(C[Se][Se]c2ccccc2)cc1</smiles>

16

$8 \%$

\section{Scheme 16: Synthesis of Dibenzyl Diselenide}

The idea was not pursued further because of the low yield obtained.

\subsection{Attempts at Ebselen via Directed Lithiation}

Unable to replicate the yields reported for the copper catalyzed synthesis, our focus shifted towards the 1989 protocol for the synthesis of ebselen from benzanilide described by Engman (Scheme 17). ${ }^{21}$

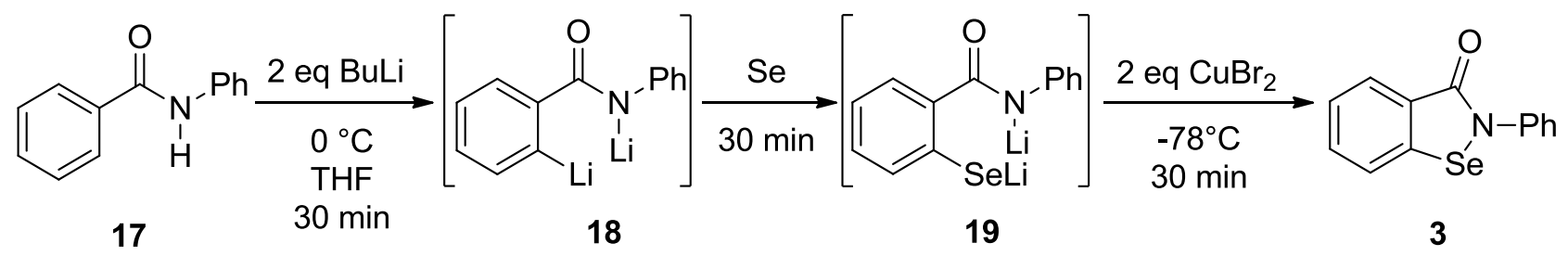

Scheme 17: Synthesis of Ebselen from Benzanilide 
This involves using butyl lithium to generate a dianionic species which then reacts with $\mathrm{Se}^{0}$. The best yield obtained was $88 \%$ following a modified procedure. During column chromatography it was noticed that foul smelling, low boiling, yellow oils eluted immediately upon commencing the purification and were suspected of being butyl selenides or diselenides due to them containing what appeared to be butyl groups (and no aromatic protons) by ${ }^{1} \mathrm{H}-\mathrm{NMR}$ analysis. To minimize the formation of low boiling, likely poisonous byproducts, 1.9 equivalents of BuLi was used rather than 2 . The crude material was purified by flash column chromatography without performing extractions beforehand. Instead of the literature procedure where the reaction mixture is poured into a $1 \%(\mathrm{v} / \mathrm{v})$ aqueous solution of $\mathrm{AcOH}$ and then extracted with DCM, the modified procedure involved adding a drop of $50 \%(\mathrm{v} / \mathrm{v}) \mathrm{AcOH}$ to the reaction mixture, diluting with $\mathrm{THF}$, filtering through celite and evaporating the solvent using a rotary evaporator.

It was thought that $N$-substituted analogs of ebselen could be made by synthesizing benzisoselenazolone first and then functionalizing the nitrogen atom in a further step (Scheme 18).

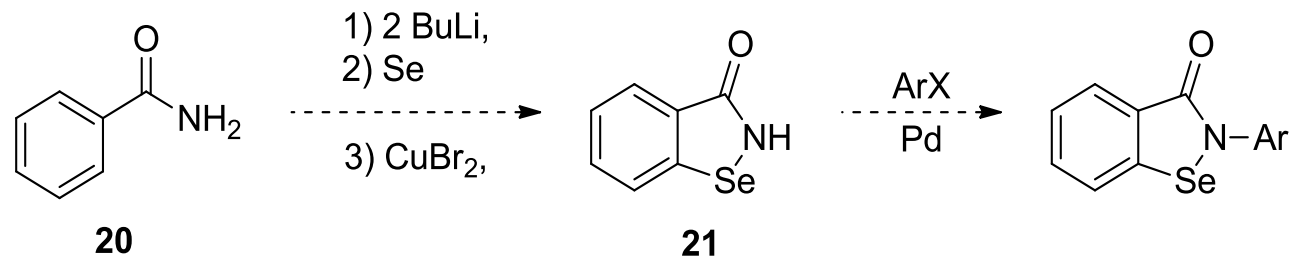

\section{Scheme 18: Possible Route to Ebselen Analogs}

Attempts made using benzamide as a starting material were unsuccessful. This was first performed in THF (Scheme 19). 


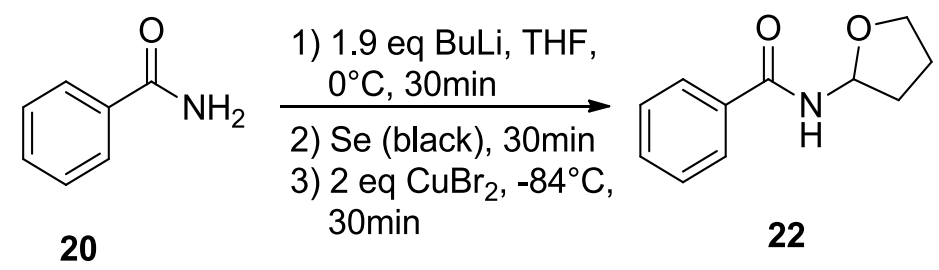

\section{Scheme 19: Unexpected Result of Benzamide Cyclization Attempt in THF}

The results of this experiment were unexpected and 1 and 2-dimensional NMR experiments were performed to identify the product.

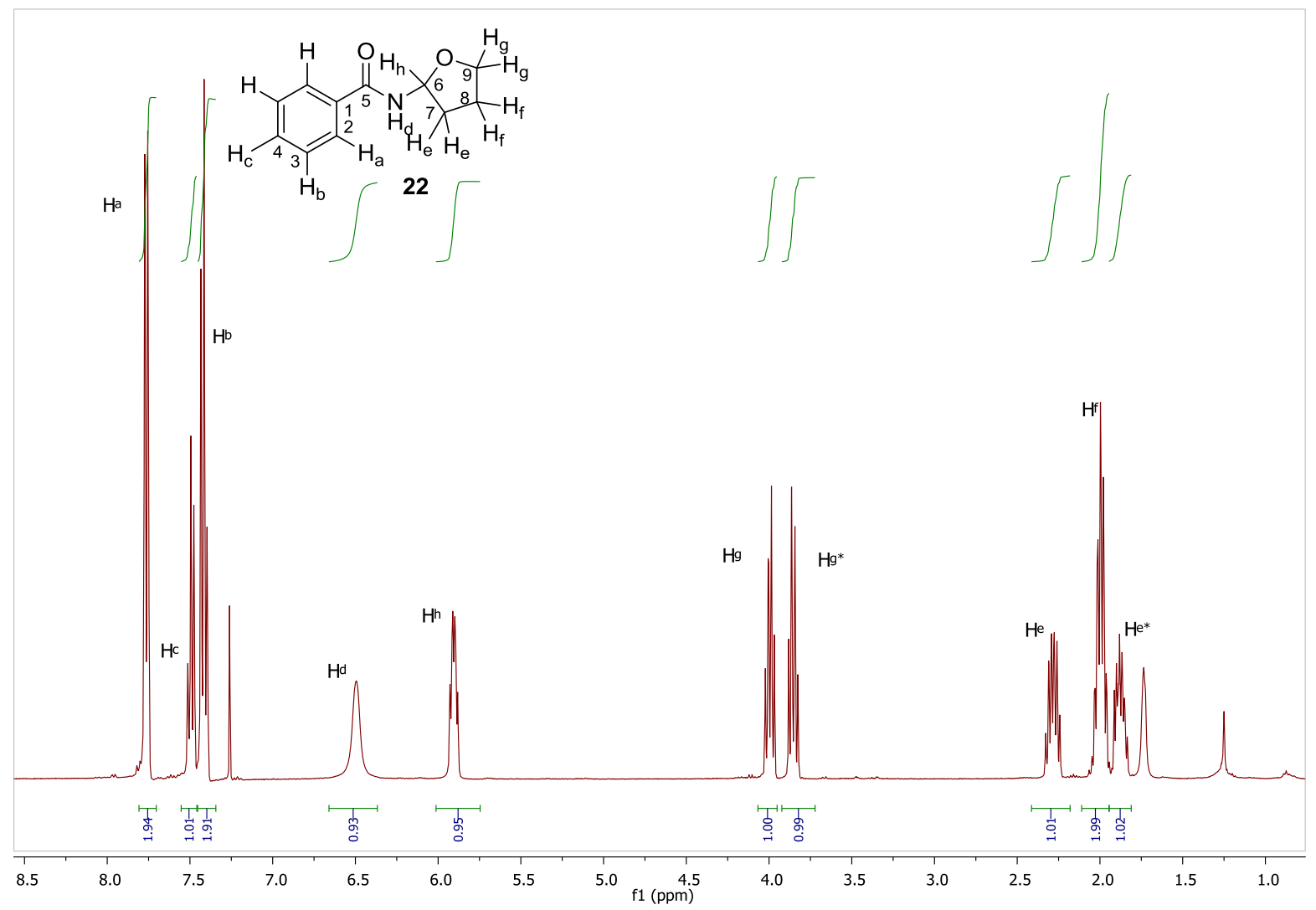

Figure 14: ${ }^{1} \mathrm{H}-\mathrm{NMR}$ of Unintended Product 


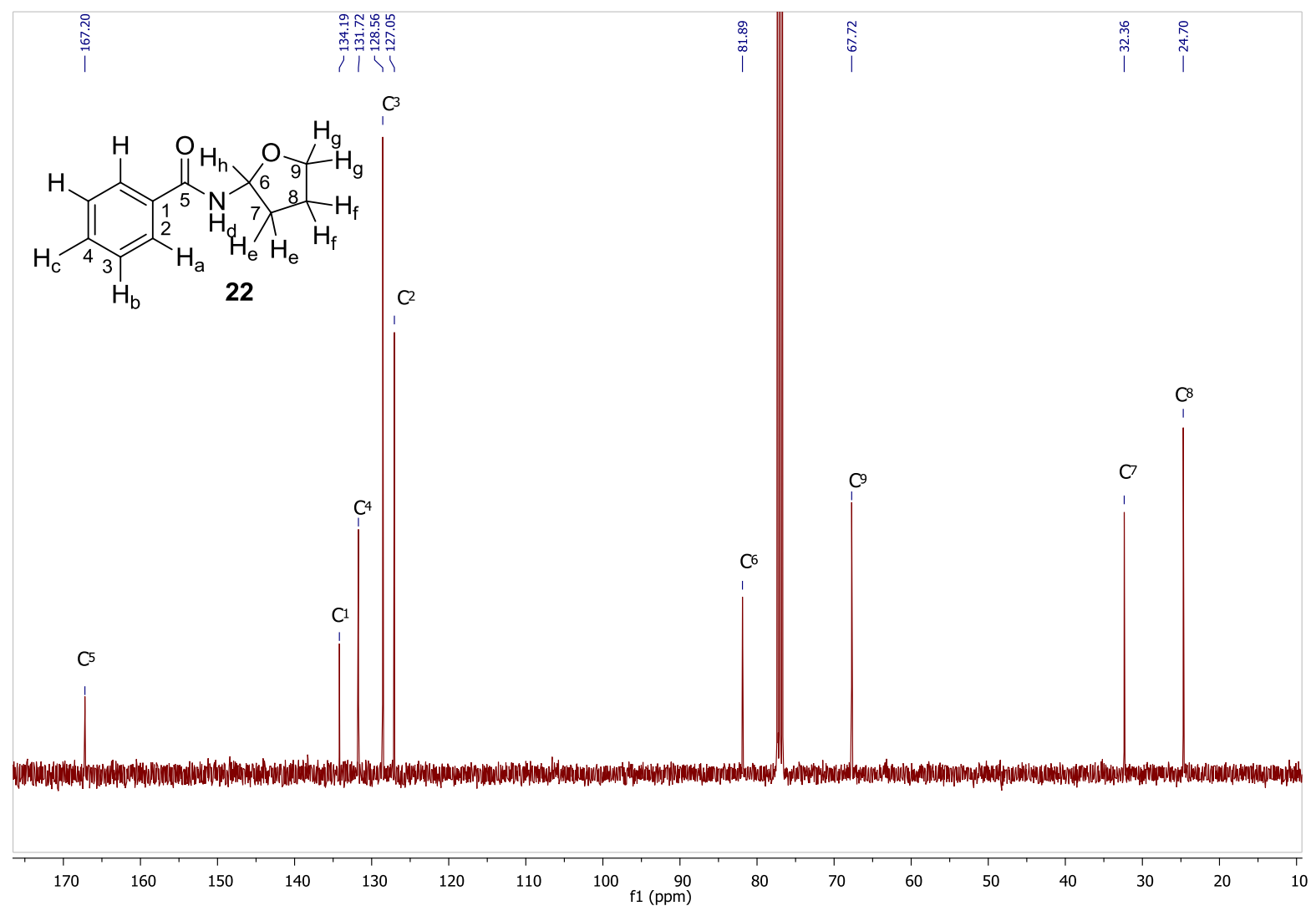

Figure 15: ${ }^{13} \mathrm{C}\left\{{ }^{1} \mathrm{H}\right\}$-NMR of Unintended Product 


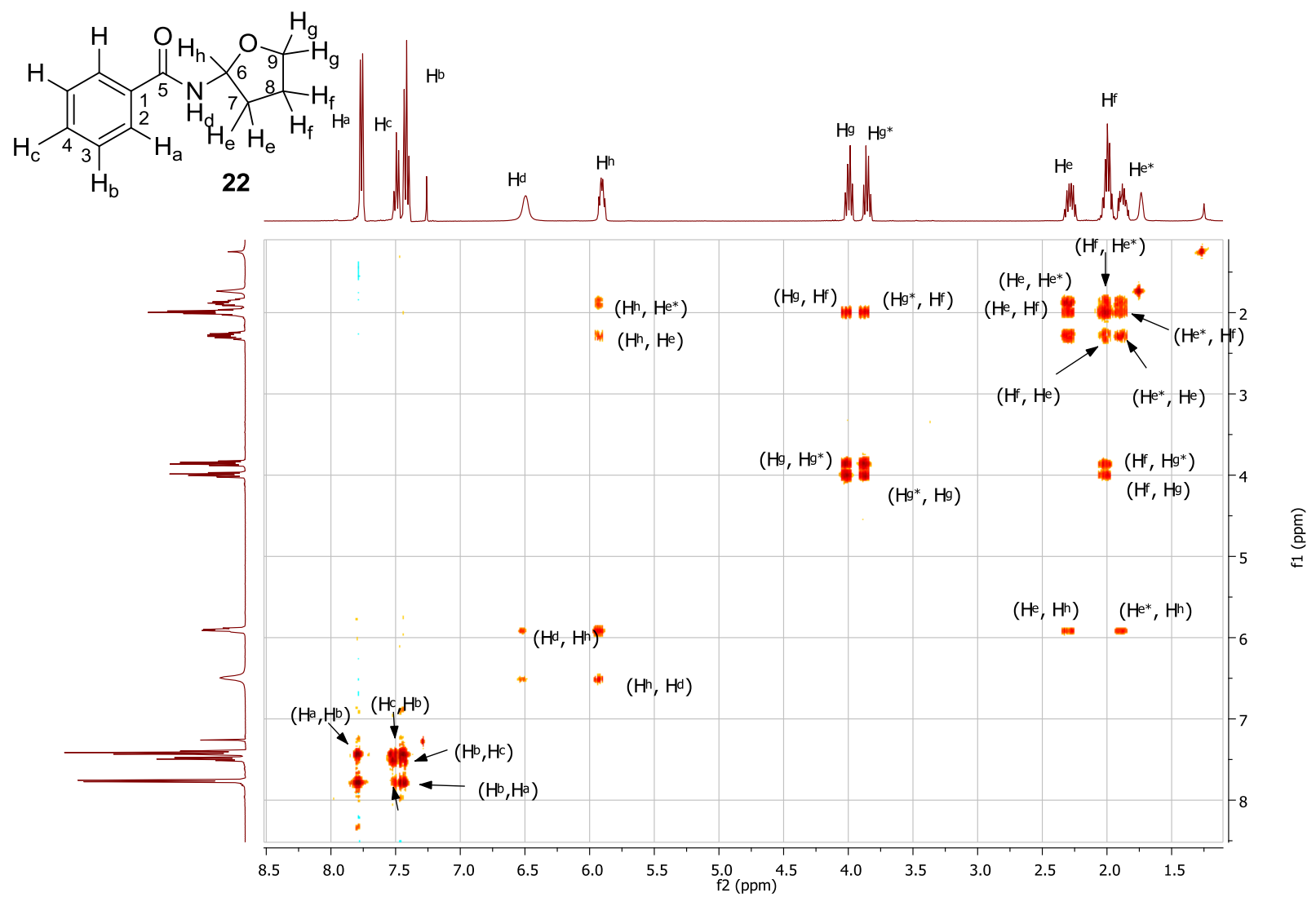

Figure 16: ${ }^{1} \mathrm{H}-{ }^{1} \mathrm{H}$ COSY of Unintended Product

From the COSY experiment, it is observed that there is correlation between $\mathrm{H}_{\mathrm{g}}$ and $\mathrm{H}_{\mathrm{g}}$ and between $\mathrm{H}_{\mathrm{e}}$ and $\mathrm{H}_{\mathrm{e}^{*}}$. From the HSQC (Figure 17) we see that $\mathrm{H}_{\mathrm{g}} / \mathrm{H}_{\mathrm{g}}$ are both bound to the same carbon (C9) and $\mathrm{H}_{\mathrm{e}}$ and $\mathrm{H}_{\mathrm{e}}{ }^{*}$ are also both bound to the same carbon (C7). This indicates that the protons in question are diastereotopic and therefore the molecule has a stereocenter. 


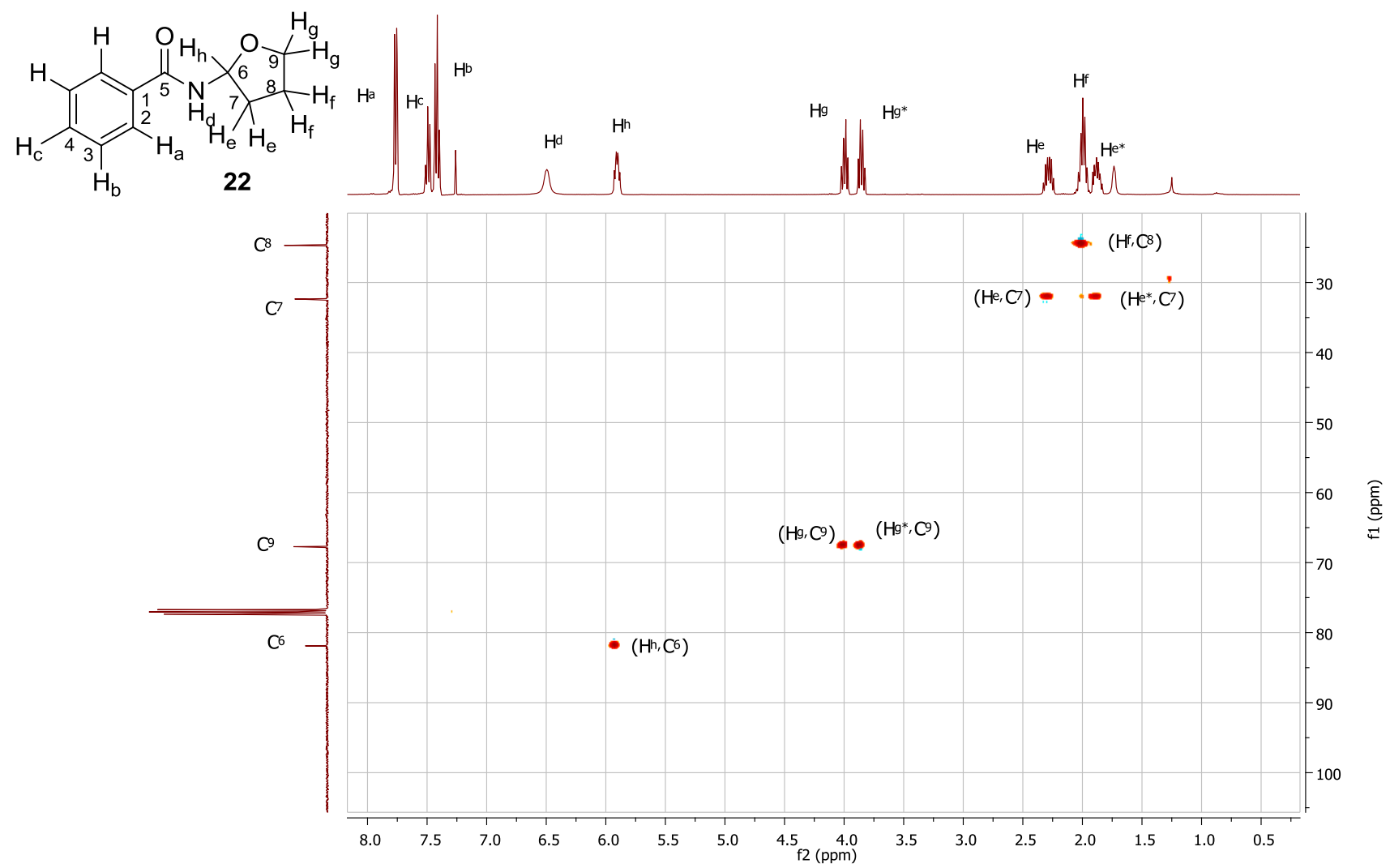

Figure 17: HSQC of Unintended Product

An HMBC (Figure 18) was also run to assist with assigning all atoms of the molecule. 


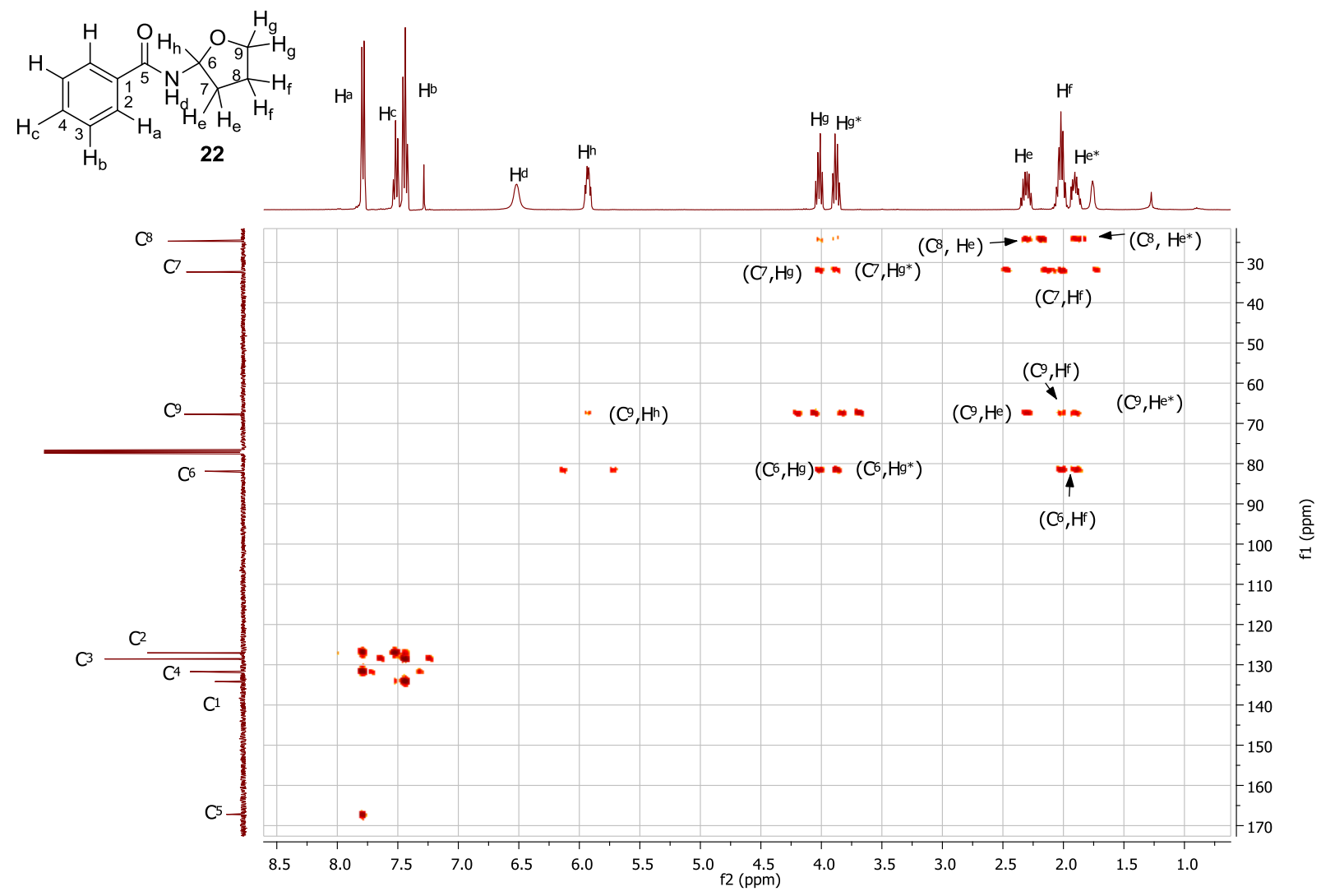

Figure 18: HMBC of Unintended Product

The reaction was repeated in $\mathrm{Et}_{2} \mathrm{O}$ and this time the $N$-butylated derivative was obtained (Scheme 20).<smiles></smiles>

Scheme 20: Unexpected Result of Benzamide Cyclization Attempt in $\mathrm{Et}_{2} \mathrm{O}$ 
After observing peaks in the alkyl region of ${ }^{1} \mathrm{H}-\mathrm{NMR}$ that resembled a butyl group, the obtained

${ }^{13} \mathrm{C}$ spectrum was compared to a literature spectrum of $N$-butyl benzamide and found to be identical (see appendix for spectral data). ${ }^{29}$

Because of the failures of using benzamide, its $\mathrm{N}$-BOC protected derivative was synthesized (Scheme 21).<smiles>NC(=O)c1ccccc1</smiles>
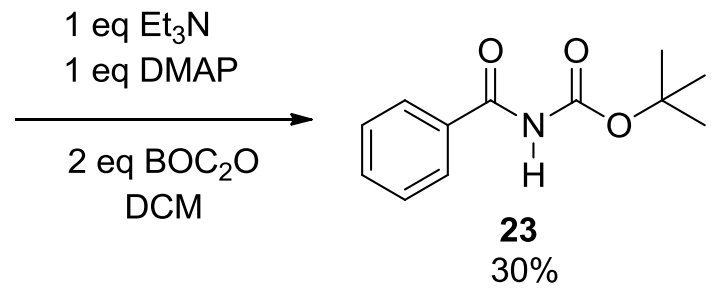

\section{Scheme 21: BOC Protection of Benzamide}

The BOC protecting group was chosen due to the simplicity of its removal and because the electron withdrawing nature of the additional carbonyl group would make the amide nitrogen more acidic. An attempt was made to synthesize the corresponding benzisoselenazolone but it was unsuccessful (Scheme 22).<smiles>CC(C)(C)OC(=O)NC(=O)c1ccccc1</smiles>

23

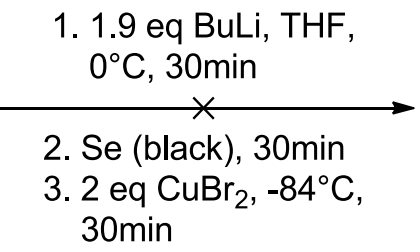<smiles>CC(C)(C)OC(=O)n1[se]c2ccccc2c1=O</smiles>

Scheme 22: Attempted Cyclization of $N$-BOC Benzamide 
The directed-metalation methodology was also applied to the synthesis of a methyl ebselen derivative (Scheme 23) in an unsatisfactory yield (27\%).

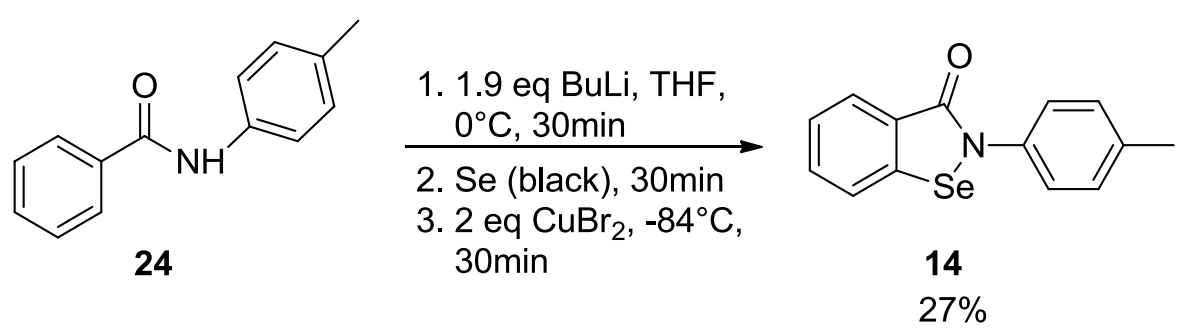

Scheme 23: Synthesis of a Methyl Derivative of Ebselen

\subsection{Attempts at Ebselen via Diazonium Displacement}

\subsubsection{Classic Synthesis}

Anthranilic acid (25) can be used to synthesize the ebselen precursor, 2,2'-bisbenzoicacid diselenide (26) via diazotization (see Scheme 24) ${ }^{30}$ A diselenide anion source is needed for the introduction of selenium. In the past, $\mathrm{Na}^{0}, \mathrm{NaBH}_{4}$, rongalite $(\mathbf{2 9}$, Scheme 28$)$ and hydrazine have been used to generate the diselenide anion. 
<smiles>CNc1ccccc1C(=O)O</smiles>

1) $\mathrm{NaNO}_{2}, \mathrm{HCl},-5^{\circ} \mathrm{C}$

2) $\left[\mathrm{Se}_{2}\right]^{-2}$<smiles>O=C(O)c1ccccc1[Se][Se]c1ccccc1C(=O)O</smiles>

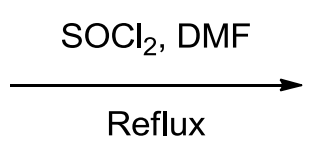<smiles>O=C(Cl)c1ccccc1[Se]Cl</smiles><smiles>CCCCC(C)(C)C</smiles><smiles>O=c1c2ccccc2[se]n1-c1ccccc1</smiles>

3

$88 \%$

(last step)

\section{Scheme 24: Original Ebselen Synthesis from Anthranilic Acid}

\subsubsection{Sodium Hydride as a Reductant}

The diazonium salt $\mathbf{2 8}$ was synthesized in aqueous solution via the use of hydrochloric acid and sodium nitrite (Scheme 25). The synthesis of diselenide 26 (Scheme 26) was performed successfully in $46 \%$ yield using $\mathrm{NaH}$ in $\mathrm{DMF}$ to generate $\mathrm{Na}_{2} \mathrm{Se}_{2} .{ }^{31}$ An aqueous solution of diazonium 28 was then slowly added to the $\mathrm{Na}_{2} \mathrm{Se}_{2}$ solution. The product was purified by dissolving it in aqueous base, filtering and then collecting the precipitate that formed after drop wise addition of $\mathrm{HCl}$ until a $\mathrm{pH}$ of about 2 was reached. The obtained ${ }^{1} \mathrm{H}-\mathrm{NMR}$ spectrum (see appendix) had chemical shifts identical to a literature entry for this compound. ${ }^{32}$<smiles>Nc1ccccc1C(=O)O</smiles>

25

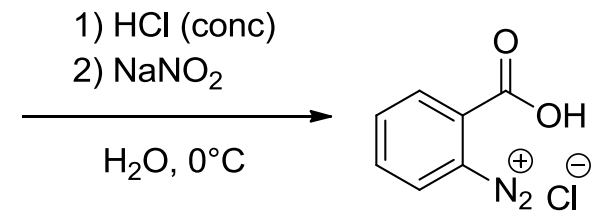

28

Scheme 25: Formation of Diazonium Salt 28 


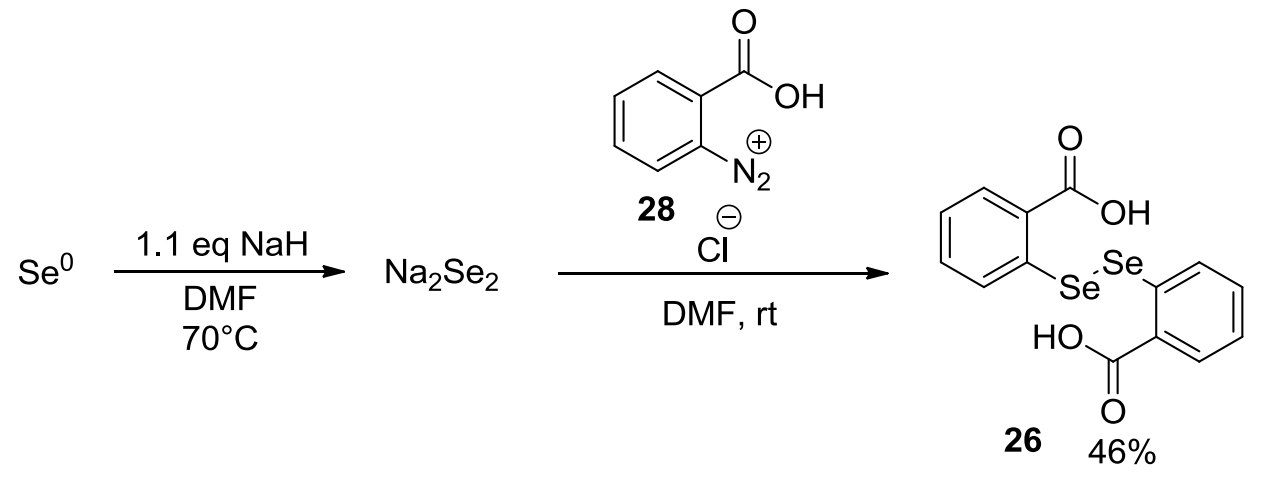

Scheme 26: Synthesis of Diselenide 26

The reaction was also performed using $t$-butyl nitrite, following a literature procedure (Scheme 27). ${ }^{33}$ This allows for the entire reaction to be performed in organic solvent, however, the attempt was unsuccessful.

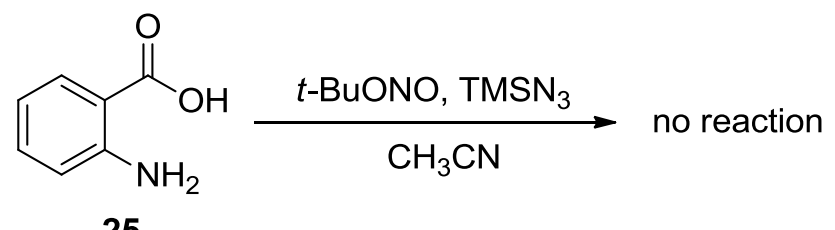

\section{Scheme 27: Attempt at Organic Diazonium Formation}

\subsubsection{Rongalite as a Reductant}

The diselenide was also obtained using rongalite (29, Scheme 28$)$ to reduce $\mathrm{Se}^{0}$ in the presence of sodium hydroxide. This was performed following a literature procedure however this gave a lower yield and it was more challenging to purify the crude product due to the formation of byproducts. ${ }^{30,34}$ 


$$
\mathrm{HO}_{\mathrm{S}}^{\mathrm{II}}{ }_{\mathrm{O}}^{\ominus}+\underset{\mathrm{Na}}{\stackrel{\mathrm{NaOH}}{\longrightarrow}} \underset{\mathrm{H}_{\mathrm{H}}}{\stackrel{\mathrm{O}}{\mathrm{O}_{\mathrm{H}}}}+\mathrm{SO}_{2}^{2-} \stackrel{2 \mathrm{Se}}{\longrightarrow} \mathrm{SO}_{2}+\mathrm{NaSeSeNa}
$$

29

\section{Scheme 28: Mechanism of the Reduction of Selenium by Rongalite}

\subsubsection{Magnesium as a Reductant}

During a routine cleaning of a flask with methanol that had previously been used to generate a selenyl Grignard reagent (see section 2.4), an exothermic reaction was observed, turning the solution in the flask red and heating it to a boil. Although the flask had sat out in open air for over a day, it appeared the magnesium had not been oxidized until the addition of the methanol. A look into the literature found that magnesium can be used to generate "bismethoxymagnesium diselenide"** from methanol and selenium, which can be used as a source of the nucleophilic diselenide anion. ${ }^{35}$

$$
\text { Se } \underset{\mathrm{MeOH}}{\stackrel{\mathrm{Mg}}{\mathrm{C}_{22} \mathrm{H}_{82} \mathrm{O}_{24} \mathrm{Mg}_{6} \mathrm{Se}_{6}}} \text { "bismethoxymagnesium diselenide" }
$$

\section{Scheme 29: Reduction of Selenium via Magnesium}

An experiment was then undertaken to intentionally generate a selenium nucleophile by reduction of elemental selenium in the presence of magnesium and methanol. This route led to a mix of products and a low crude yield.

\footnotetext{
** The crystal structure of "bismethoxymagnesium diselenide" showed this reagent to actually be dodecamethanoltetramethoxy-di( $\mu 4$-hydroxy)tetra( $\mu 3$-methoxy)hexamagnesium hexaselenide. ${ }^{35}$
} 


\subsection{Possible Route From $o$-lithiation of Protected Selenol}

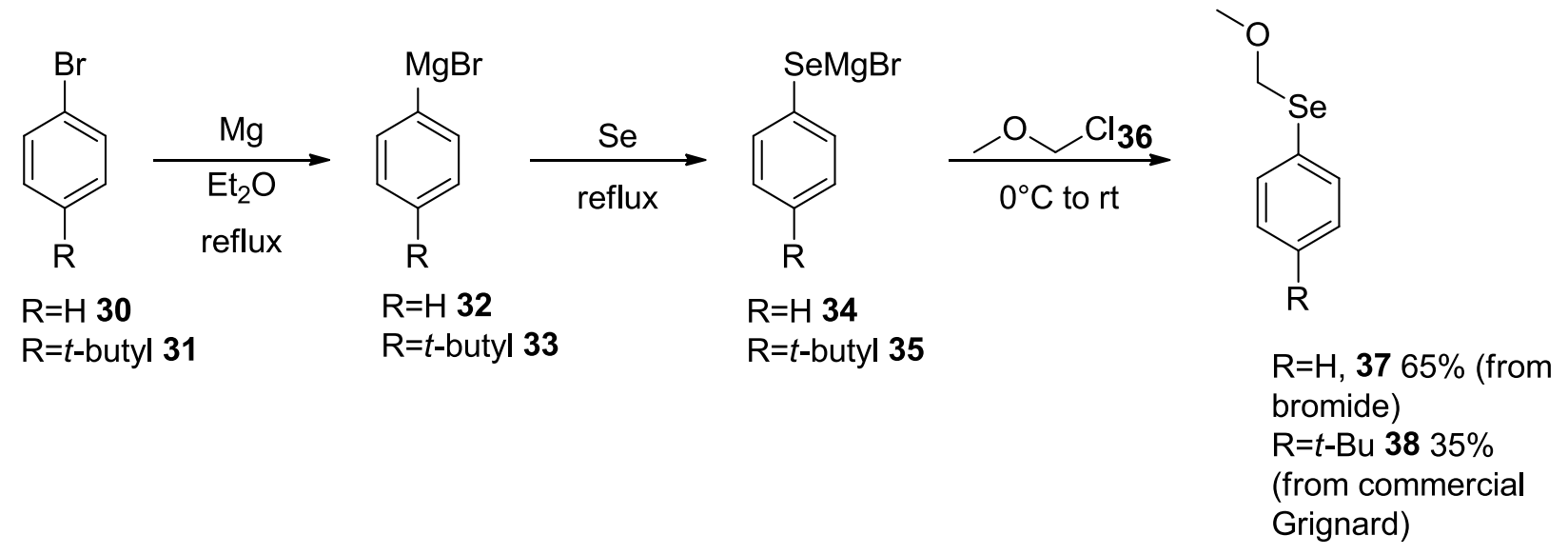

\section{Scheme 30: Synthetic Route Toward MOM-Protected Phenyl Selenols}

Due to the challenges encountered in forming the C-Se bond through other methods, it was envisioned that it could be incorporated through Grignard chemistry as in the literature synthesis of phenyl selenol 39 (Scheme 31). ${ }^{36}$

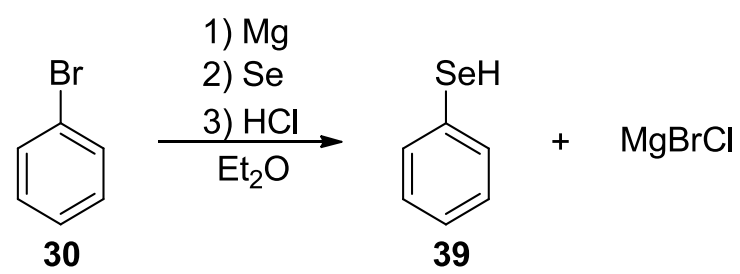

\section{Scheme 31: Literature Synthesis of Phenyl Selenol via Selenyl Grignard Formation}

By quenching selenyl Grignard 34 or 35 (Scheme 30) with $\mathrm{MOM}-\mathrm{Cl}$ in place of $\mathrm{HCl}$, the product of the reaction would be a MOM protected selenol. MOM protected phenols have been shown to direct lithiation to the ortho-position. ${ }^{25}$ If the same was applicable for the MOM protected selenol it would allow the phenyl amide moiety of ebselen to be incorporated via the reaction of phenylisocyanate and the ortho-lithiated protected selenol. An oxidative ring-closure and selenol deprotection sequence would then yield ebselen (Scheme 32). This method would be advantageous 
as it would allow for the synthesis of $N$-substituted derivatives of ebselen simply by using different isocyanate reagents.

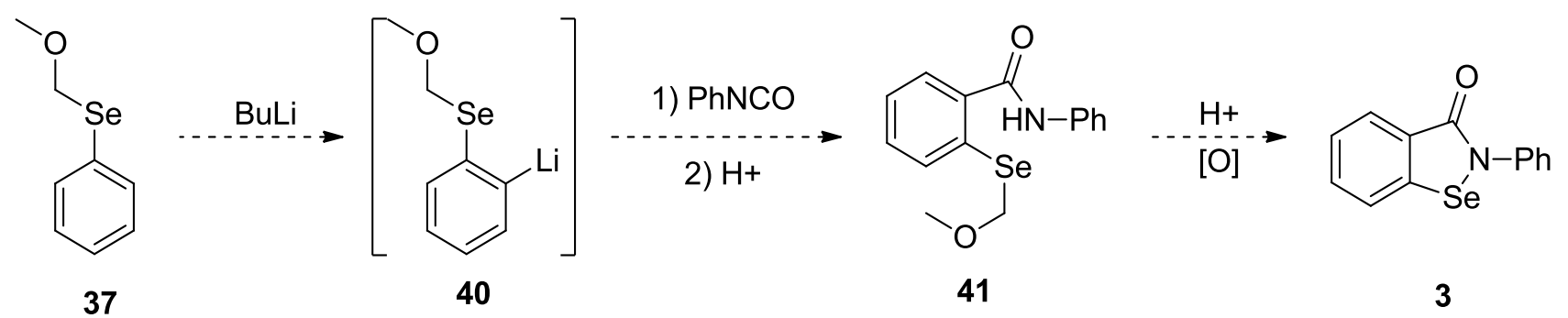

\section{Scheme 32: Proposed Benzisoselenazolone Synthesis from Protected Selenol 37}

\subsubsection{Synthesis of a Protected Selenol}

MOM protected phenyl selenol $\mathbf{3 7}$ was first synthesized via Grignard chemistry using bromobenzene (30). Following the formation of the Grignard reagent, elemental selenium was added to the mixture, which was then quenched with a solution of MOM-Cl (36, (Scheme 30). After purification via column chromatography in DCM, a $65 \%$ yield and clean ${ }^{1} \mathrm{H}-\mathrm{NMR}$ (Figure 19) and ${ }^{13} \mathrm{C}-\mathrm{NMR}$ (Figure 20) were obtained. 


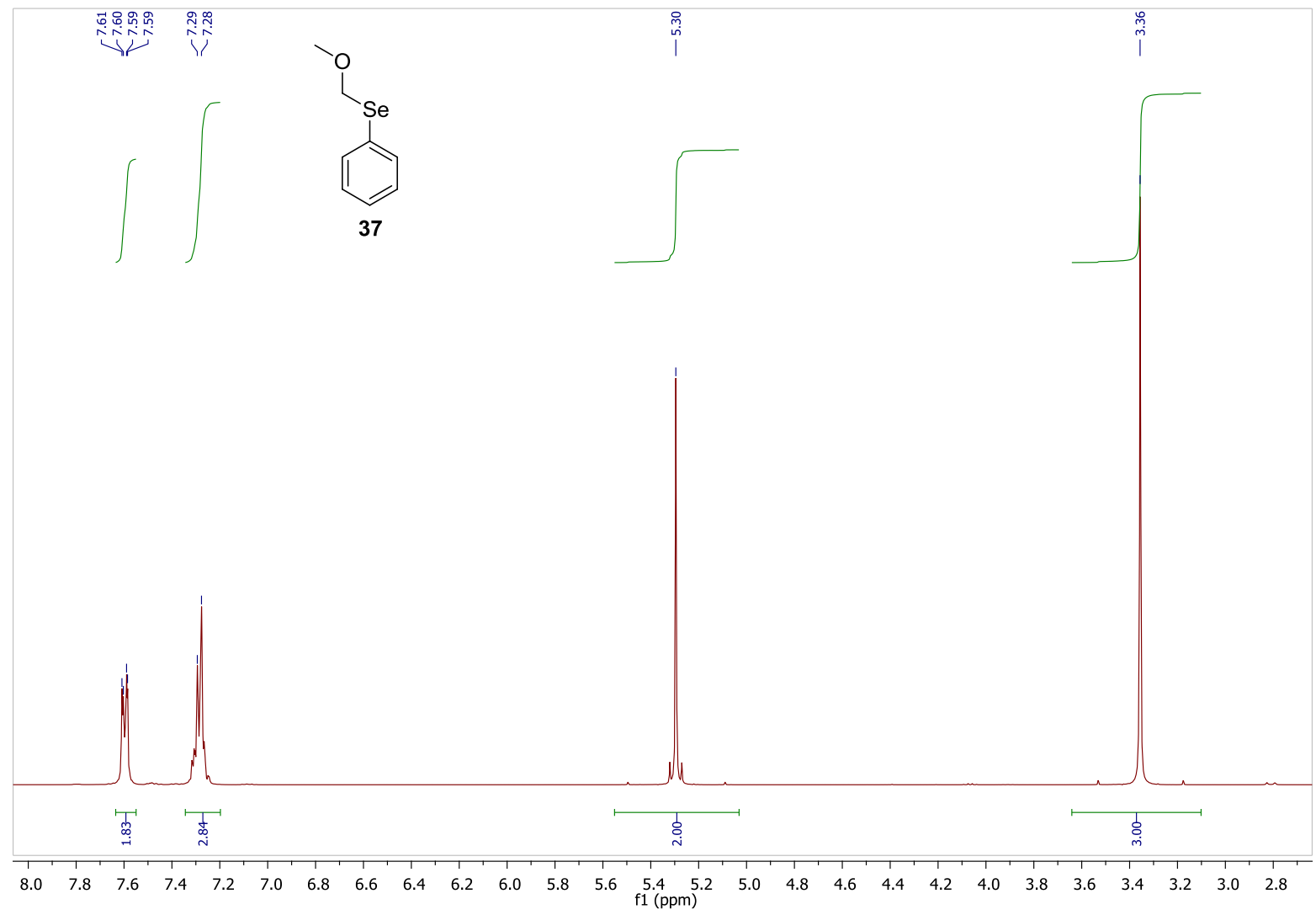

Figure 19: ${ }^{1} \mathrm{H}-\mathrm{NMR}$ of MOM-Protected Selenol

Because ${ }^{77} \mathrm{Se}$ is NMR active and has a natural abundance of $7.63 \%$, satellites are observed on the methylene singlet occurring at $5.30 \mathrm{ppm}(J=20.0 \mathrm{~Hz})$. This provides convincing evidence that the product formed is the desired product. Both the methylene singlet at 5.30 and the methyl singlet at 3.36 also exhibit ${ }^{13} \mathrm{C}$ satellites. 


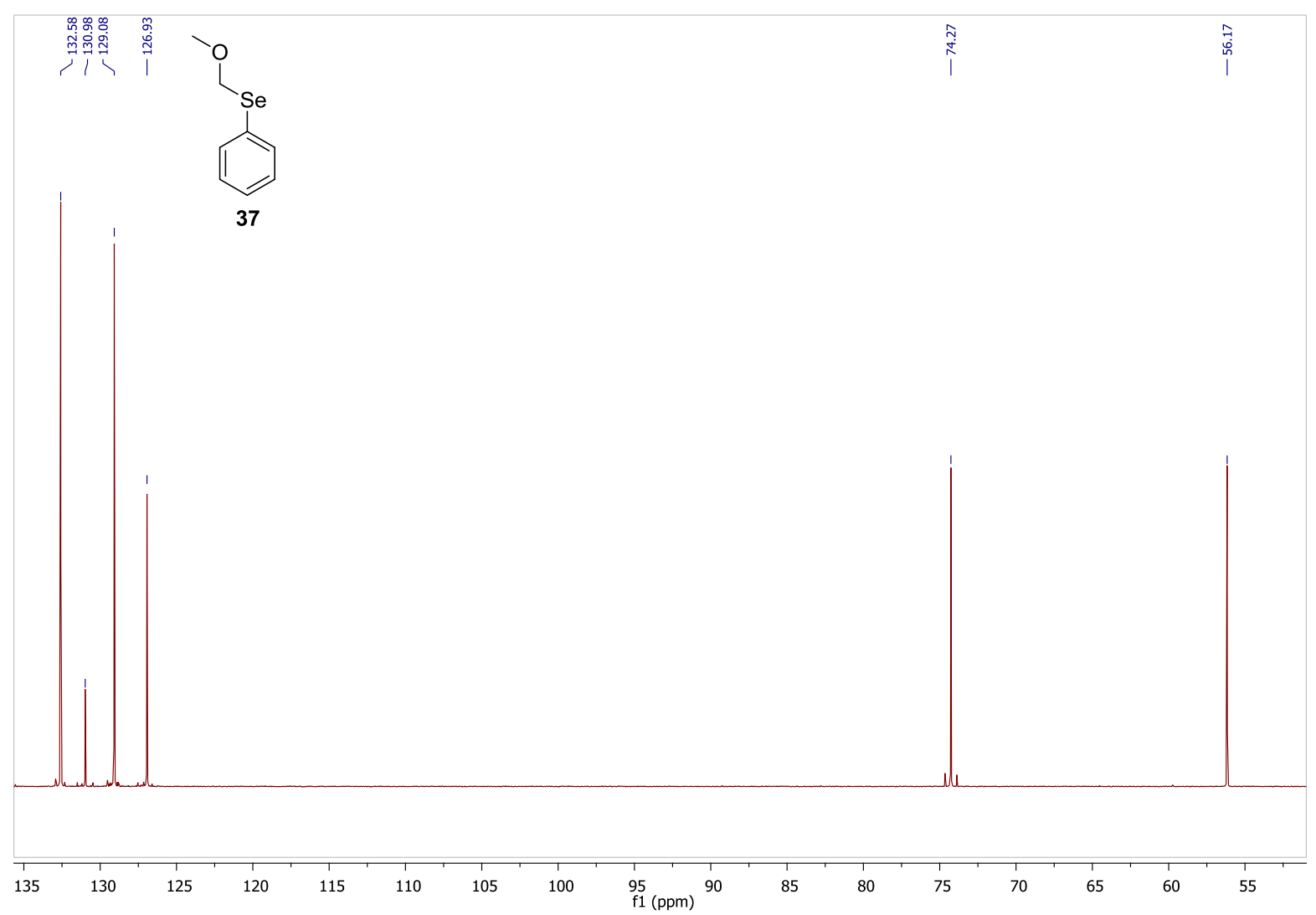

Figure 20: ${ }^{13} \mathrm{C}-\mathrm{NMR}$ of MOM-Protected Selenide

Similar ${ }^{77}$ Se satellites are observed on the peak at $74.3 \mathrm{ppm}$ in the ${ }^{13} \mathrm{C}-\mathrm{NMR}$ spectrum $(J=77.8$, Figure 20) providing evidence that selenium has been incorporated into the molecule.

The tert-butyl MOM-protected selenide was synthesized first from 4-tert-butyl-bromobenzene and then from pre-purchased 4-tert-butylphenylmagnesium bromide. This was to provide an integration handle for the alkyl region of ${ }^{1} \mathrm{H}-\mathrm{NMR}$, as well as symmetric aromatic signals. The bulky $t$-butyl group may also disfavour undesired lithiation at the meta positions. Crude ${ }^{1} \mathrm{H}-\mathrm{NMR}$ 
data was obtained and an expansion of the methylene region (as identified in the previous product) (Figure 21) showed a mix of products with the same satellite pattern.

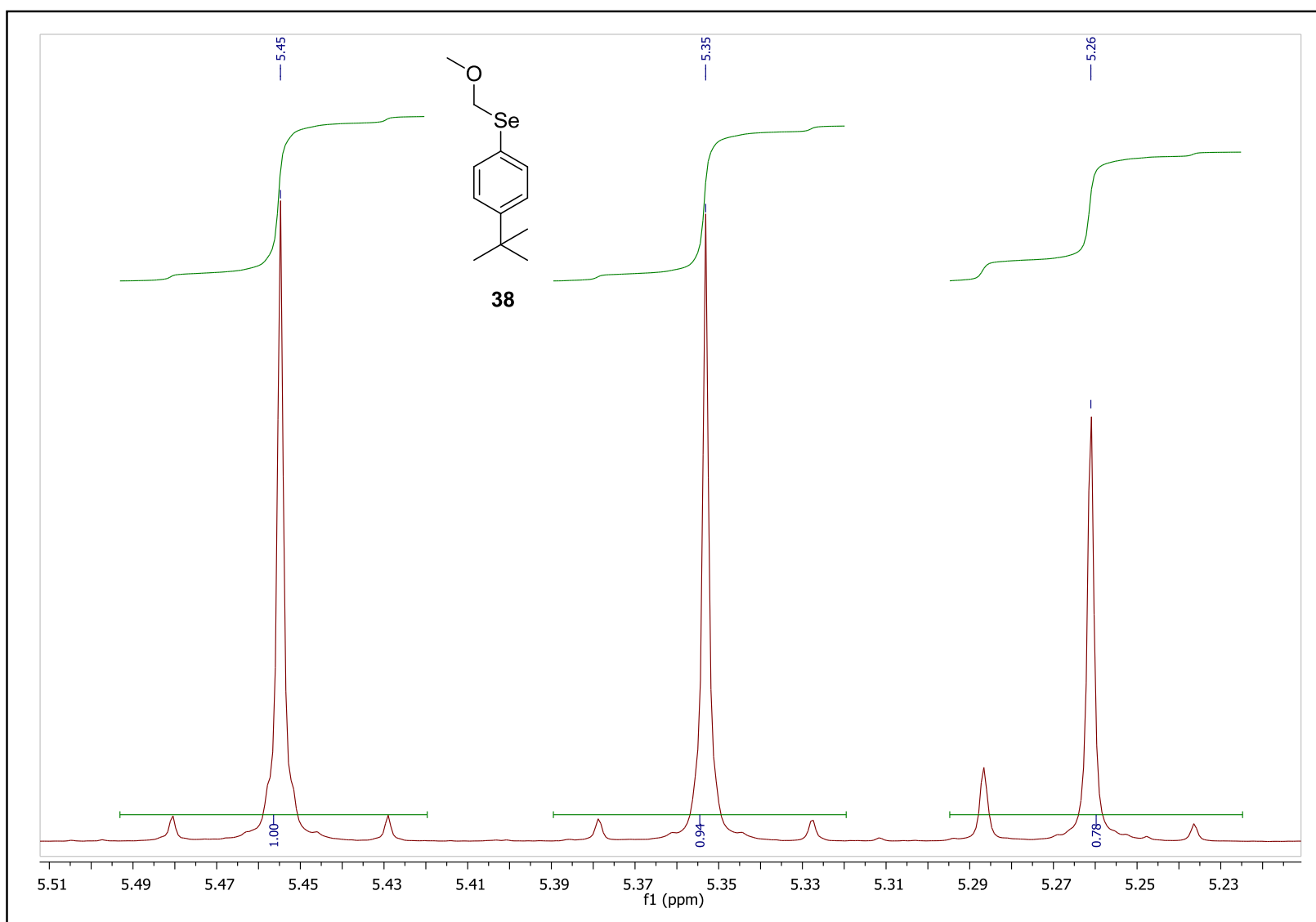

Figure 21: Expansion of 1H-NMR Spectrum for 4-t-butylphenyl MOM Selenide

This result could be explained by the formation of the corresponding selenone (42) or selenoxide (43, Figure 22). 

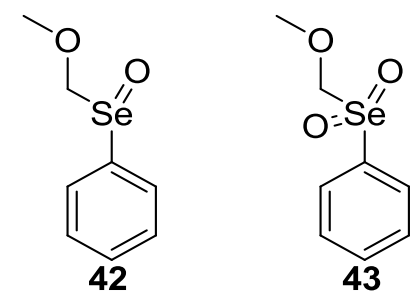

Figure 22: Possible Byproducts of Selenide Synthesis

These byproducts would have the same splitting patterns on ${ }^{1} \mathrm{H}-\mathrm{NMR}$ and thus further spectroscopic techniques are required to identify the desired product.

\subsubsection{Directed Lithiation Trials}

A lithiation and subsequent isocyanate quench was performed following a procedure designed for MOM protected alcohols (Scheme 33). ${ }^{25}$

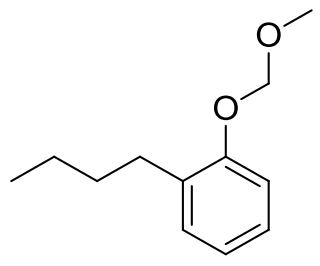

44
1) 1.3 eq TMEDA, 1.3 eq $n$-BuLi $\mathrm{Et}_{2} \mathrm{O},-30{ }^{\circ} \mathrm{C}$ to $-5^{\circ} \mathrm{C}, 5 \mathrm{~h}$

2) 9 eq $t$-BuNCO, $-5^{\circ} \mathrm{C}$ to $\mathrm{rt}, \mathrm{O} / \mathrm{N}$

3) $1 \mathrm{M} \mathrm{HCl}$

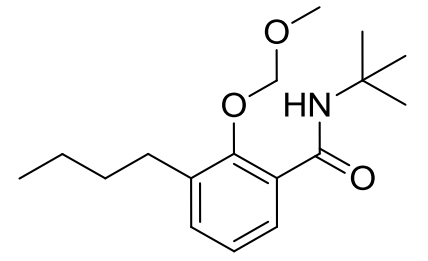

45

\section{Scheme 33: Literature Procedure for Directed Lithiation Followed by Isocyanate Quench}

The first attempt at adapting this procedure for MOM-protected selenols was unsuccessful (Scheme 34). 

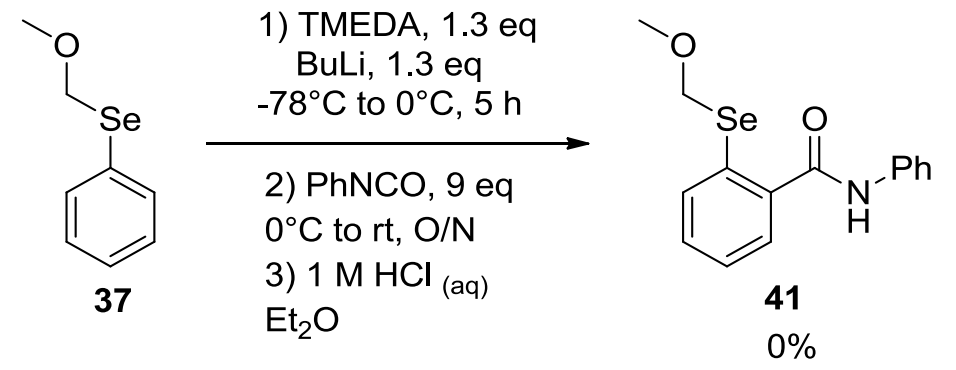

\section{Scheme 34: Attempted ortho-lithiation/Aromatic Substitution}

Dichloromethane was used for extraction and upon contact with the reaction mixture it warmed up considerably. This was unexpected as addition of $\mathrm{HCl}$ solution was assumed to have quenched any remaining aryl lithium species, which could have reacted with the electrophilic DCM. Analysis of the recovered crude material via ${ }^{1} \mathrm{H}-\mathrm{NMR}$ was not promising and the reaction was deemed unsuccessful.

Reactions were undertaken to test if the MOM group could direct lithiation and if the phenyl amide moiety could be incorporated. This involved attempting lithiation via BuLi or LDA and quenching with $\mathrm{MeI}$ or $\mathrm{D}_{2} \mathrm{O}$ to provide a quick way (using ${ }^{1} \mathrm{H}-\mathrm{NMR}$ spectroscopy) to see if $o$-lithiation was successful (Scheme 35). 


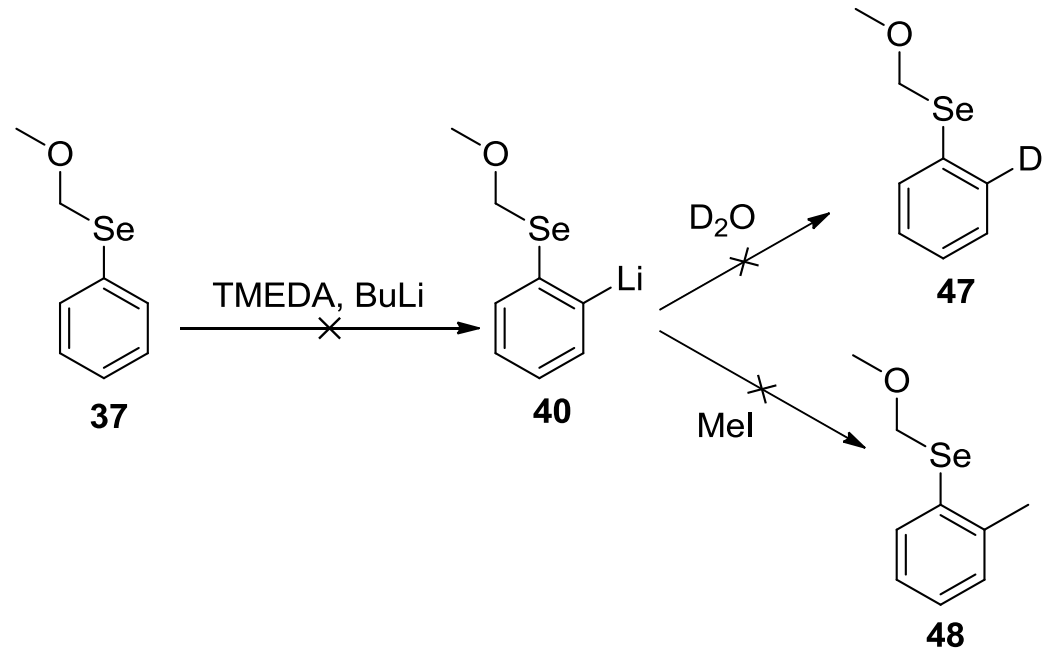

\section{Scheme 35: Test to Indicate Whether or not $o$-Lithiation Occurred}

A report from 1975 describing the cleavage of aryl-Se bonds with BuLi was found after an exploration into past literature (see Scheme 36) ${ }^{37}$ The reaction investigated led us to believe that these MOM protected selenides would not be able to withstand lithiation conditions.

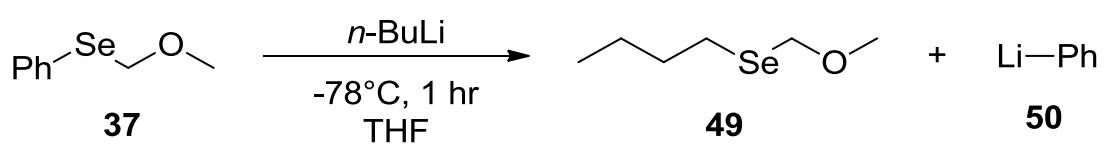

\section{Scheme 36: Published Reaction Between MOM-protected Selenol and BuLi}

\subsection{Possible Route via C-H Bond Activation}

Attempts were made towards forming the benzisoselenazolone ring via $\mathrm{C}-\mathrm{H}$ bond activation. In a paper published in 2015, a palladium catalyzed C-H activation of an $\mathrm{N}$-pyrimidin-2-yl amide followed by the formation of an aryl sulfide was exhibited (Scheme 37). ${ }^{23}$ It was thought that elemental selenium could be used as opposed to the organic dichalcogenide used in the literature. Due to selenium existing as an octacyclic species, both the literature and proposed reactions involve the breaking of a chalcogen-chalcogen bond. 


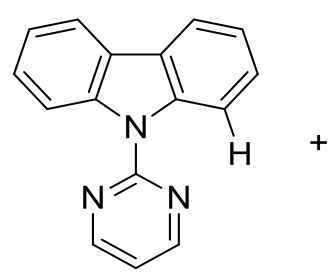

51

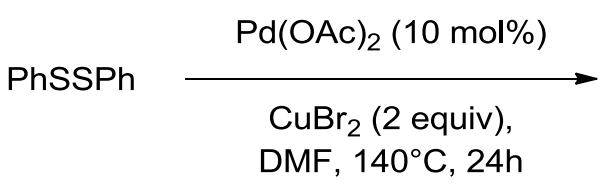

52

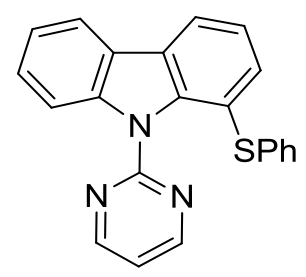

53

\section{Scheme 37: Sulfenylation of a Carbazole via C-H Activation}

The pyrimidinyl amide 54 was chosen due to its potential coordinative ability (Scheme 38). ${ }^{23}$

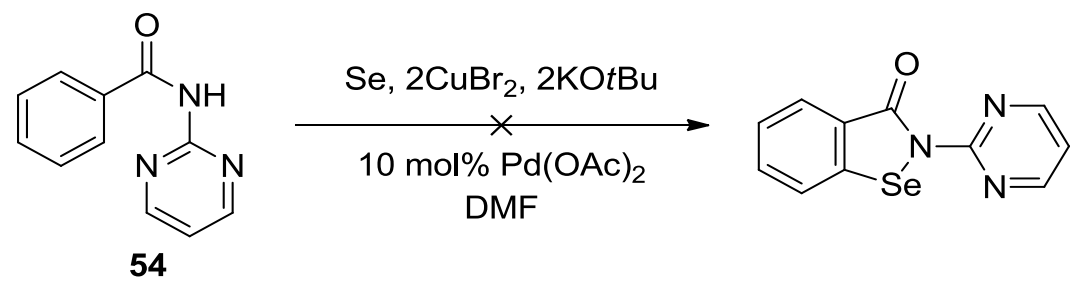

\section{Scheme 38: C-H Activation Experiment on a Pyrimidinyl Benzamide}

The same conditions were also applied to benzanilide (Scheme 39).<smiles>O=C(Nc1ccccc1)c1ccccc1</smiles>
17

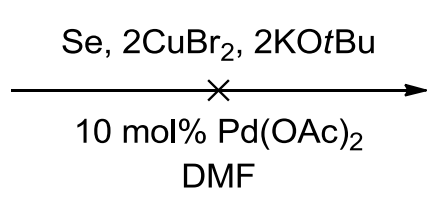
DMF<smiles>O=c1c2ccccc2[se]n1-c1ccccc1</smiles>

3

\section{Scheme 39: C-H Activation Experiment on Benzanilide}

A summary of the reaction conditions applied can be seen in Table 3. 
Table 3: C-H Bond Activation Attempts

\begin{tabular}{|c|c|c|c|c|c|}
\hline $\begin{array}{l}\text { Starting } \\
\text { Material }\end{array}$ & Solvent & Base & Catalyst & CuBr2 & Outcome \\
\hline 54 & DMF & $\mathrm{KO} t \mathrm{Bu}$ & $10 \% \mathrm{Pd}(\mathrm{OAc})_{2}$ & $2 \mathrm{eq}$ & No Rxn. \\
\hline 54 & $\overline{\mathrm{DMF}}$ & $\mathrm{Cs}_{2} \mathrm{CO}_{3}$ & $10 \% \mathrm{Pd}(\mathrm{OAc})_{2}$ & 2 eq & No Rxn. \\
\hline 17 & DMF & $\mathrm{KO} t \mathrm{Bu}$ & $10 \% \mathrm{Pd}(\mathrm{OAc})_{2}$ & $2 \mathrm{eq}$ & No Rxn. \\
\hline 17 & DMF & $\mathrm{Cs}_{2} \mathrm{CO}_{3}$ & $10 \% \mathrm{Pd}(\mathrm{OAc})_{2}$ & $2 \mathrm{eq}$ & No Rxn. \\
\hline 54 & 1,4-Dioxane & $\mathrm{KO} t \mathrm{Bu}$ & $10 \% \mathrm{Pd}(\mathrm{OAc})_{2}$ & 2 eq & $\begin{array}{l}\text { Hydrolysis of } \\
\text { amide }\end{array}$ \\
\hline 54 & 1,4-Dioxane & $\mathrm{Cs}_{2} \mathrm{CO}_{3}$ & $10 \% \mathrm{Pd}(\mathrm{OAc})_{2}$ & 2 eq & $\begin{array}{l}\text { Hydrolysis of } \\
\text { amide }\end{array}$ \\
\hline 17 & 1,4-Dioxane & $\mathrm{KO} t \mathrm{Bu}$ & $10 \% \mathrm{Pd}(\mathrm{OAc})_{2}$ & 2 eq & No Rxn. \\
\hline 17 & 1,4-Dioxane & $\mathrm{Cs}_{2} \mathrm{CO}_{3}$ & $10 \% \mathrm{Pd}(\mathrm{OAc})_{2}$ & 2 eq & No Rxn. \\
\hline 54 & 1,4-Dioxane & N/A & $10 \% \mathrm{Pd}(\mathrm{OAc})_{2}$ & 2 eq & No Rxn. \\
\hline 54 & DMF & N/A & $10 \% \mathrm{Pd}(\mathrm{OAc})_{2}$ & $2 \mathrm{eq}$ & No Rxn. \\
\hline
\end{tabular}

No trials led to any reaction except for the hydrolysis of $\mathbf{5 4}$ in the presence of 1,4-dioxane and base.

\subsection{Generation of Selenium Nucleophiles}

A paper published by the Balkrishna group in 2014 led us to consider using sources of selenium other than $\mathrm{Se}^{0}$, in the copper catalyzed cross-coupling methodology. ${ }^{38}$ They were able to synthesize 
substituted benzisoselenazolones without the use of the $\mathrm{CuI}$, phenanthroline catalyst system (Scheme 40).

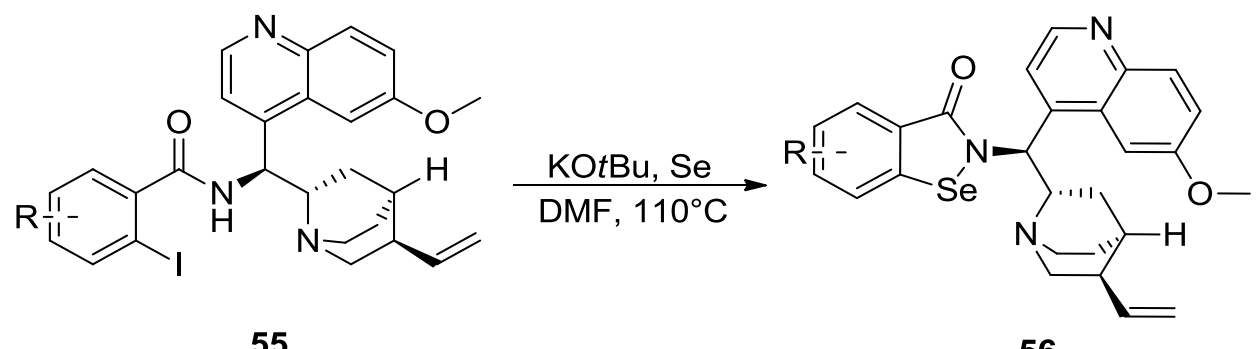

\section{Scheme 40: CuI/phen-Free Literature Benzisoselenazolone Synthesis}

The authors claimed that a reaction between $\mathrm{KO} t \mathrm{Bu}$ and $\mathrm{Se}^{0}$, formed the nucleophilic $[\mathrm{SeO} t \mathrm{Bu}]^{1-}$ anion. With this in mind, a series of experiments were undertaken in an attempt to generate selenium nucleophiles and react them with $o$-iodobenzamides.

Selenium was first treated with a base or reducing agent in DMF. At the same time, in another flask, copper-iodide and 1,10-phenanthroline were stirred together in DMF in an effort to make the corresponding copper complex. The aryl iodide $\mathbf{2}$ was then introduced to the catalyst mixture and the whole solution was added to the flask containing selenium. Table 4 contains a summary for reactions performed. 
Table 4: Attempts at Synthesizing Ebselen via Generation of Selenium Nucleophiles

\begin{tabular}{|l|l|l|l|l|l|}
\hline Reagent & Temp & Starting & $\mathbf{3}$ (d at & d at & s at \\
material & $\mathbf{8 . 0 9})$ & $\mathbf{8 . 5 5}$ & $\mathbf{9 . 1 0}$ \\
\hline 1 eq $\mathrm{K}_{2} \mathrm{CO}_{3}$ & $110^{\circ} \mathrm{C}$ & Consumed & $\mathrm{N}$ & $\mathrm{Y}$ & $\mathrm{N}$ \\
\hline 1 eq $\mathrm{KO} t \mathrm{Bu}$ & $110^{\circ} \mathrm{C}$ & Consumed & $\mathrm{N}$ & $\mathrm{Y}$ & $\mathrm{Y}$ \\
\hline 1 eq $\mathrm{NaH}$ & $70{ }^{\circ} \mathrm{C}$ & Consumed & $\mathrm{N}$ & $\mathrm{Y}$ & $\mathrm{Y}$ \\
\hline $2 \mathrm{q} \mathrm{NaH}$ & $70^{\circ} \mathrm{C}$ & Consumed & $\mathrm{N}$ & $\mathrm{Y}$ & $\mathrm{Y}$ \\
\hline 1 eq rongalite & $70^{\circ} \mathrm{C}$ & Present & $\mathrm{N}$ & $\mathrm{N}$ & $\mathrm{N}$ \\
\hline $\mathrm{H}_{2} \mathrm{~N}_{2}, \mathrm{LiOH}$ & $120^{\circ} \mathrm{C}$ & Consumed & $\mathrm{N}$ & $\mathrm{N}$ & $\mathrm{N}$ \\
\hline
\end{tabular}

The sodium hydride reactions were performed following the same literature procedure described in section 2.3.2. ${ }^{31}$ The hydrazine reaction was modelled after a literature procedure (Scheme 41$) .{ }^{39}$ Each reaction led to the complete consumption of starting material except for the reaction where selenium was prestirred with rongalite. However, a base is necessary for the mechanism of reduction via rongalite and therefore the reactions should be redone prestirring with rongalite as well as a base. These reactions were worked up via precipitation from saturated $\mathrm{NaCl}_{(\mathrm{aq})}$ and analyzed by ${ }^{1} \mathrm{H}-\mathrm{NMR}$. None of the NMR samples of the crude material shimmed well but the spectra obtained were clear enough to rule out the presence of ebselen and starting material. Interestingly, several of the crude samples displayed a doublet at $8.55 \mathrm{ppm}$ on ${ }^{1} \mathrm{H}-\mathrm{NMR}$. This product has not yet been identified. The spectra were compared to literature spectra for ebselen and its related mono and diselenide and were not found to contain them. The reactions where $\mathrm{NaH}$ or $\mathrm{KO} t \mathrm{Bu}$ was used also displayed an unidentified singlet at 9.10. 


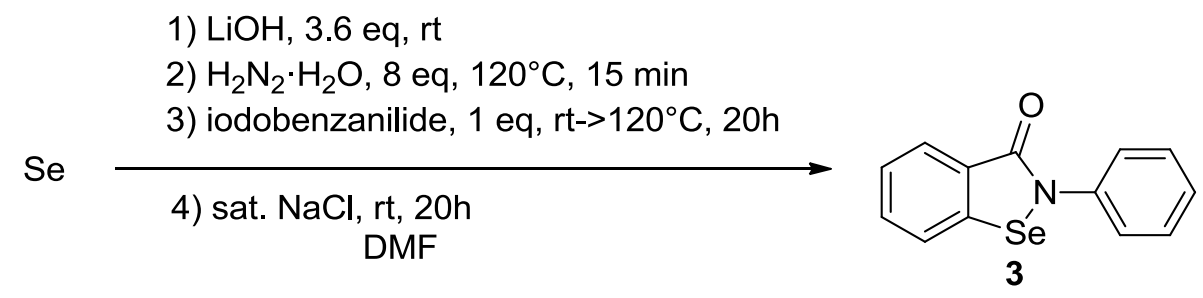

\section{Scheme 41: Synthesis of Ebselen via Selenium Reduced by Hydrazine}

\subsection{Engman Synthesis Revisited}

After finding the lithiation route toward ebselen to be the most reliable, it was decided that this route would be used to synthesize novel derivatives. Compound $\mathbf{6 0}$ does not exist in the literature and it and its derivative could be obtained starting from $p$-aminobenzoic acid (PABA) (Scheme 42).
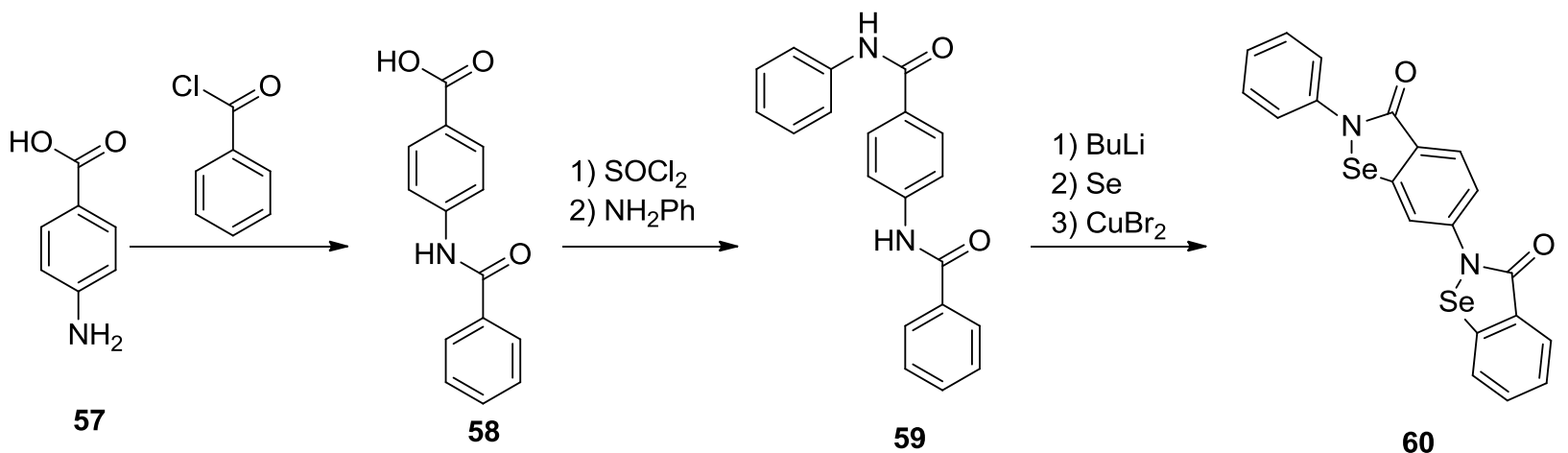

Scheme 42: Proposed Synthetic Pathway Toward Novel Ebselen Derivatives

\subsection{Preparation of Amide Precursors}

In order to simplify ${ }^{1} \mathrm{H}-\mathrm{NMR}$ analysis, diamide $\mathbf{6 1}$ (Scheme 43) was chosen as the first target. 


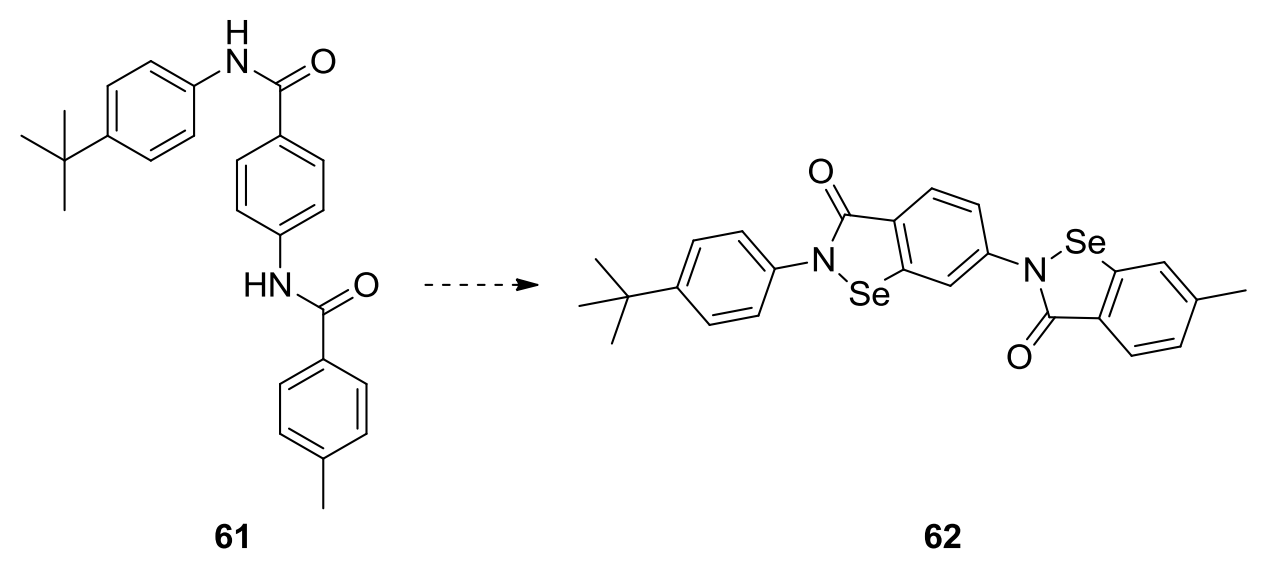

\section{Scheme 43: Cyclization of Target Diamide to Yield a Novel Ebselen Derivative}

The synthesis of amide $\mathbf{6 1}$ was attempted (Scheme 44), loosely following a literature procedure for reaction of anthranilic acid with benzoyl chlorides.<smiles>Nc1ccc(C(=O)O)cc1</smiles><smiles>Cc1ccc(C(=O)Cl)cc1C(F)(F)F</smiles><smiles>O=C(O)c1ccc(NC(=O)c2ccc(Br)cc2)cc1</smiles>

\section{Scheme 44: Synthesis of 4-(4-methylbenzamido)benzoic acid}

During work-up, the reaction mixture was poured into $1 \mathrm{M} \mathrm{HCl}$ and a precipitate formed, was collected by filtration, and found by ${ }^{1} \mathrm{H}-\mathrm{NMR}$ to be $p$-toluic acid. It was hypothesized that the acid chloride remained unreacted until the work-up.

The reaction was repeated in neat pyridine and the product showed pyridine contamination by ${ }^{1} \mathrm{H}-$ NMR as well as 2 singlets as opposed to the single expected methyl singlet (Figure 23). 


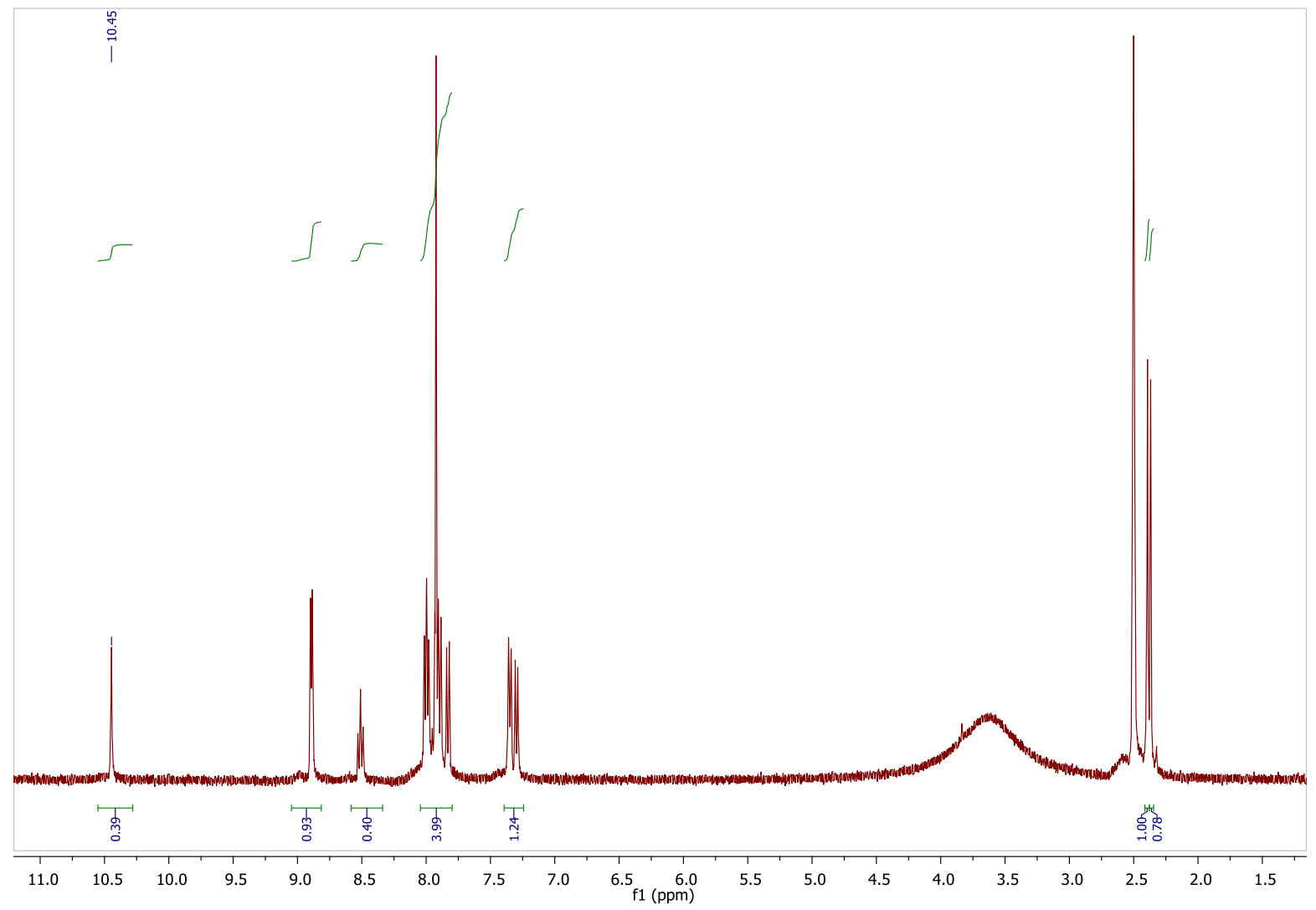

Figure 23: ${ }^{1} \mathrm{H}-\mathrm{NMR}$ of Crude Product in DMSO

A drop of $\mathrm{D}_{2} \mathrm{O}$ was added to the NMR tube to aid in identifying exchangeable protons (Figure 24). This caused the downfield proton resonating at $10.45 \mathrm{ppm}$ to be reduced in intensity considerably, providing evidence that it is the carboxyl proton. 


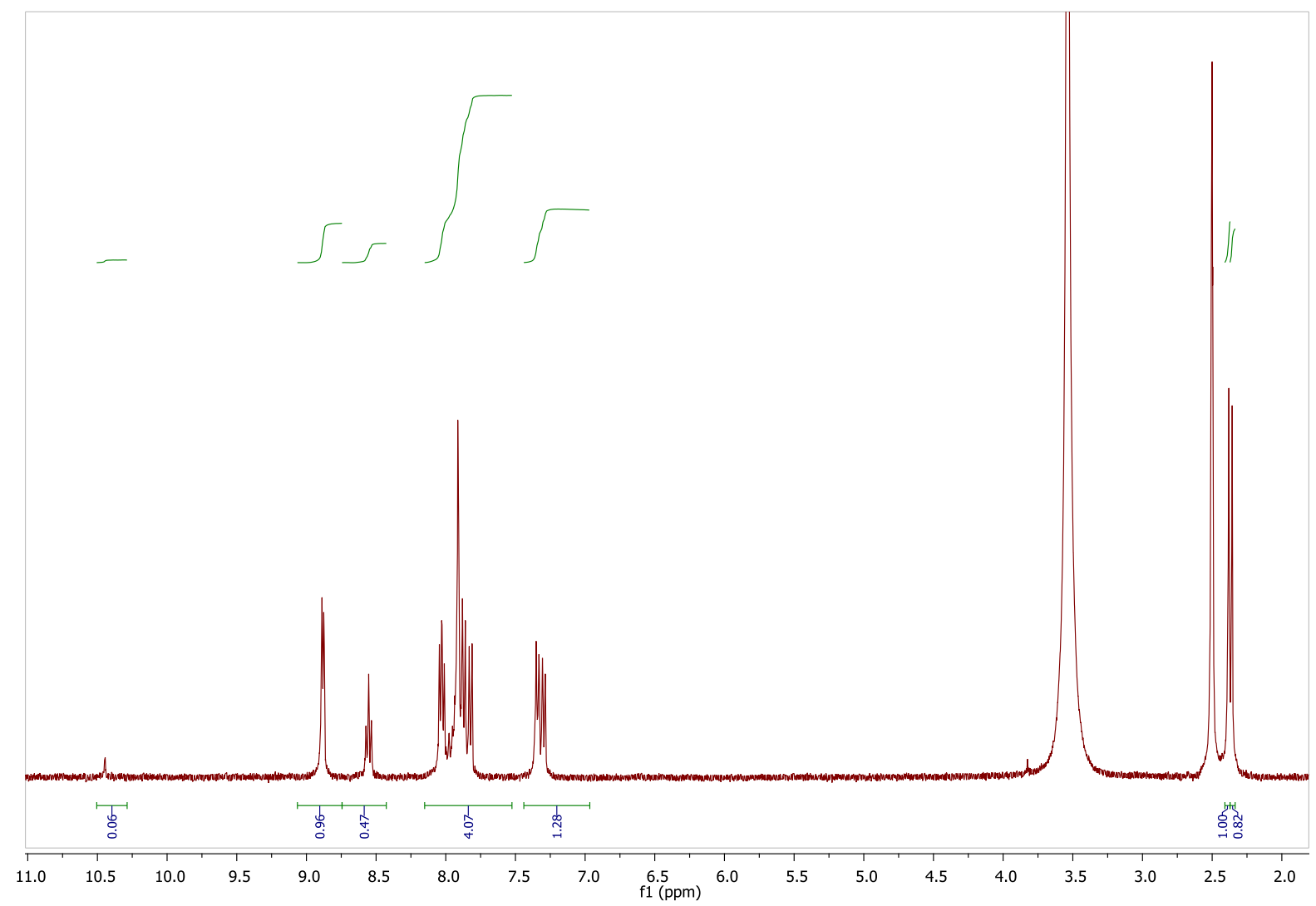

Figure 24: ${ }^{1} \mathrm{H}-\mathrm{NMR}$ of Crude Amide in DMSO + $\mathrm{D}_{2} \mathrm{O}$

The solid mass was washed with $\mathrm{Et}_{2} \mathrm{O}$ in an effort to remove pyridine. Further analysis needs to be done to decide if the extra singlet is due to contamination or due to the presence of rotational isomers.

\subsection{Future Work}

The cross-coupling reactions performed suffered low yields due to monoselenide formation. Diaryl monoselenides have medicinal value and a method for their simple preparation would be valuble. Further exploration needs to be done into which ligands, solvents and substrates favour selenide formation over benzisoselenazolone formation and vice-versa in order to optimize methods to selectively synthesize either the isoselenazolone or selenide product. The relationship between the 
$\mathrm{N}$-substituent and the extent of monoselenide formation should be investigated in an effort to verify Balkrishna's hypothesis regarding the effect of steric bulk. Various substitutions on the amido nitrogen would be tested and the ratio of selenide to benzisoselenazolone would be observed (Scheme 45).

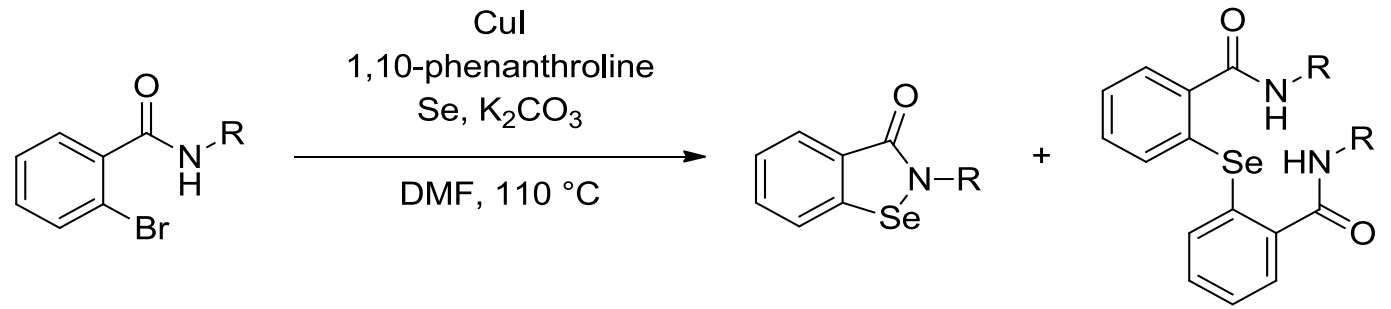

\section{Scheme 45: Analysis of Substituent Effect on Selenide Formation}

Efforts were unsuccessful in synthesizing benzisoselenazolone via directed metalation but its synthesis has been reported by Balkrishna et al. via the copper catalyzed methodology. If $\mathrm{N}$ substituent size does control selenide formation, it would be expected that the lack of an $\mathrm{N}$ substituent would lead to less selenide formation and therefore higher yields than those obtained for ebselen. While Balkrishnas group does not mention monoselenide formation in any of their benzisoselenazolone syntheses except for the $N$-t-butyl analog, they do report a higher yield for benzisoselenazolone than ebselen. ${ }^{22}$ The benzisoselenazolone synthesized could then be functionalized via a Buchwald-Hartwig type cross-coupling reaction (Scheme 46).

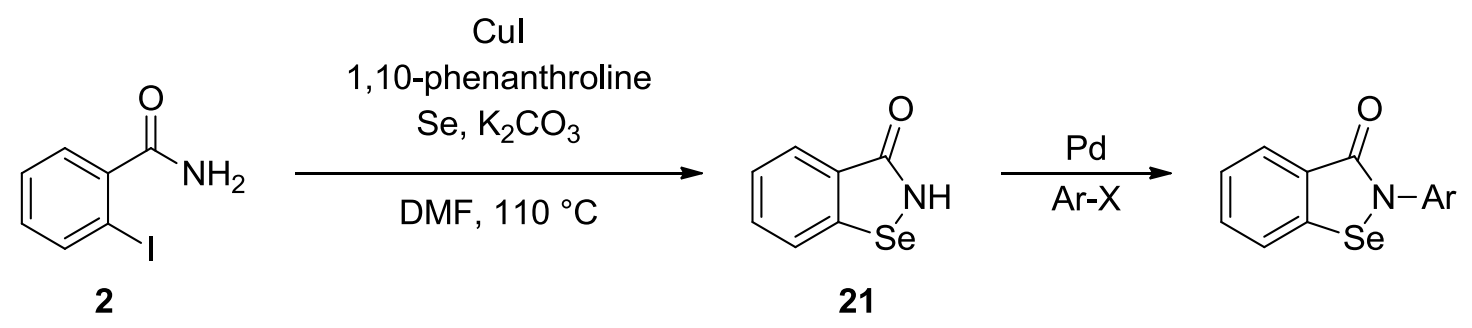

Scheme 46: Possible Route to Ebselen Analogs via CuI and Pd-Catalyzed Cross-Coupling 
As it has now been shown that palladium catalysis can be used to obtain benzisoselenazolones, experiments should be done to evaluate different ligands and optimize yields (Scheme 47).

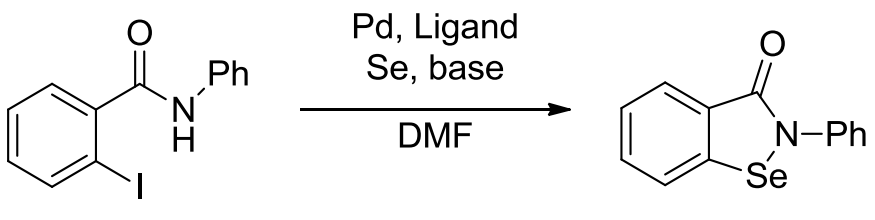

2

3

\section{Scheme 47: Palladium Catalyzed Ebselen Synthesis}

The directed metalation synthesis of benzisoselenazolones should be applied towards the synthesis of novel benzisoselenazolones based on the scaffold shown in Figure 25 in order to generate a library of compounds for biological testing. The starting benzamides would be synthesized from PABA and a library of derivatives.

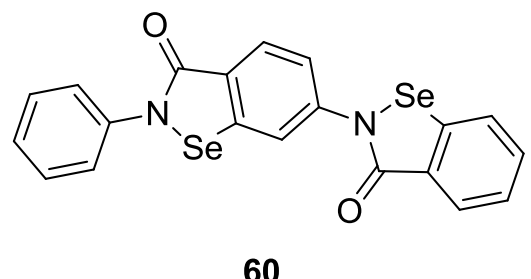

Figure 25: A Scaffold for Derivitization

\section{Conclusion}

While complications arose during the synthesis of ebselen, viable pathways were discovered. The optimization of the $o$-metalation reaction led to an $88 \%$ yield which was higher than reported in the literature). While the milder conditions of the cross-coupling would be ideal, the issue of 
monoselenide production still needs further investigation. This could lead to higher yields of ebselen or to a simple procedure for the synthesis of medicinal diarylselenides. 


\section{Experimental}

\section{General Information}

Nuclear magnetic resonance (NMR) experiments were done with a Bruker $400 \mathrm{MHz} \mathrm{NMR}$ spectrometer. Melting points were obtained in open air using a Fisher-Johns melting point apparatus and are uncorrected. All dry solvents were obtained from sure-sealed containers, from a solvent purification system or were distilled immediately prior to use. DMF for cross-coupling reactions was subjected to a freeze-pump-thaw cycle prior to use. TLC analysis was done using silica gel 60 F244 aluminium-backed TLC plates. Flash column chromatography was performed using Silicycle® 230-400 mesh silica gel. BuLi solutions were titrated against menthol with 2,2'bipyridine as an indicator. Reagents were sourced from Sigma-Aldrich unless otherwise noted. All transition metal catalyzed reactions were performed under nitrogen atmosphere. All spectral data is located in the appendix. NMR data was obtained using a Bruker Avance $400 \mathrm{Mhz}$ instrument. All reported ${ }^{13} \mathrm{C}$-NMR data was ${ }^{1} \mathrm{H}$-decoupled.

\subsection{Benzamides}

\section{General procedure}

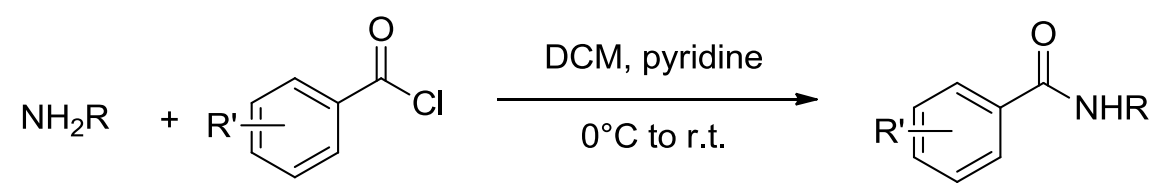

To a solution of the appropriate amine $(1.2 \mathrm{eq}, 2.4 \mathrm{M})$ and pyridine $(2 \mathrm{eq}, 4.1 \mathrm{M})$ in $\mathrm{DCM}$ at $0{ }^{\circ} \mathrm{C}$ was added dropwise via dropping funnel, a solution of the necessary benzoyl chloride (1.0 eq, 2.1 M) in DCM. The reaction was allowed to warm to room temperature and stirred for 12 hours. The reaction mixture was extracted five times with $0.1 \mathrm{M} \mathrm{HCl}_{(\mathrm{aq})}$, once with saturated $\mathrm{NaHCO}_{3(\mathrm{aq})}$ and 
once with saturated $\mathrm{NaCl}_{(\mathrm{aq})}$, the organic layer was dried with $\mathrm{MgSO}_{4}$ and the solvent was removed via rotary evaporator. The obtained solid was washed with diethyl ether to remove pyridine and no further purification was necessary. An additional portion of clean product was obtained via crystallization from the ether filtrate.

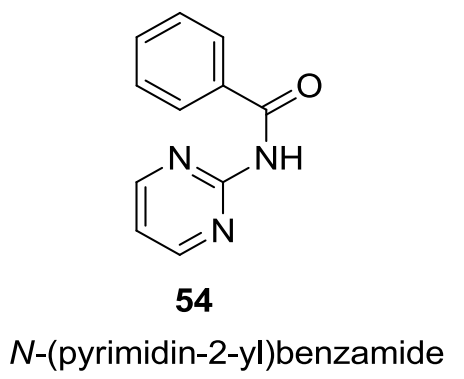

Yield: $7.5 \mathrm{~g}(75 \%) \mathrm{mp} 144.5-146{ }^{\circ} \mathrm{C}{ }^{1} \mathrm{H}$ NMR $\left(400 \mathrm{MHz},(\mathrm{CD})_{3} \mathrm{SO}\right) \delta 10.98(\mathrm{~s}, 1 \mathrm{H}), 8.73(\mathrm{~d}, J=$ $8.0 \mathrm{~Hz}, 2 \mathrm{H}), 7.97(\mathrm{~d}, J=8.0 \mathrm{~Hz}, 2 \mathrm{H}), 7.63-7.47(\mathrm{~m}, 3 \mathrm{H}), 7.25(\mathrm{t}, J=4.0 \mathrm{~Hz}, 1 \mathrm{H}) .{ }^{13} \mathrm{C}$ NMR $(101$ $\left.\mathrm{MHz},(\mathrm{CD})_{3} \mathrm{SO}\right) \quad \delta 166.0,158.8,158.7,134.7,132.5,128.8,128.7,117.8$

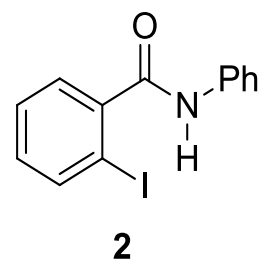

2-iodo- $N$-phenylbenzamide

Starting acid chloride was prepared by refluxing 2-iodobenzoic acid in $\mathrm{SOCl}_{2}$ overnight followed by the removal of $\mathrm{SOCl}_{2}$ by rotary evaporator.

Yield: $15 \mathrm{~g}(75 \%) \mathrm{mp} 148-151{ }^{\circ} \mathrm{C}^{1} \mathrm{H}$ NMR $\left(400 \mathrm{MHz}, \mathrm{CDCl}_{3}\right) \delta 7.89(\mathrm{~d}, J=8.0 \mathrm{~Hz}, 1 \mathrm{H}), 7.63(\mathrm{~d}$, $J=8.0 \mathrm{~Hz}, 2 \mathrm{H}), 7.58(\mathrm{~s}, 1 \mathrm{H}), 7.52-7.46(\mathrm{~m}, 1 \mathrm{H}), 7.45-7.32(\mathrm{~m}, 3 \mathrm{H}), 7.22-7.07(\mathrm{~m}, 2 \mathrm{H}) .{ }^{13} \mathrm{C}$ $\operatorname{NMR}\left(101 \mathrm{MHz}, \mathrm{CDCl}_{3}\right) \delta 167.3,142.1,140.0,137.6,131.5,129.1,128.6,128.3,124.9,120.2$ 92.4. 


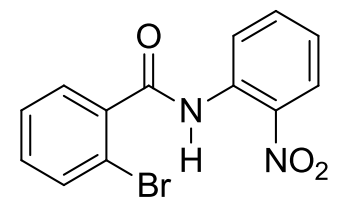

2-bromo-N-(2-nitrophenyl)benzamide

Yield: $2.4 \mathrm{~g}(48 \%) \mathrm{mp} 100-102{ }^{\circ} \mathrm{C}{ }^{1} \mathrm{H}$ NMR $\left(400 \mathrm{MHz},\left(\mathrm{CD}_{3}\right)_{2} \mathrm{CO}\right) \delta 10.40(\mathrm{~s}, 1 \mathrm{H}), 8.65-8.50$ (m, 1H), $8.22(\mathrm{~d}, J=8.4 \mathrm{~Hz}, 1 \mathrm{H}), 7.84(\mathrm{dd}, J=7.9 \mathrm{~Hz}, J=7.9 \mathrm{~Hz}, 1 \mathrm{H}), 7.78-7.70(\mathrm{~m}, 2 \mathrm{H}), 7.56$ $(\mathrm{dd}, J=7.4 \mathrm{~Hz}, J=7.4 \mathrm{~Hz}, 1 \mathrm{H}), 7.48(\mathrm{dd}, J=7.6 \mathrm{~Hz}, J=7.6 \mathrm{~Hz}, 1 \mathrm{H}), 7.43(\mathrm{dd}, J=7.8 \mathrm{~Hz}, J=$ 7.8 Hz, 1H). ${ }^{13} \mathrm{C}$ NMR (101 MHz, $\left.\mathrm{CDCl}_{3}\right) \delta 166.3,137.5,136.9,136.1,134.4,134.0,132.1,129.3$, $127.9,125.9,123.9,122.5,119.6$.<smiles>O=C(Nc1ccccc1)c1ccccc1Br</smiles>

2-bromo- $N$-phenylbenzamide

Yield: $5 \mathrm{~g}(99 \%) \mathrm{mp} 110-112{ }^{\circ} \mathrm{C}{ }^{1} \mathrm{H}$ NMR $\left(400 \mathrm{MHz},\left(\mathrm{CD}_{3}\right)_{2} \mathrm{CO}\right) \delta 9.50(\mathrm{bs}, 1 \mathrm{H}), 7.82(\mathrm{~d}, J=7.8$ $\mathrm{Hz}, 2 \mathrm{H}), 7.67(\mathrm{dd}, J=8.0 \mathrm{~Hz}, J=0.6 \mathrm{~Hz}, 1 \mathrm{H}), 7.57(\mathrm{dd}, J=7.6 \mathrm{~Hz}, J=1.7 \mathrm{~Hz}, 1 \mathrm{H}), 7.47(\mathrm{td}, J=$ $7.4 \mathrm{~Hz}, J=0.8 \mathrm{~Hz}, 1 \mathrm{H}), 7.42-7.22(\mathrm{~m}, 3 \mathrm{H}), 7.13(\mathrm{t}, J=7.4 \mathrm{~Hz}, 1 \mathrm{H}) .{ }^{13} \mathrm{C} \mathrm{NMR}(101 \mathrm{MHz}$, $\left.\left(\mathrm{CD}_{3}\right)_{2} \mathrm{CO}\right) \delta 165.9,137.8,137.7,133.4,131.4,129.4,129.0,127.5,124.8,120.2,119.4$.<smiles>COc1ccc(NC(=O)c2ccccc2Br)cc1</smiles>

2-bromo-N-(4-methoxyphenyl)benzamide 
Yield:1.2 g (40\%) mp 153-155 ${ }^{\circ} \mathrm{C}^{1} \mathrm{H}$ NMR $\left(400 \mathrm{MHz},\left(\mathrm{CD}_{3}\right)_{2} \mathrm{CO}\right) \delta 9.31(\mathrm{~s}, 1 \mathrm{H}), 7.73(\mathrm{~d}, J=9.0$ $\mathrm{Hz}, 2 \mathrm{H}), 7.66(\mathrm{~d}, J=8.0 \mathrm{~Hz}, 1 \mathrm{H}), 7.59-7.51(\mathrm{~m}, 1 \mathrm{H}), 7.46(\mathrm{dd}, J=7.1 \mathrm{~Hz}, J=7.1 \mathrm{~Hz} 1 \mathrm{H}), 7.41-$ $7.34(\mathrm{~m}, 1 \mathrm{H}), 6.94(\mathrm{~d}, J=9.0 \mathrm{~Hz}, 2 \mathrm{H}), 3.80(\mathrm{~s}, 3 \mathrm{H}) .{ }^{13} \mathrm{C} \mathrm{NMR}\left(101 \mathrm{MHz}, \mathrm{CDCl}_{3}\right) \delta$ 165.4, 156.9, $137.9,133.5,131.56,130.6,129.9,127.7,122.0,119.3,114.3,55.5$.

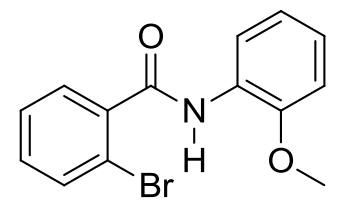

2-bromo-N-(2-methoxyphenyl)benzamide

Yield: $2.3 \mathrm{~g}(78 \%) \mathrm{mp} 90-91{ }^{\circ} \mathrm{C}{ }^{1} \mathrm{H}$ NMR $\left(400 \mathrm{MHz},\left(\mathrm{CD}_{3}\right)_{2} \mathrm{CO}\right) \delta 8.79(\mathrm{~s}, 1 \mathrm{H}), 8.44(\mathrm{~d}, J=7.8$ $\mathrm{Hz}, 1 \mathrm{H}), 7.69(\mathrm{~d}, J=8.0 \mathrm{~Hz}, 1 \mathrm{H}), 7.63(\mathrm{~d}, J=8.0 \mathrm{~Hz}, 1 \mathrm{H}), 7.49(\mathrm{dd}, J=8.0 \mathrm{~Hz}, J=8.0 \mathrm{~Hz}, 1 \mathrm{H})$, 7.44-7.36 (m, 1H), 7.16-6.96 (m, 3H), 3.87 (s, 3H). $\left.{ }^{13} \mathrm{C} \mathrm{NMR} \mathrm{(101} \mathrm{MHz,}\left(\mathrm{CD}_{3}\right)_{2} \mathrm{CO}\right) \delta$ 165.2, 149.0, 139.0, 133.2, 131.3, 129.3, 127.9, 127.7, 124.3, 120.5, 120.3, 119.0, 110.7, 55.4.

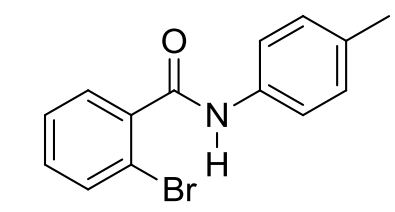

\section{2-bromo- $N$-( $p$-tolyl)benzamide}

Yield: $2.7 \mathrm{~g}(90 \%){ }^{1} \mathrm{H}$ NMR (400 MHz, DMSO) $\delta 10.37$ (s, 1H), 7.71 (d, $\left.J=7.9 \mathrm{~Hz}, 1 \mathrm{H}\right), 7.61(\mathrm{~d}$, $J=8.3 \mathrm{~Hz}, 2 \mathrm{H}), 7.56-7.45(\mathrm{~m}, 2 \mathrm{H}), 7.41(\mathrm{ddd}, J=7.7 \mathrm{~Hz}, J=7.7 \mathrm{~Hz}, J=1.7 \mathrm{~Hz}, 1 \mathrm{H}), 7.15(\mathrm{~d}$, $J=8.3 \mathrm{~Hz}, 2 \mathrm{H}), 2.28(\mathrm{~s}, 3 \mathrm{H}) .{ }^{13} \mathrm{C} \mathrm{NMR}\left(101 \mathrm{MHz}, \mathrm{CDCl}_{3}\right) \delta 165.4,156.9,137.9,133.5,131.6$, $130.6,129.9,127.7,122.0,119.3,114.3,55.5$. 


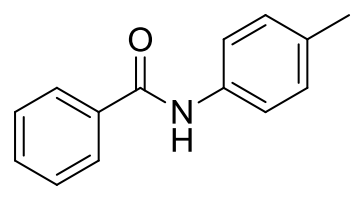

$N$-(p-tolyl)benzamide

Yield: $4.8 \mathrm{~g}(96 \%){ }^{1} \mathrm{H}$ NMR (400 MHz, $\left.\left(\mathrm{CD}_{3}\right)_{2} \mathrm{CO}\right) \delta 9.41(\mathrm{~s}, 1 \mathrm{H}), 7.98(\mathrm{~d}, J=7.3 \mathrm{~Hz}, 2 \mathrm{H}), 7.72$ (d, $J=8.3 \mathrm{~Hz}, 2 \mathrm{H}), 7.60-7.40(\mathrm{~m}, 3 \mathrm{H}), 7.16(\mathrm{~d}, J=8.2 \mathrm{~Hz}, 2 \mathrm{H}), 2.30(\mathrm{~s}, 3 \mathrm{H}) .{ }^{13} \mathrm{C} \mathrm{NMR}(101 \mathrm{MHz}$, $\left.\left(\mathrm{CD}_{3}\right)_{2} \mathrm{CO}\right) \delta 165.2,137.0,135.6,133.0,131.3,129.0,128.3,127.4,120.2,20.0$.

\subsection{BOC-Protected Benzamide}

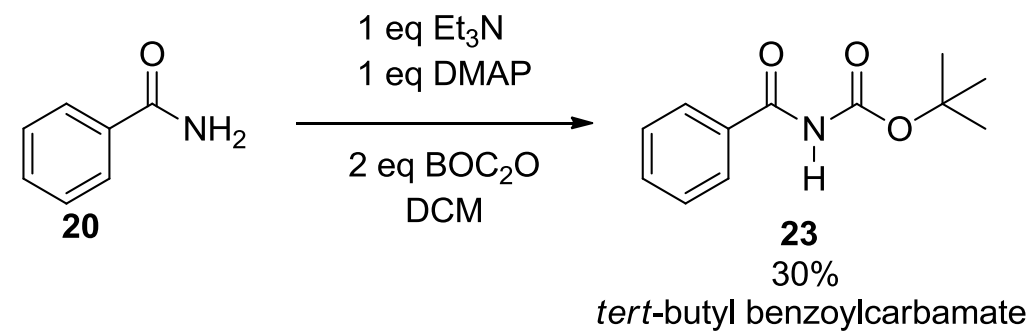

A solution containing triethylamine $(1.2 \mathrm{~mL}, 8.25 \mathrm{mmol})$ and DMAP $(1 \mathrm{~g}, 8.25 \mathrm{mmol})$ was charged with $1 \mathrm{~g}(8.25 \mathrm{mmol})$ of benzamide. The solution was then cooled to $0^{\circ} \mathrm{C}$ and $3.6 \mathrm{~g}(16.5$ mmol) of BOC anhydride were added. The reaction was allowed to warm to room temperature and was stirred overnight. The organic layer was then was then extracted with 3 times with $0.1 \mathrm{M}$ $\mathrm{HCl}_{(\mathrm{aq})}$, once with saturated $\mathrm{NaHCO}_{3(\mathrm{aq})}$ and once with saturated $\mathrm{NaCl}(\mathrm{aq})$. The organic layer was then dried with $\mathrm{MgSO}_{4}$ and removed via rotary evaporator. Column chromatography (20\% EtOAc in hexanes) yielded a bright white powder. Recrystallization from ethyl acetate provided needlelike crystals.

Yield: $0.9 \mathrm{~g}(30 \%){ }^{1} \mathrm{H}$ NMR $\left(400 \mathrm{MHz}, \mathrm{CDCl}_{3}\right) \delta 8.04(\mathrm{~s}, 1 \mathrm{H}), 7.83-7.78(\mathrm{~m}, 2 \mathrm{H}), 7.58-7.52(\mathrm{~m}$, 1H) $7.48-7.52(\mathrm{~m}, 2 \mathrm{H}), 1.52(\mathrm{~s}, 9 \mathrm{H}) .{ }^{13} \mathrm{C}$ NMR $\left(101 \mathrm{MHz}, \mathrm{CDCl}_{3}\right) \delta$ 165.3, 149.7, 133.4, 132.7, $128.8,127.5,82.8,28.0$. 


\subsection{Selenides}

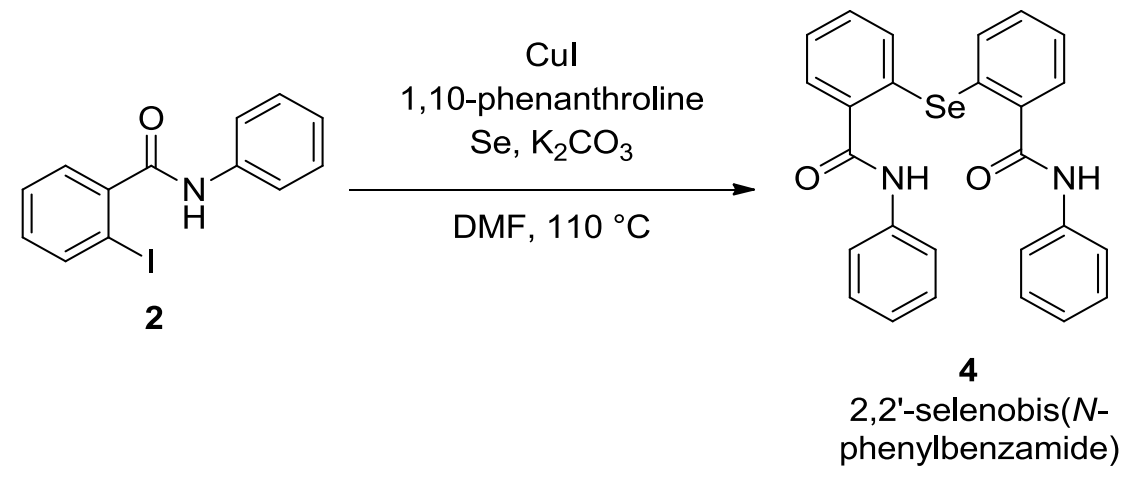

Copper iodide (114 mg, $0.6 \mathrm{mmol})$ and 1,10-phenanthroline $(108 \mathrm{mg}, 0.6 \mathrm{mmol})$ were stirred in 3 $\mathrm{mL}$ of DMF at room temperature for 15 minutes. Iodobenzanilide $(0.97 \mathrm{~g}, 3.0 \mathrm{mmol})$, selenium $(0.29 \mathrm{~g}, 3.6 \mathrm{mmol})$ and potassium $t$-butoxide $(0.53 \mathrm{~g}, 4.7 \mathrm{mmol})$ were then added sequentially. The reaction was heated to $110^{\circ} \mathrm{C}$ and monitored by TLC. After 12 hours, the reaction was poured into $60 \mathrm{~mL}$ of saturated brine solution and stirred for 3 hours. The mixture was then filtered through a Buchner funnel, washed with $\mathrm{H}_{2} \mathrm{O}$ and dried in air. Column chromatography was performed in $20 \%$ EtOAc in hexanes. The collected solid was then further purified by washing it with ethyl acetate to remove ebselen.

Yield: $0.25 \mathrm{~g}(35 \%){ }^{1} \mathrm{H}$ NMR $\left(400 \mathrm{MHz},\left(\mathrm{CD}_{3}\right)_{2} \mathrm{SO}\right) \delta 10.41(\mathrm{~s}, 2 \mathrm{H}), 7.75-7.60(\mathrm{~m}, 6 \mathrm{H}), 7.50-7.25$ (m, 10H), $7.09(\mathrm{dd}, J=7.4 \mathrm{~Hz}, J=7.4 \mathrm{~Hz}, 2 \mathrm{H}) .{ }^{13} \mathrm{C} \mathrm{NMR}\left(101 \mathrm{MHz},\left(\mathrm{CD}_{3}\right)_{2} \mathrm{SO}\right) \delta 167.2,139.6$ $139.4,134.5,132.3,131.3,129.1,128.6,127.7,124.2,120.42$. 

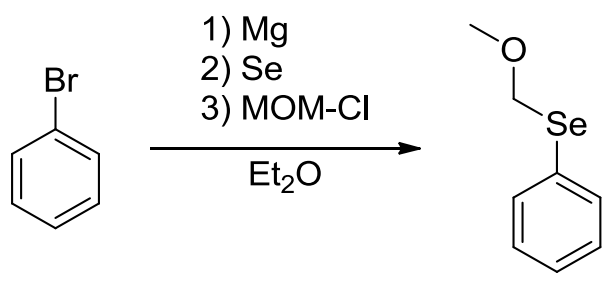

37

(methoxymethyl)(phenyl)selane

To a $100 \mathrm{~mL} 3$-neck flask containing $40 \mathrm{~mL}$ of diethyl ether were added $0.29 \mathrm{~g}$ of magnesium turnings (11.93 mmol, $1.2 \mathrm{eq}$ ) and a small crystal of iodine. This mixture was allowed to stir until it became colourless, at which point $1.0 \mathrm{~mL}(9.94 \mathrm{mmol}, 1 \mathrm{eq})$ of bromobenzene were added. The solution was then warmed until reflux. Elemental selenium ( $0.744 \mathrm{~g}, 9.42 \mathrm{mmol}, 0.95 \mathrm{eq})$ was then added slowly at a rate that maintained the refluxing of the solvent without further heating. The solution was then added drop wise to a stirring $0{ }^{\circ} \mathrm{C}$ solution of MOM-Cl $(2.3 \mathrm{~mL}, 29.82 \mathrm{mmol}, 3$ eq) in $60 \mathrm{~mL}$ diethyl ether. The solution was allowed to warm to room temperature and monitored by TLC. Once the Grignard reagent appeared to be consumed, the reaction was diluted with diethyl ether, extracted $3 \mathrm{x}$ with distilled water and purified via column chromatography (neat DCM).

Yield: $1.3 \mathrm{~g}(65 \%){ }^{1} \mathrm{H}$ NMR (400 MHz, $\left.\left(\mathrm{CD}_{3}\right)_{2} \mathrm{CO}\right) \delta$ 7.65-7.55 (m, 2H), 7.35-7.20 (m, 3H), 5.30 $\left(\mathrm{s}, 2 \mathrm{H},{ }^{77} \mathrm{Se}\right.$ satellite observed, $\left.{ }^{2} J=20.0 \mathrm{~Hz}\right), 3.36(\mathrm{~s}, 3 \mathrm{H}) .{ }^{13} \mathrm{C}$ NMR $\left(101 \mathrm{MHz},\left(\mathrm{CD}_{3}\right)_{2} \mathrm{CO}\right) \delta 132.6$ $\left({ }^{77}\right.$ Se satellite observed, $\left.J=9.0 \mathrm{~Hz}\right), 131.0\left({ }^{77} \mathrm{Se}\right.$ satellite observed, $\left.J=105.0 \mathrm{~Hz}\right) 129.1,127.0$, 74.3, $56.2\left({ }^{77}\right.$ Se satellite observed, $\left.{ }^{1} J=77.8 \mathrm{~Hz}\right)$. 


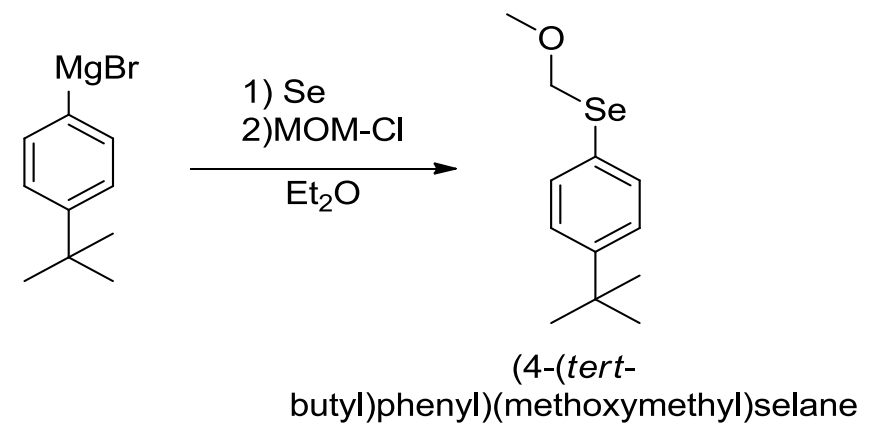

To a $100 \mathrm{~mL} 3$-neck flask containing $60 \mathrm{~mL}$ of diethyl ether were added $7.8 \mathrm{~mL}$ of a $2 \mathrm{M}$ solution of $t$-butylphenylmagnesium bromide $(15.6 \mathrm{mmol}, 1 \mathrm{eq})$. The solution was then warmed until reflux. Elemental selenium ( $1.156 \mathrm{~g}, 14.8 \mathrm{mmol}, 0.95 \mathrm{eq})$ was then added slowly at a rate that maintained the refluxing of the solvent without further heating. The solution was then added drop wise to a stirring $0{ }^{\circ} \mathrm{C}$ solution of MOM-Cl $(3.6 \mathrm{~mL}, 46.8 \mathrm{mmol}, 3 \mathrm{eq})$ in $90 \mathrm{~mL}$ diethyl ether. The solution was allowed to warm to room temperature and monitored by TLC. Once the Grignard reagent appeared to be consumed, the reaction was diluted with diethyl ether, extracted $3 \times$ with distilled water and purified via column chromatography (neat DCM).

Yield: $1.4 \mathrm{~g}(35 \%){ }^{1} \mathrm{H}$ NMR $\left(400 \mathrm{MHz}, \mathrm{CDCl}_{3}\right) \delta$ 7.55-7.45 (m, 2H), 7.35-7.27 (m, 2H), $5.21(\mathrm{~s}$, $2 \mathrm{H},{ }^{77} \mathrm{Se}$ satellite observed, $\left.{ }^{1} \mathrm{~J}=20.0 \mathrm{~Hz}\right), 3.41(\mathrm{~s}, 3 \mathrm{H}), 1.30(\mathrm{~s}, 9 \mathrm{H}) .{ }^{13} \mathrm{C} \mathrm{NMR}\left(101 \mathrm{MHz}, \mathrm{CDCl}_{3}\right)$ $\delta 150.4,133.0,126.9,126.2,74.7,57.0,34.5,31.3$. 


\subsection{Diselenides}

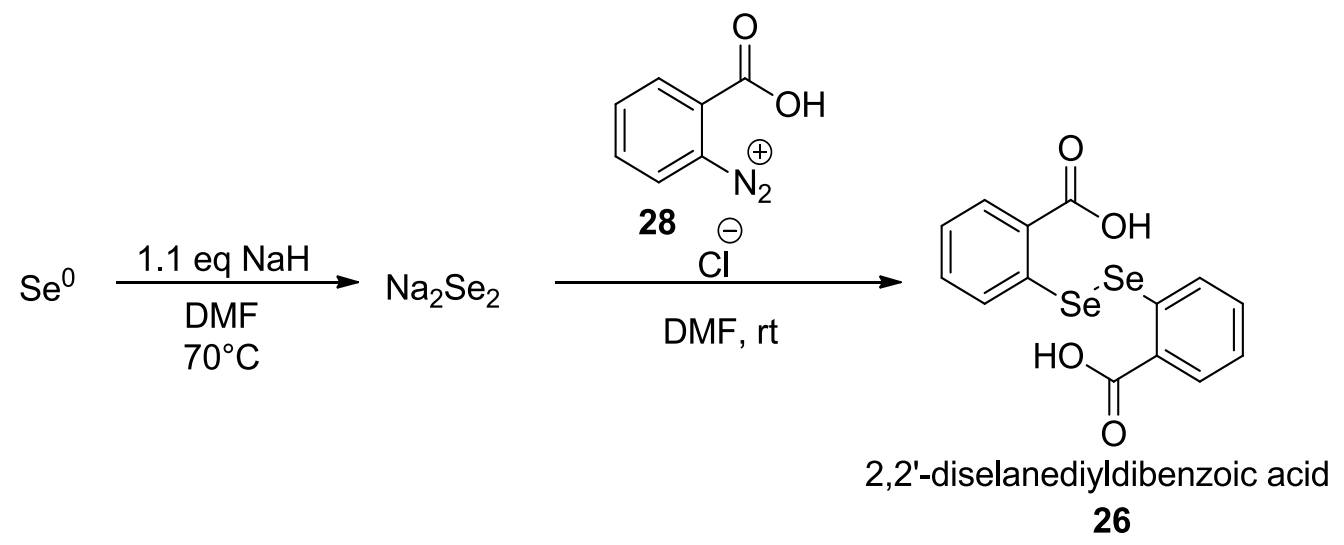

A solution of sodium nitrite $1.1 \mathrm{~g}(16 \mathrm{mmol})$ in $3 \mathrm{~mL}$ water was added dropwise to a solution containing $1.75 \mathrm{~g}(12.8 \mathrm{mmol})$ anthranilic acid and $3 \mathrm{~mL}$ concentrated $\mathrm{HCl}$ in $3 \mathrm{~mL}$ water. The resulting solution was added dropwise to a solution of sodium hydride $(0.335 \mathrm{~g}, 14 \mathrm{mmol})$ and selenium (0.998 $\mathrm{g}, 12.8 \mathrm{mmol})$ that had been stirring in $30 \mathrm{~mL} \mathrm{DMF}$ at $70{ }^{\circ} \mathrm{C}$ for 2 hours before being cooled to room temperature. After 2 hours, the reaction was acidified with $\mathrm{HCl}$ and the precipitate was collected by filtration. The precipitate was further purified by dissolving it in aqueous base, filtering, and then collecting the precipitate that formed upon acidification.

Yield: $0.62 \mathrm{~g}(24 \%){ }^{1} \mathrm{H}$ NMR $\left(400 \mathrm{MHz},\left(\mathrm{CD}_{3}\right)_{2} \mathrm{SO}\right) \delta 13.72(\mathrm{~s}, 2 \mathrm{H}), 8.03(\mathrm{~d}, J=7.7 \mathrm{~Hz}, 2 \mathrm{H}), 7.67$ $(\mathrm{d}, J=8.1 \mathrm{~Hz}, 2 \mathrm{H}), 7.49(\mathrm{dd}, J=7.6 \mathrm{~Hz}, J=7.6 \mathrm{~Hz} 2 \mathrm{H}), 7.36(\mathrm{dd}, J=7.5 \mathrm{~Hz}, J=7.5 \mathrm{~Hz} 2 \mathrm{H})$. 
<smiles>BrCc1ccccc1</smiles>

15

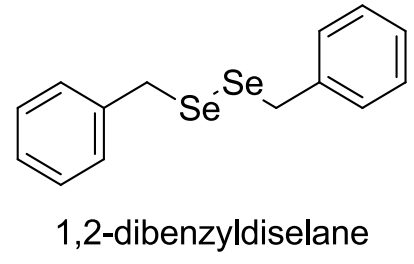

16

To a solution of PEG-200 (0.025 mmol, $5 \mathrm{mg})$ and $3 \mathrm{~mL}$ of $10 \mathrm{M} \mathrm{NaOH}_{(\mathrm{aq})}(30 \mathrm{mmol}$,$) in 10 \mathrm{~mL}$ toluene was added selenium powder $(3.67 \mathrm{mmol}, 0.286 \mathrm{~g})$. The reaction was then stirred at $70^{\circ} \mathrm{C}$ until 3 hours had elapsed, at which point benzyl bromide $(2.94 \mathrm{mmol}, 0.35 \mathrm{~mL})$ was added and the reaction was stirred for an additional hour. The organic layer was separated, washed with water and evaporated by rotary evaporator. The resulting crude compound was purified by crystallization from hexane.

Yield: $0.08 \mathrm{~g}(8 \%){ }^{1} \mathrm{H}$ NMR $\left(400 \mathrm{MHz},\left(\mathrm{CD}_{3}\right)_{2} \mathrm{CO}\right) \delta 7.39-7.18(\mathrm{~m}, 10 \mathrm{H}), 3.94(\mathrm{~s}, 4 \mathrm{H}) .{ }^{13} \mathrm{C} \mathrm{NMR}$ $\left(101 \mathrm{MHz},\left(\mathrm{CD}_{3}\right)_{2} \mathrm{CO}\right) \delta 139.4,129.0,128.4,127.0,32.1$.

\subsection{Benzisoselenazolones}

\subsubsection{Cross Coupling}

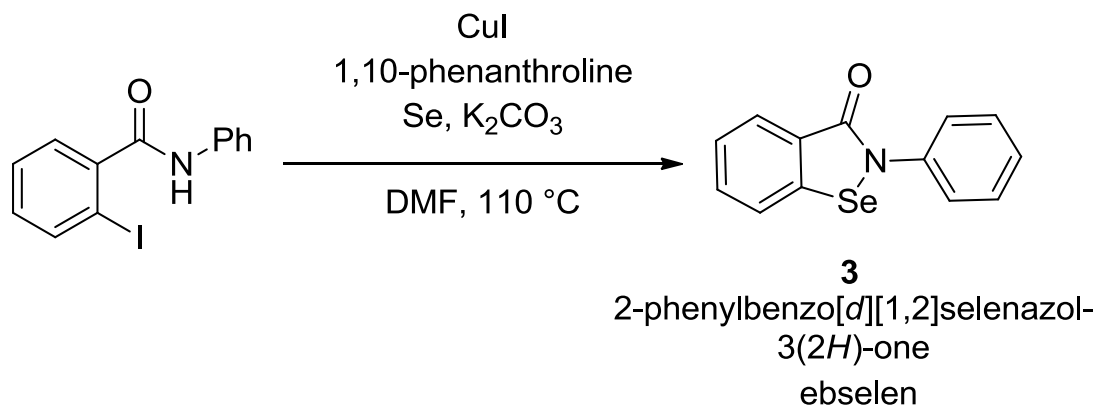

A solution of 1,10-phenanthroline $(108 \mathrm{mg}, 0.6 \mathrm{mmol})$, Iodobenzanilide $(0.97 \mathrm{~g}, 3.0 \mathrm{mmol})$, selenium $(0.29 \mathrm{~g}, 3.6 \mathrm{mmol})$ and potassium $t$-butoxide $(0.53 \mathrm{~g}, 4.7 \mathrm{mmol})$ in $3 \mathrm{~mL}$ of DMF was heated to $110{ }^{\circ} \mathrm{C}$. Copper iodide $(114 \mathrm{mg}, 0.6 \mathrm{mmol})$ was then added and the reaction was 
monitored by TLC. After 12 hours, the reaction was poured into $60 \mathrm{~mL}$ of saturated brine solution and stirred for 3 hours. The mixture was then filtered through a Büchner funnel, washed with $\mathrm{H}_{2} \mathrm{O}$ and dried in air. Column chromatography was performed in 20\% EtOAc in hexanes. The collected solid was then further purified by dissolving in ethyl acetate, filtering the undissolved monoselenide and then evaporating the solvent via rotary evaporator.

Yield: $0.33 \mathrm{~g}(40 \%)$

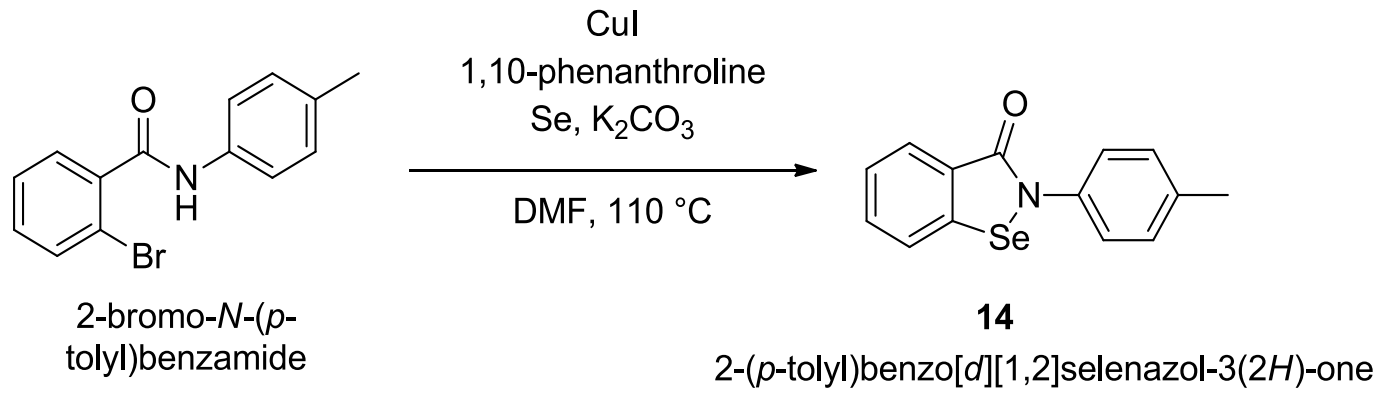

Copper iodide (114 mg, $0.6 \mathrm{mmol})$ and 1,10-phenanthroline (108 mg, $0.6 \mathrm{mmol})$ were stirred in 3 $\mathrm{mL}$ of DMF at room temperature for 15 minutes. Bromo- $N$-( $p$-tolyl)benzamide $(0.870 \mathrm{~g}, 3.0$ $\mathrm{mmol})$, selenium $(0.29 \mathrm{~g}, 3.6 \mathrm{mmol})$ and potassium $t$-butoxide $(0.53 \mathrm{~g}, 4.7 \mathrm{mmol})$ were then added sequentially. The reaction was heated to $110{ }^{\circ} \mathrm{C}$ and monitored by TLC. After 12 hours, the reaction was poured into $60 \mathrm{~mL}$ of saturated brine solution and stirred for 3 hours. The mixture was then filtered through a Buchner funnel, washed with $\mathrm{H}_{2} \mathrm{O}$ and dried in air. Column chromatography was performed in $20 \%$ EtOAc in hexanes.

Yield: $0.199 \mathrm{~g}(23 \%)$ 


\subsubsection{Directed Metalation}

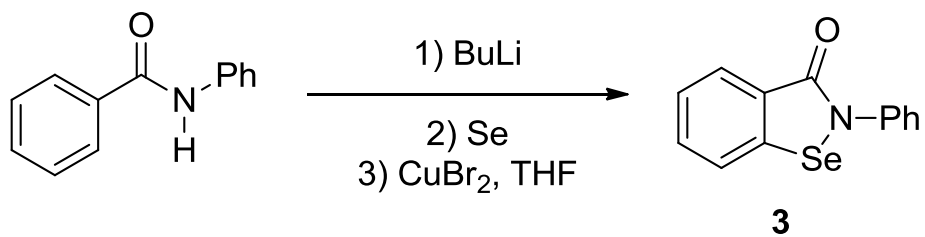

To a solution of benzanilide $(1.0 \mathrm{~g}, 5.1 \mathrm{mmol})$ in $35 \mathrm{~mL}$ THF at $0^{\circ} \mathrm{C}$ was added $n$-butyl lithium (10.2 mmol). After 30 minutes, $0.4 \mathrm{~g}$ of selenium $(5.1 \mathrm{mmol})$ was added. After another 30 minutes, the solution was cooled to $-85^{\circ} \mathrm{C}$ in an $\mathrm{EtOAc} / \mathrm{N}_{2(1)}$ bath and $2.28 \mathrm{~g}(10.2 \mathrm{mmol})$ of $\mathrm{CuBr}_{2}$ were added. After 30 minutes the reaction was allowed to slowly warm to room temperature at which point a drop of $1 / 1(\mathrm{v} / \mathrm{v}) \mathrm{AcOH}$ and $\mathrm{H}_{2} \mathrm{O}$ were added to the reaction mixture, it was then diluted with $30 \mathrm{~mL} \mathrm{THF}$, filtered through celite and evaporated on rotary evaporator. Column chromatography from neat DCM afford a white solid.

Yield: $1.23 \mathrm{~g}(88 \%){ }^{1} \mathrm{H}-\mathrm{NMR}\left(400 \mathrm{MHz}, \mathrm{CDCl}_{3}\right) \delta 8.14(\mathrm{~d}, \mathrm{~J}=7.7 \mathrm{~Hz}, 1 \mathrm{H}), 7.70-7.62(\mathrm{~m}, 4 \mathrm{H})$, 7.52-7.42 (m,3H), $7.31(\mathrm{~m}, 1 \mathrm{H}) .{ }^{13} \mathrm{C}-\mathrm{NMR}\left(101 \mathrm{MHz}, \mathrm{CDCl}_{3}\right) \delta 165.7,139.0,137.6,132.6,129.4$, $129.3,129.2,126.8,126.6,125.4,123.7$.

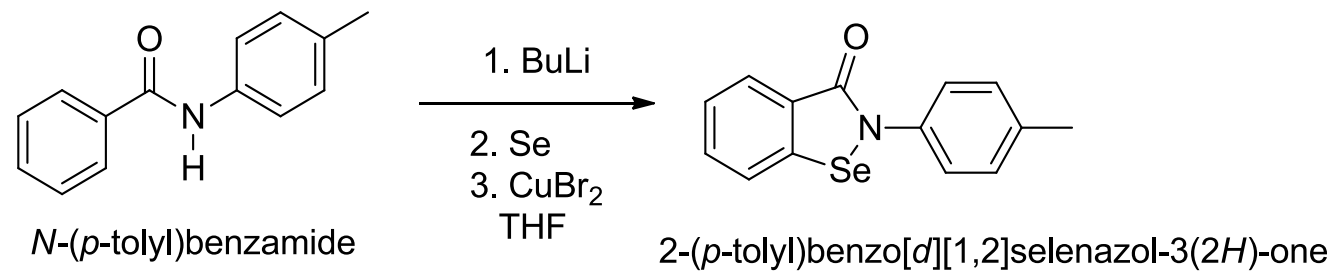

To a solution of $N$-(p-tolyl)benzamide $(1.1 \mathrm{~g}, 5.1 \mathrm{mmol})$ in $35 \mathrm{~mL}$ THF at $0^{\circ} \mathrm{C}$ was added $n$-butyl lithium (10.2 mmol). After 30 minutes $0.4 \mathrm{~g}$ of selenium $(5.1 \mathrm{mmol})$ was added. After 30 minutes the solution was cooled to $-85^{\circ} \mathrm{C}$ in an EtOAc/ $\mathrm{N}_{2(1)}$ bath and $2.28 \mathrm{~g}(10.2 \mathrm{mmol})$ of $\mathrm{CuBr}_{2}$ were added. After 30 minutes the reaction was allowed to slowly warm to room temperature at which point a drop of $1 / 1(\mathrm{v} / \mathrm{v}) \mathrm{AcOH}$ and $\mathrm{H}_{2} \mathrm{O}$ were added to the reaction mixture, it was then diluted 
with $30 \mathrm{~mL}$ THF, filtered through celite and evaporated on rotary evaporator. Column chromatography from neat DCM afford a white solid.

Yield: $0.397 \mathrm{~g}(27 \%){ }^{1} \mathrm{H}$ NMR $\left(400 \mathrm{MHz},\left(\mathrm{CD}_{3}\right)_{2} \mathrm{SO}\right) \delta 8.08(\mathrm{~d}, J=8.1 \mathrm{~Hz}, 1 \mathrm{H}), 7.89(\mathrm{~d}, J=7.8$ $\mathrm{Hz}, 1 \mathrm{H}), 7.68(\mathrm{t}, J=7.6 \mathrm{~Hz}, 1 \mathrm{H}), 7.55-7.37(\mathrm{~m}, 3 \mathrm{H}), 7.25(\mathrm{~d}, J=8.2 \mathrm{~Hz}, 2 \mathrm{H}), 2.33(\mathrm{~s}, 3 \mathrm{H}) .{ }^{13} \mathrm{C}$ NMR (101 MHz, $\left.\left(\mathrm{CD}_{3}\right)_{2} \mathrm{SO}\right) \delta 165.4,139.3,137.6,135.7,132.6,130.1,129.0,128.4,126.7,126.3$, 125.1, 21.0. 


\section{Appendix}

${ }^{1} \mathrm{H}-\mathrm{NMR}$ of $\mathbf{5 4}$ in $\left(\mathrm{CD}_{3}\right)_{2} \mathrm{CO}$

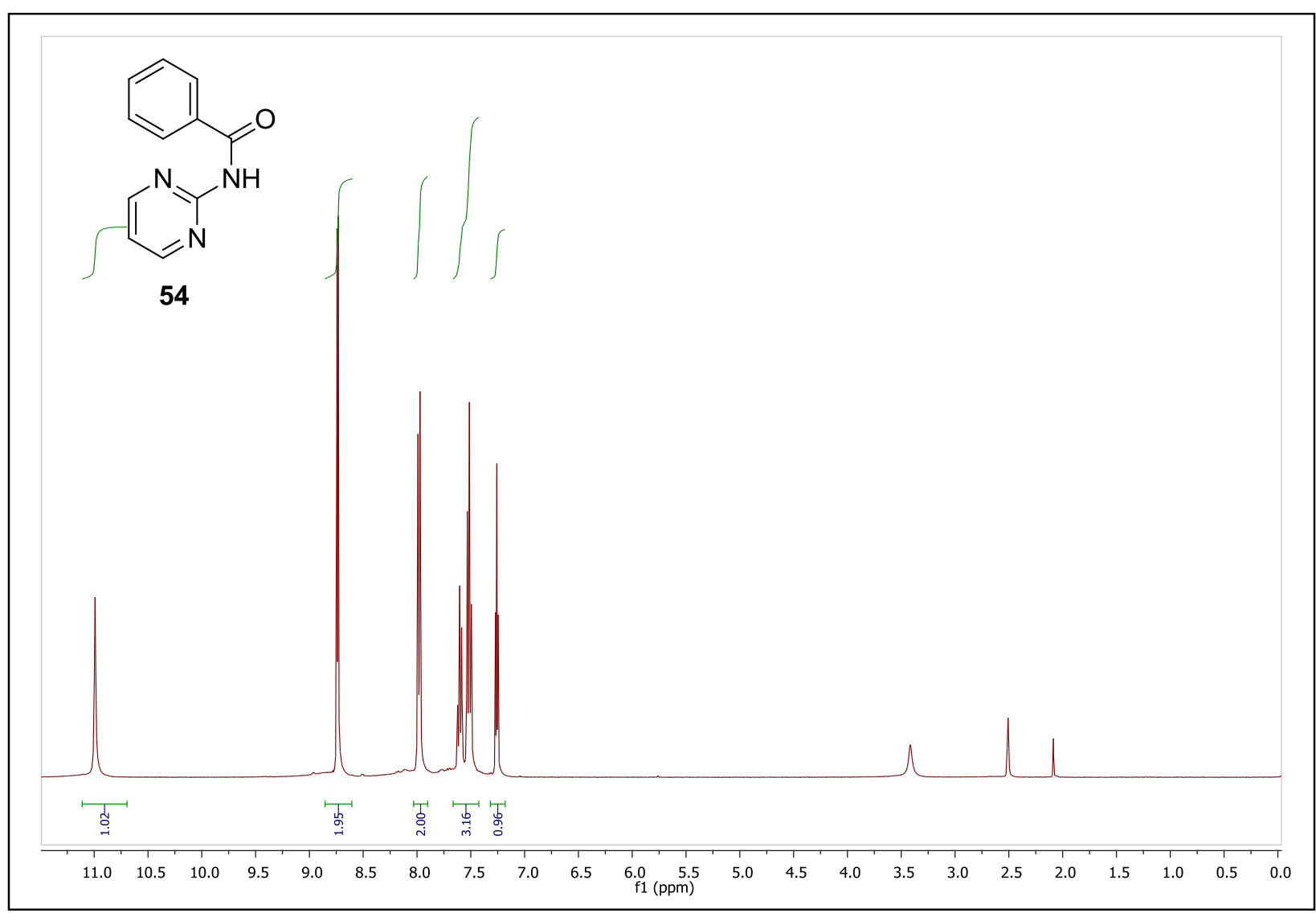


${ }^{13} \mathrm{C}-\mathrm{NMR}$ of $\mathbf{5 4}$ in $\left(\mathrm{CD}_{3}\right)_{2} \mathrm{CO}$

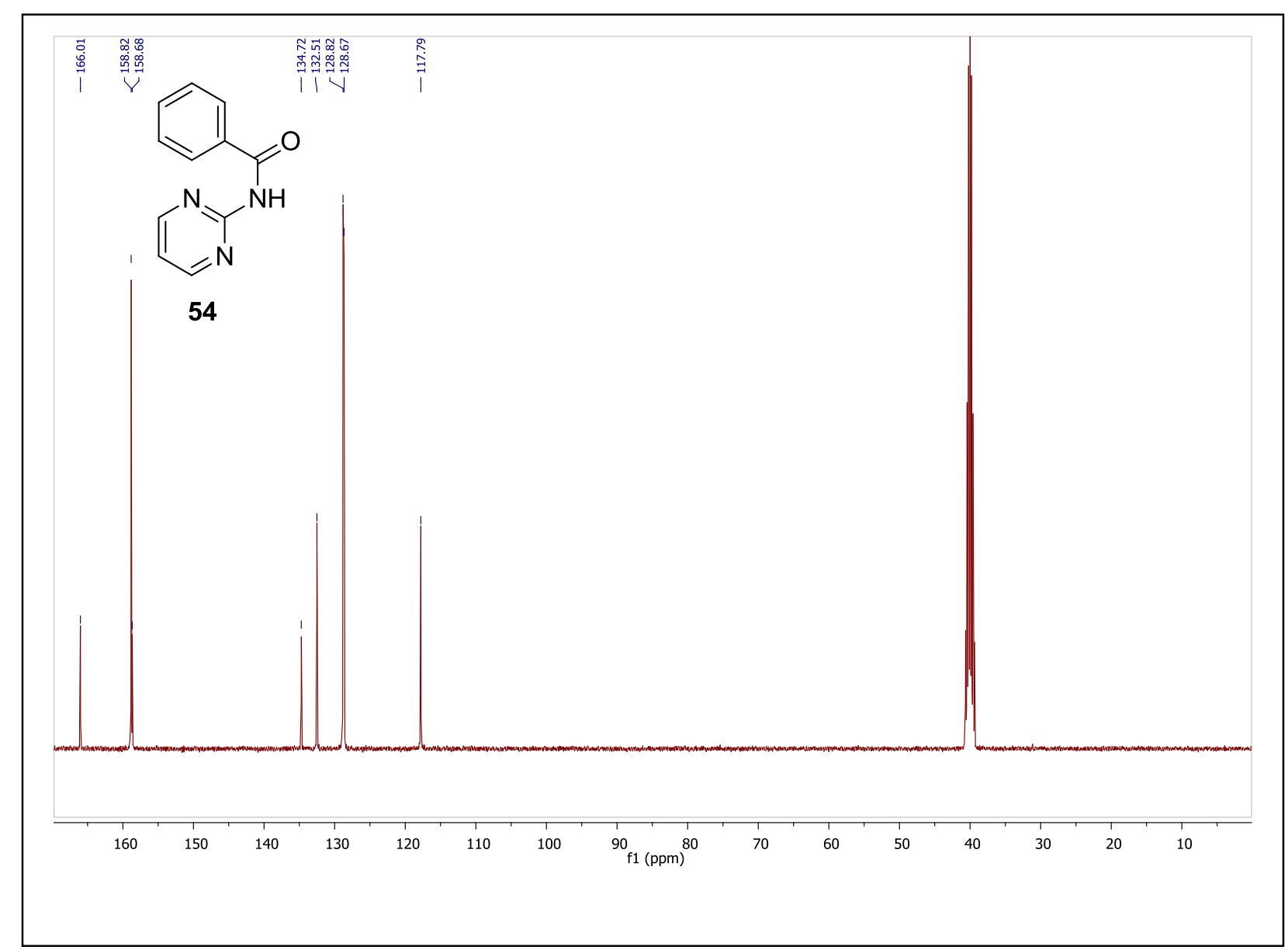


${ }^{1} \mathrm{H}-\mathrm{NMR}$ of 54 in $\left(\mathrm{CD}_{3}\right)_{2} \mathrm{CO}$ (aromatic expansion)

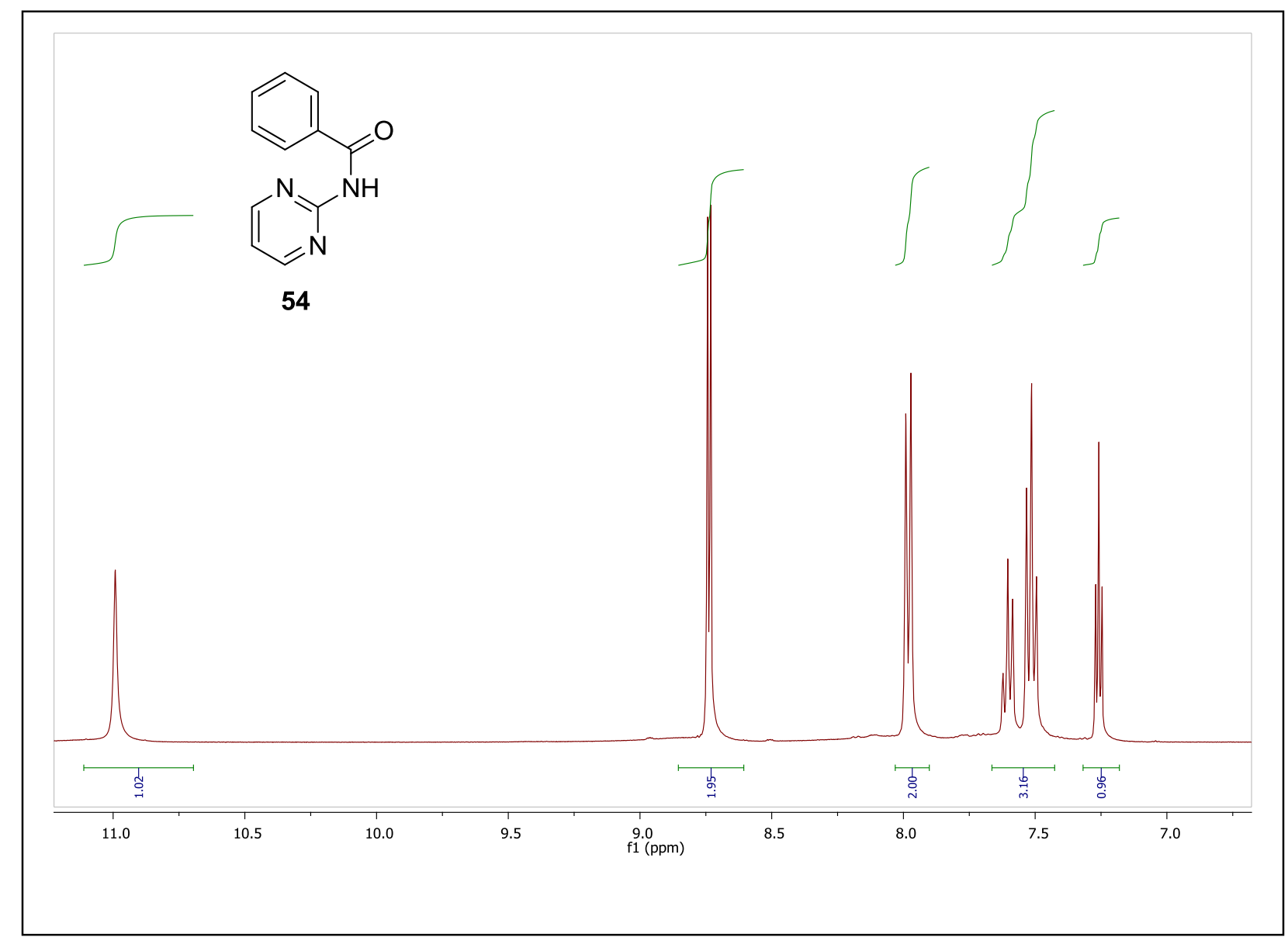


${ }^{1} \mathrm{H}-\mathrm{NMR}$ of 2 in $\left(\mathrm{CD}_{3}\right)_{2} \mathrm{CO}$

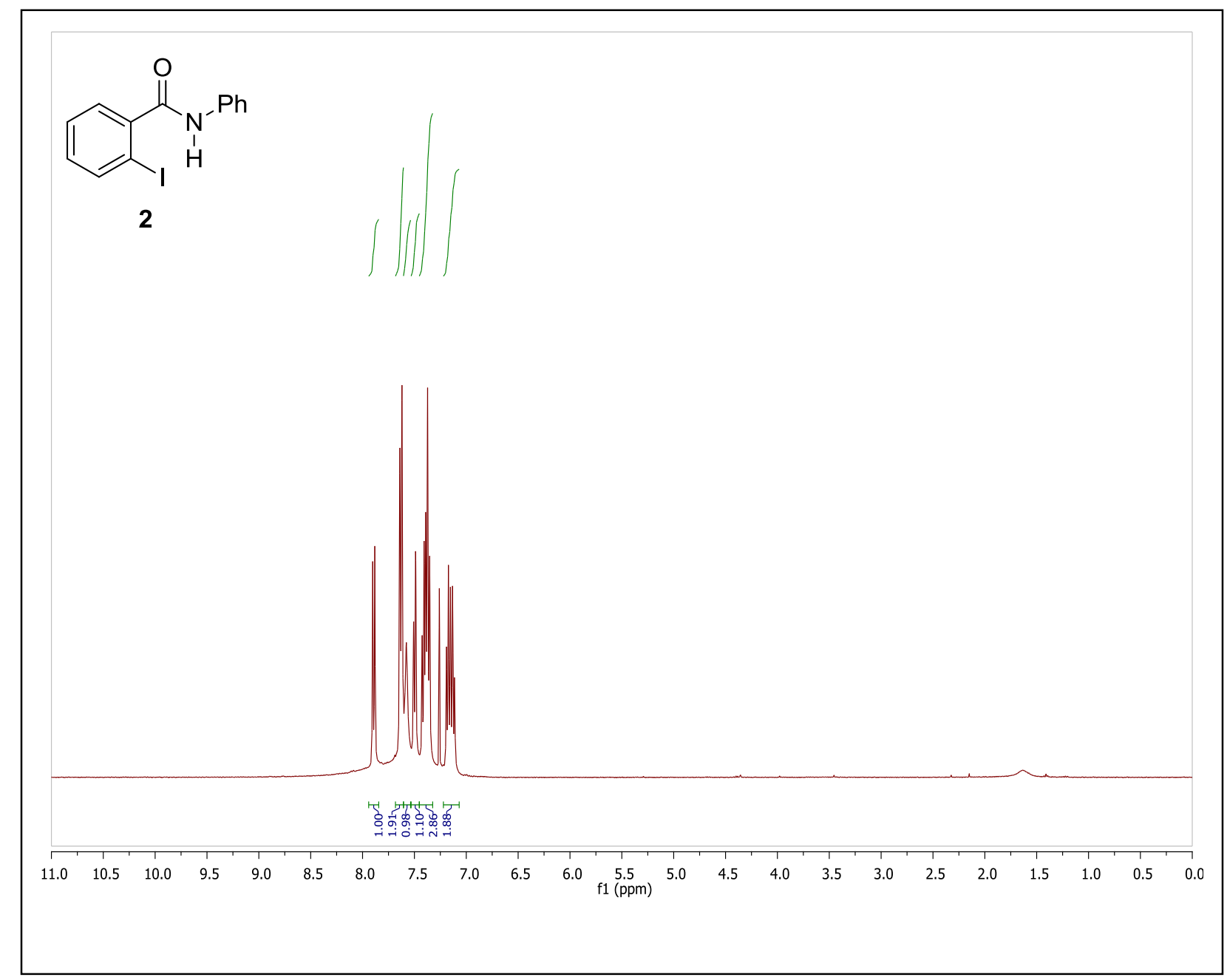


${ }^{13} \mathrm{C}-\mathrm{NMR}$ of 2 in $\mathrm{CDCl}_{3}$

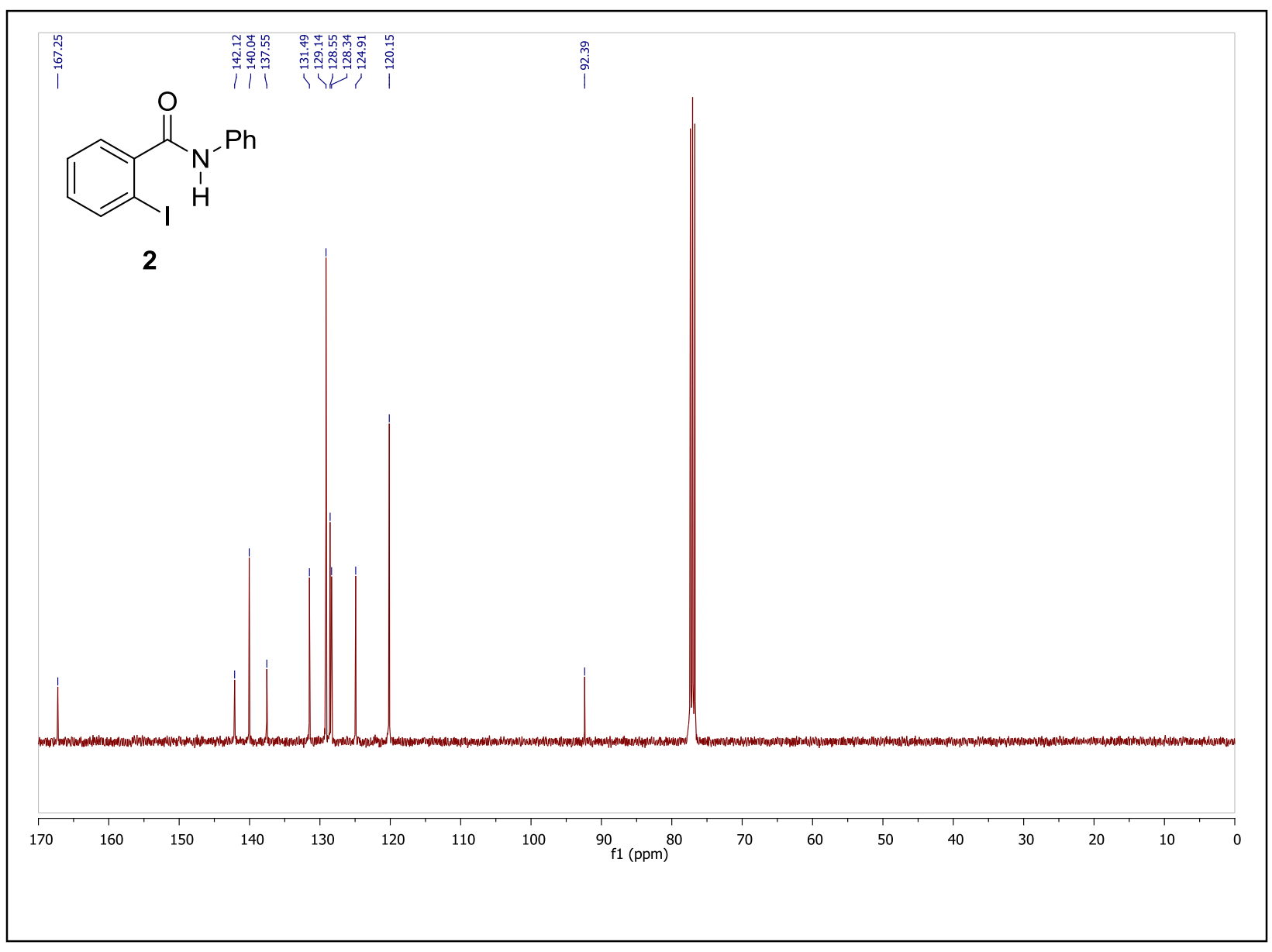


${ }^{1} \mathrm{H}-\mathrm{NMR}$ of 2 in $\mathrm{CDCl}_{3}$ (aromatic expansion)

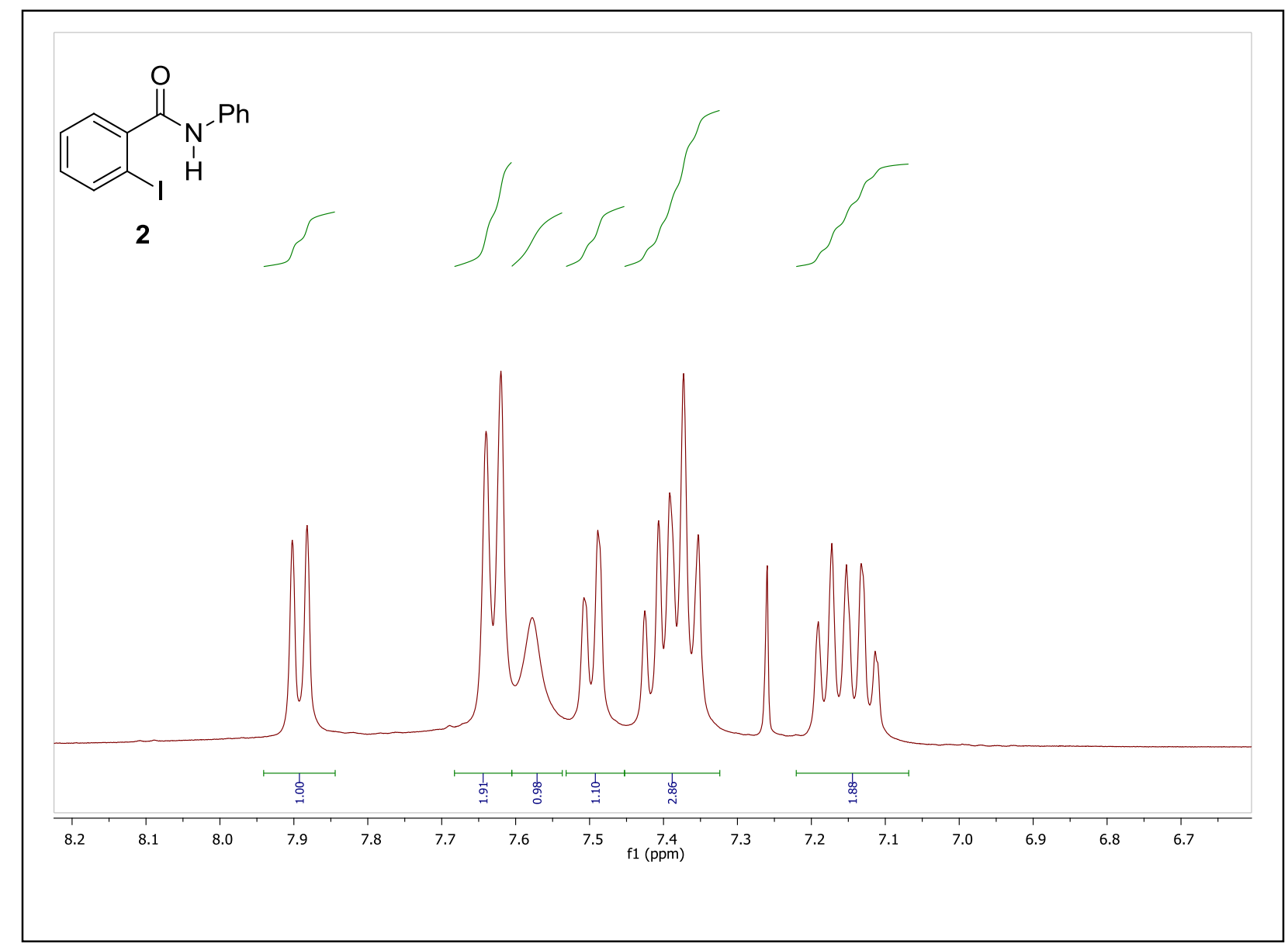


${ }^{1} \mathrm{H}-\mathrm{NMR}$ of 2-bromo- $\mathrm{N}$-(2-nitrophenyl)benzamide in $\left(\mathrm{CD}_{3}\right)_{2} \mathrm{CO}$

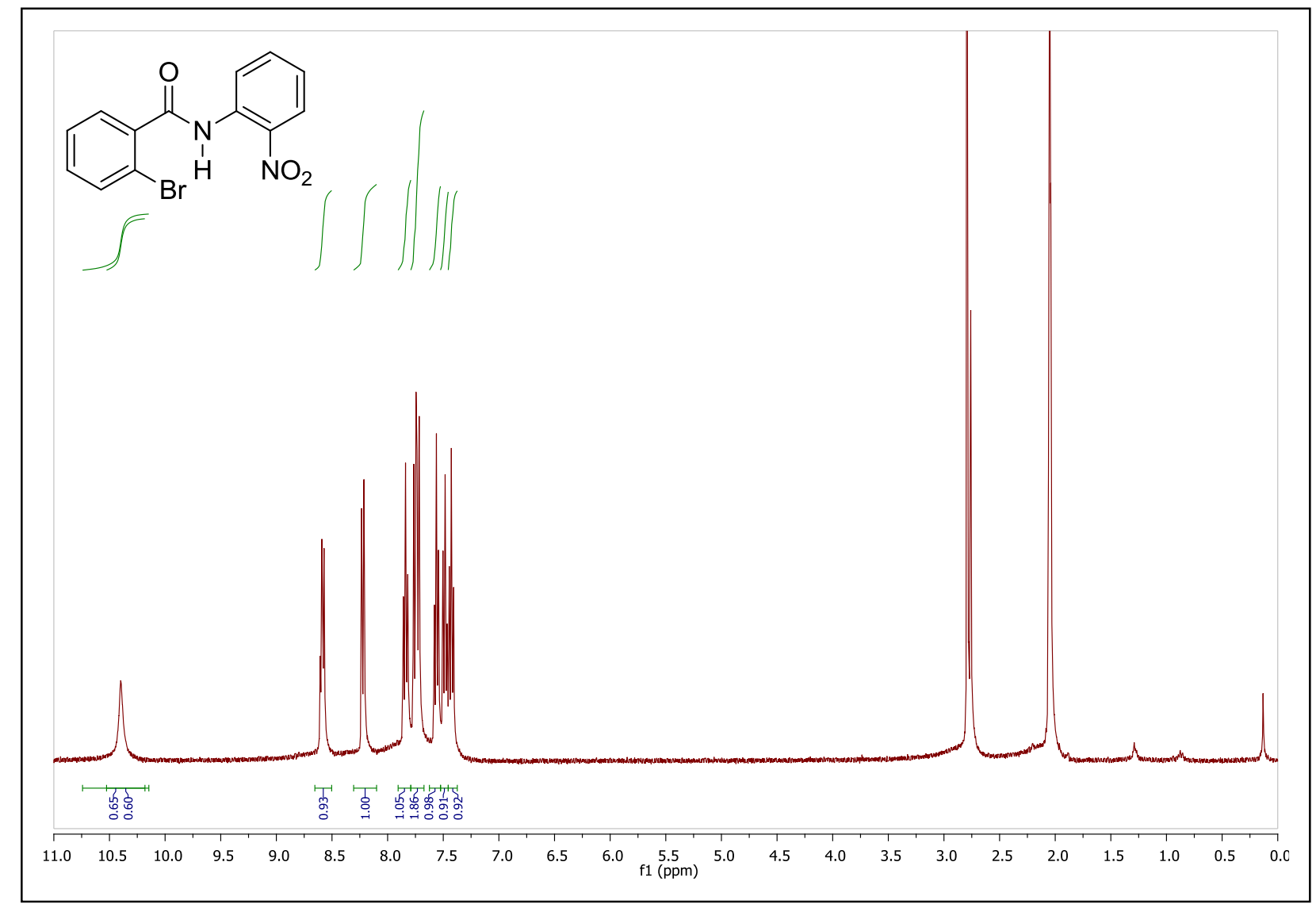


${ }^{1} \mathrm{H}-\mathrm{NMR}$ of 2-bromo- $\mathrm{N}$-(2-nitrophenyl)benzamide in $\mathrm{CDCl}_{3}$

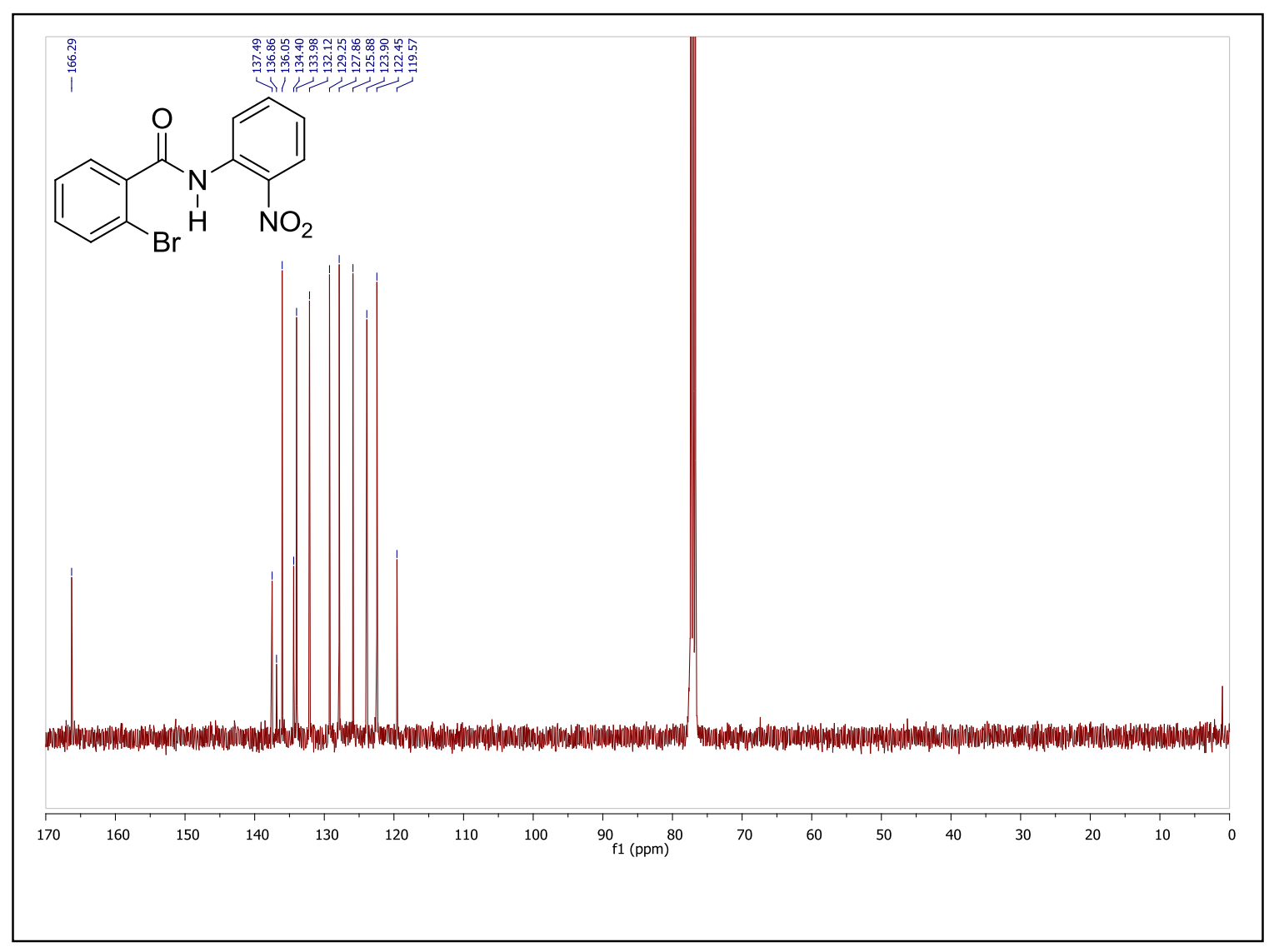


${ }^{1} \mathrm{H}-\mathrm{NMR}$ of 2-bromo- $\mathrm{N}$-(2-nitrophenyl)benzamide in $\left(\mathrm{CD}_{3}\right)_{2} \mathrm{CO}$ (aromatic expansion)

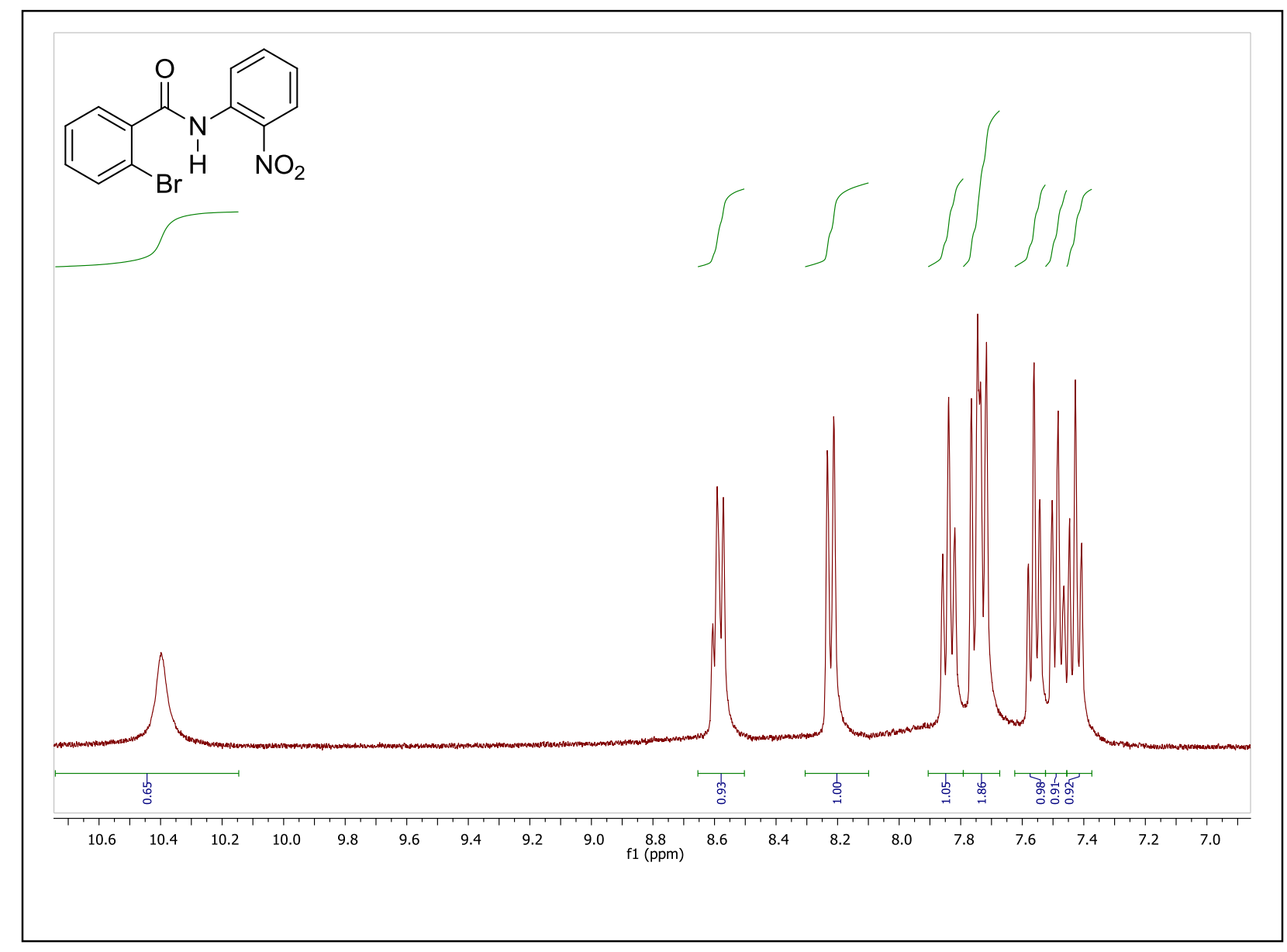


${ }^{1} \mathrm{H}-\mathrm{NMR}$ of 2-bromo- $\mathrm{N}$-(4-methoxyphenyl)benzamide in $\left(\mathrm{CD}_{3}\right)_{2} \mathrm{CO}$

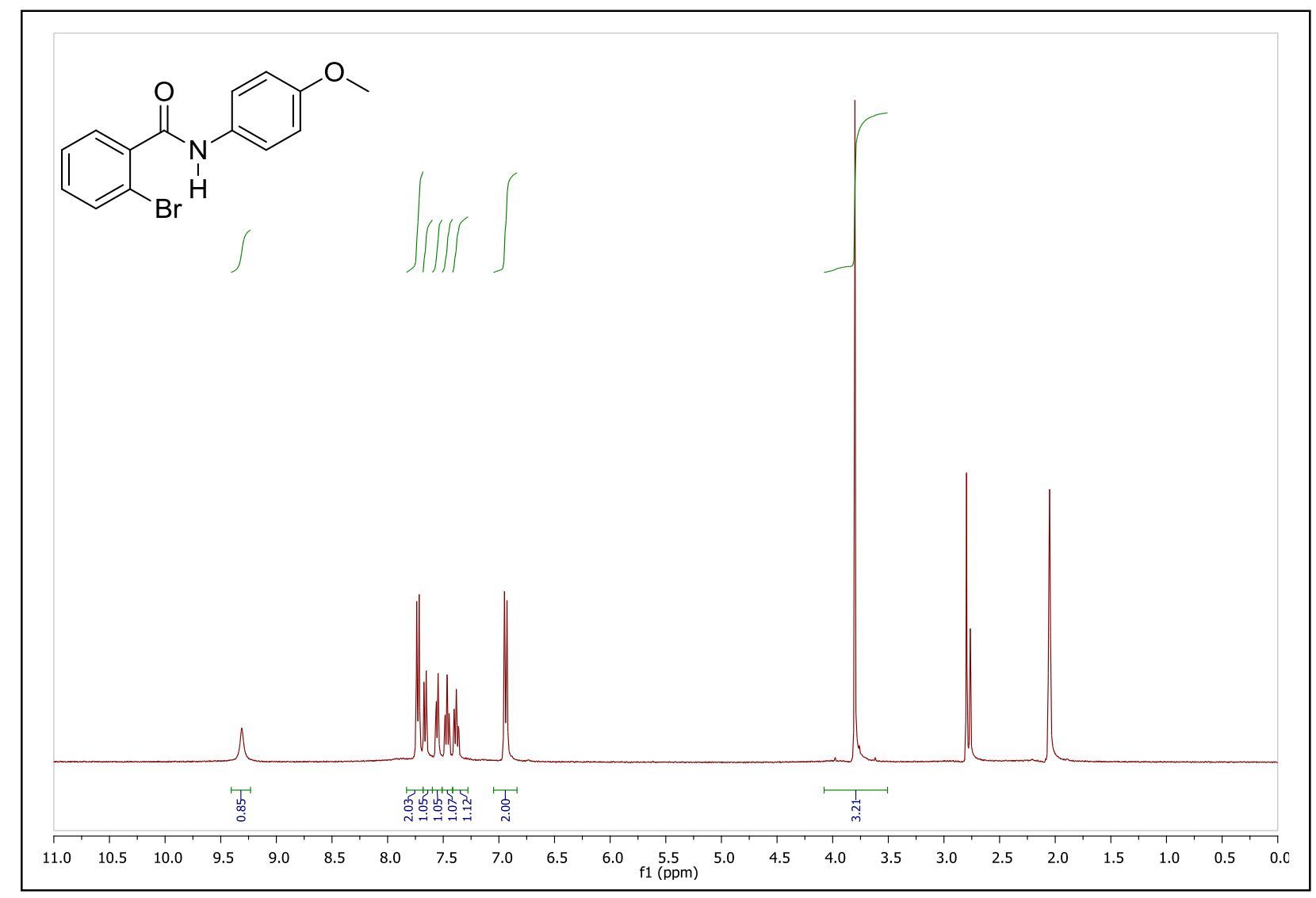


${ }^{13} \mathrm{C}$-NMR of 2-bromo- $N$-(4-methoxyphenyl) benzamide in $\mathrm{CDCl}_{3}$

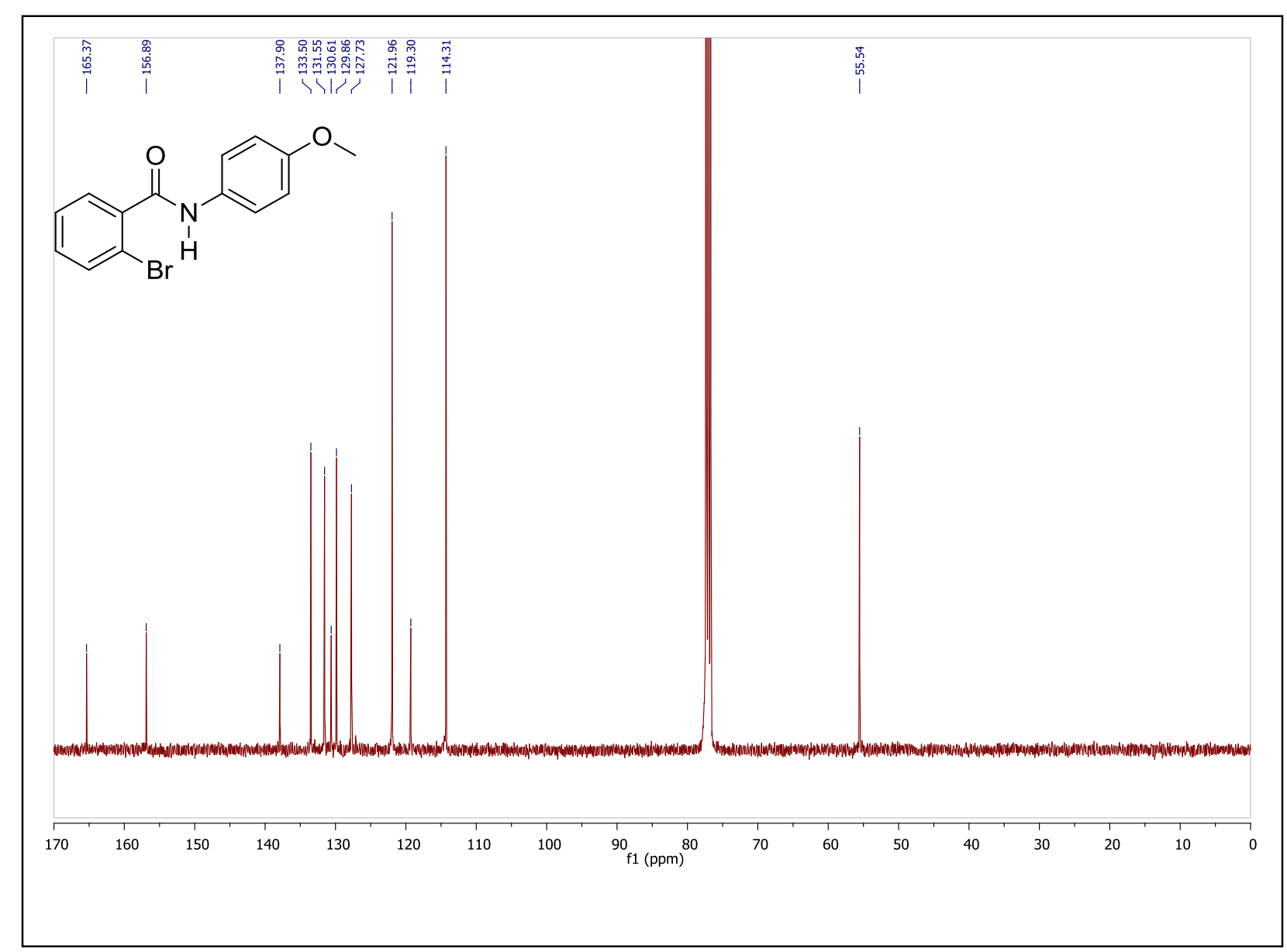


${ }^{1} \mathrm{H}-\mathrm{NMR}$ of 2-bromo- $\mathrm{N}$-(4-methoxyphenyl)benzamide in $\left(\mathrm{CD}_{3}\right)_{2} \mathrm{CO}$ (aromatic expansion)

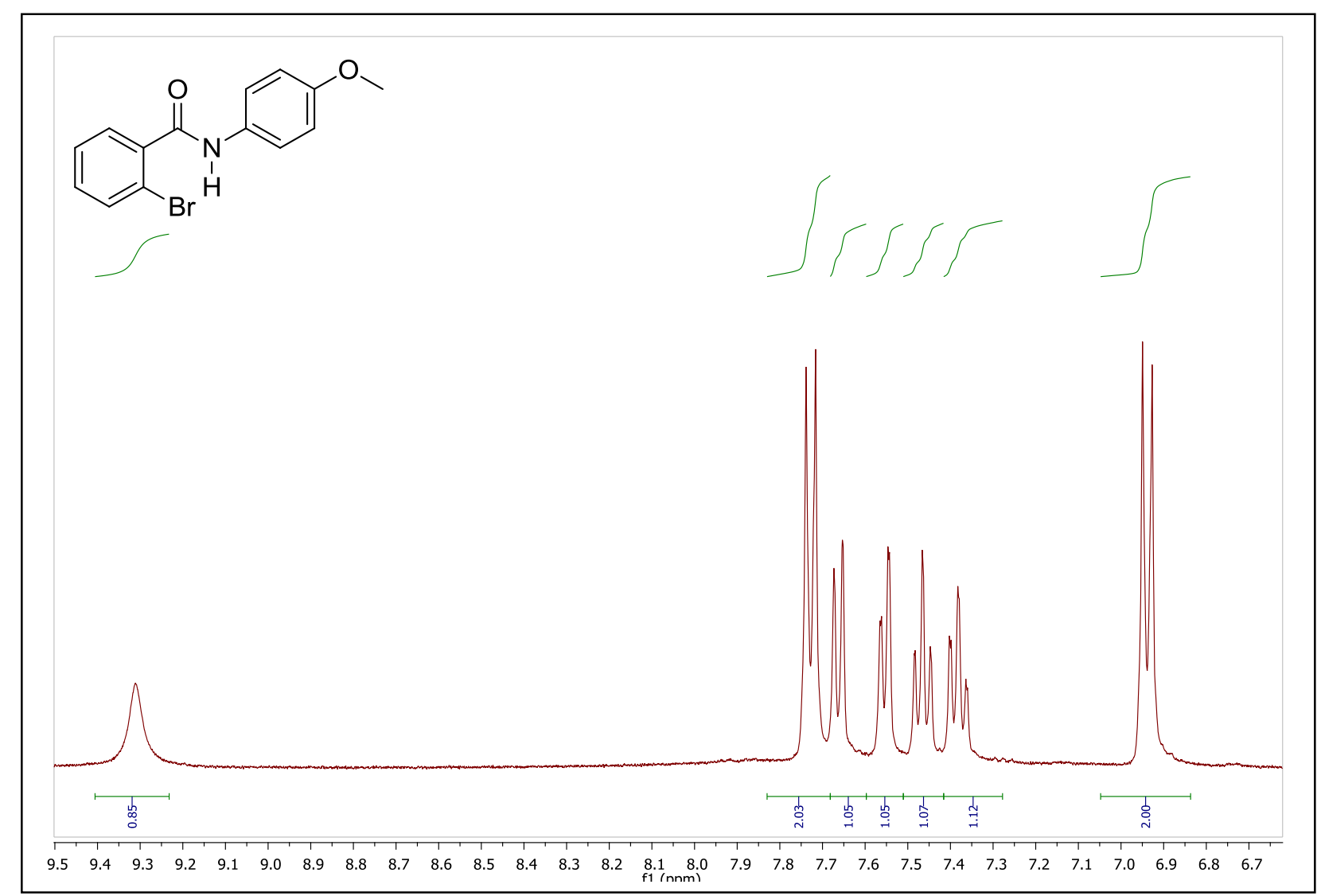


${ }^{1} \mathrm{H}-\mathrm{NMR}$ of 2-bromo- $\mathrm{N}$-(2-methoxyphenyl)benzamide in $\left(\mathrm{CD}_{3}\right)_{2} \mathrm{CO}$

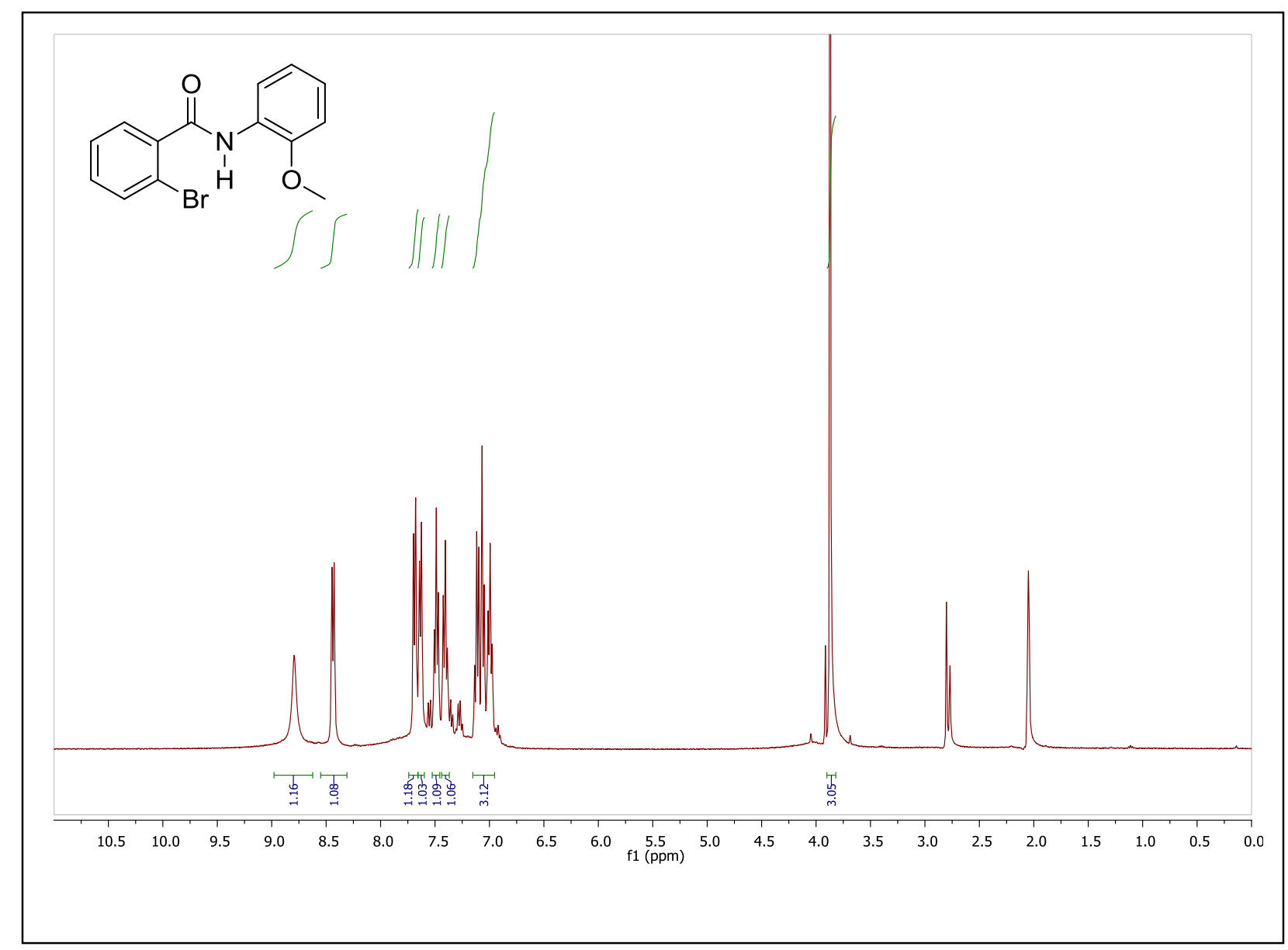


${ }^{13} \mathrm{C}-\mathrm{NMR}$ of 2-bromo- $N$-(2-methoxyphenyl)benzamide in $\left(\mathrm{CD}_{3}\right)_{2} \mathrm{CO}$

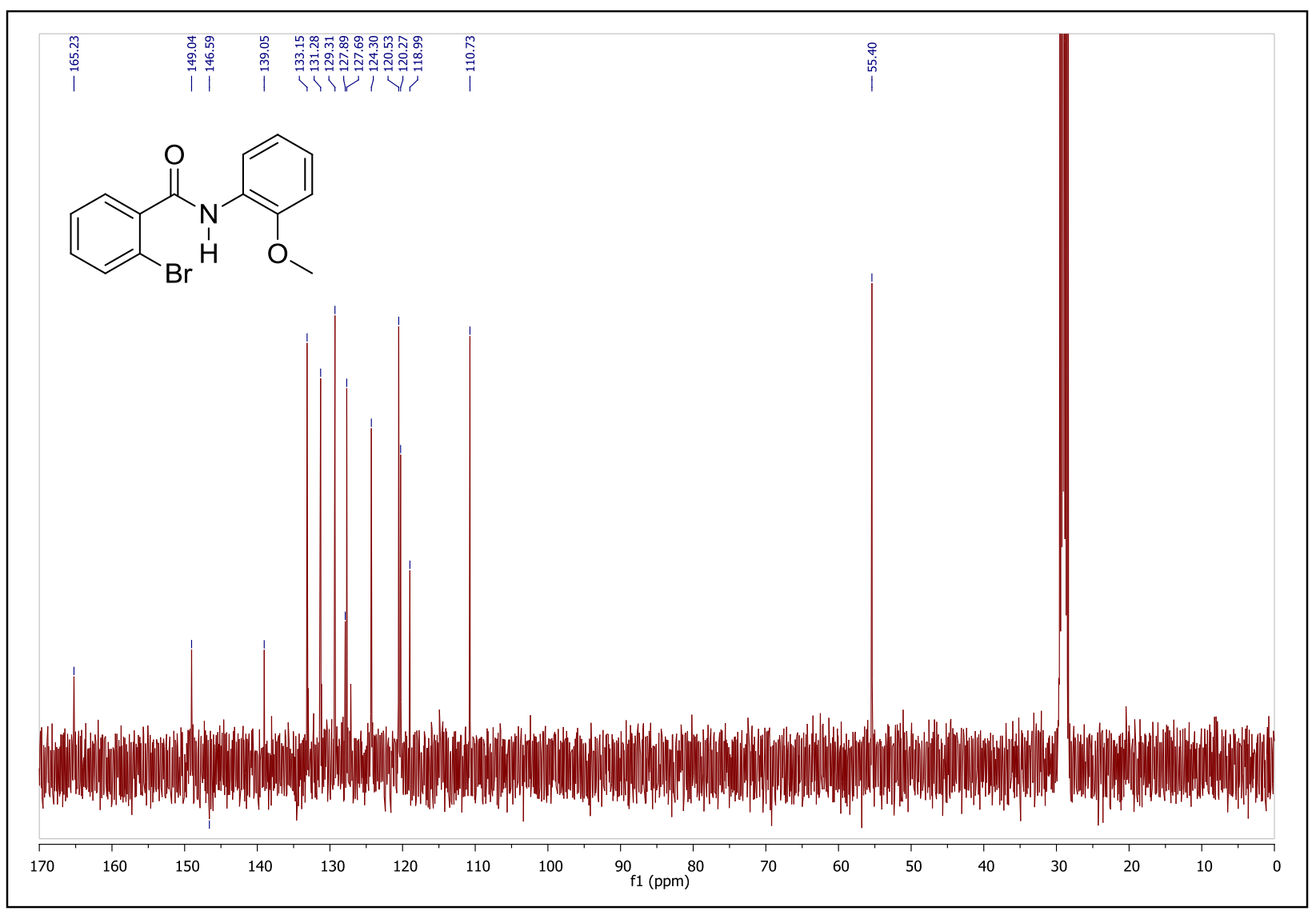


${ }^{1} \mathrm{H}-\mathrm{NMR}$ of 2-bromo- $\mathrm{N}$-(2-methoxyphenyl)benzamide in $\left(\mathrm{CD}_{3}\right)_{2} \mathrm{CO}$ (aromatic expansion)

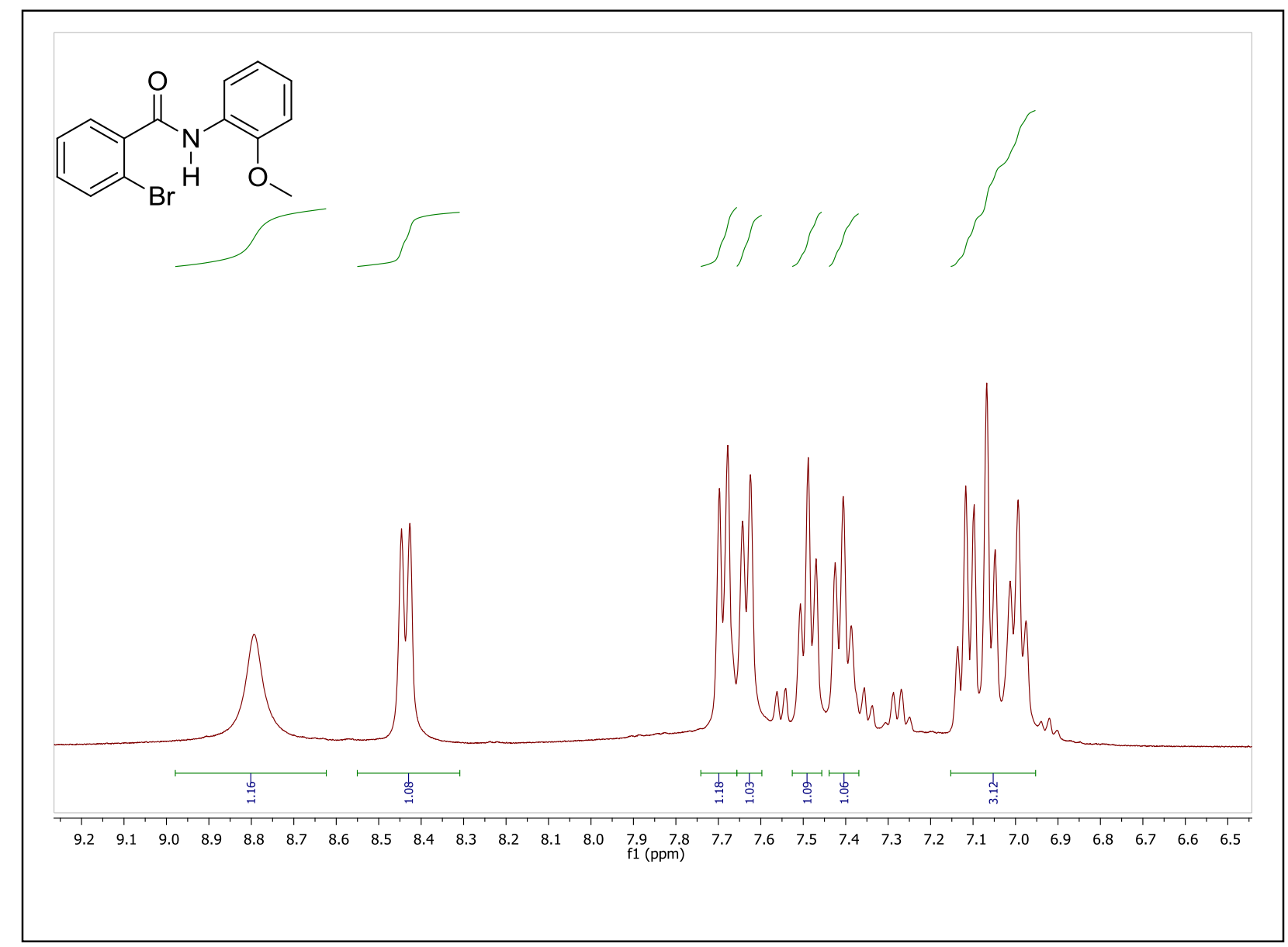


${ }^{1} \mathrm{H}-\mathrm{NMR}$ of 2-bromo- $\mathrm{N}$-( $p$-tolyl)benzamide in $\left(\mathrm{CD}_{3}\right)_{2} \mathrm{SO}$

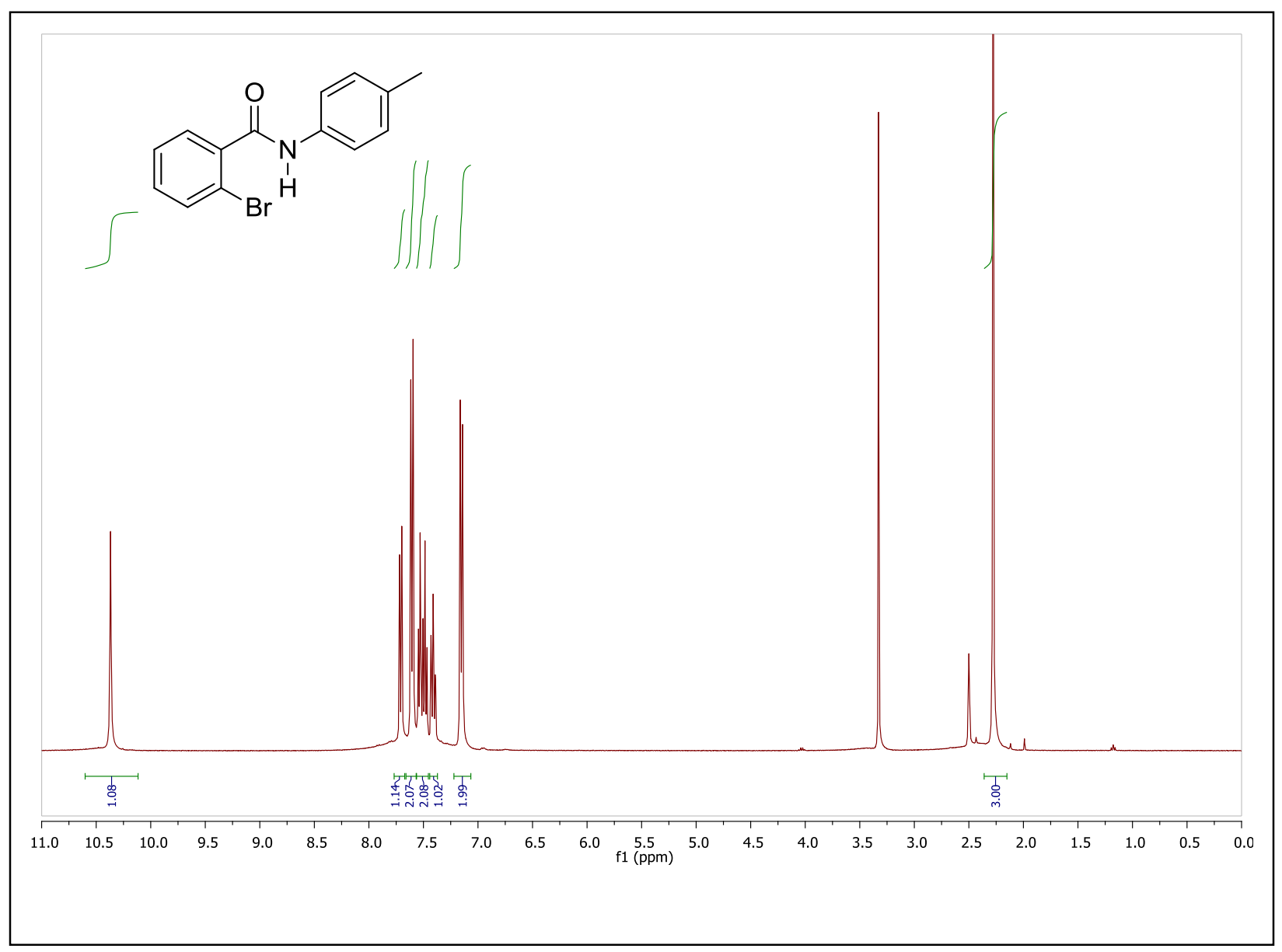


${ }^{13} \mathrm{C}$-NMR of 2-bromo- $N$-(p-tolyl)benzamide in $\left(\mathrm{CD}_{3}\right)_{2} \mathrm{SO}$

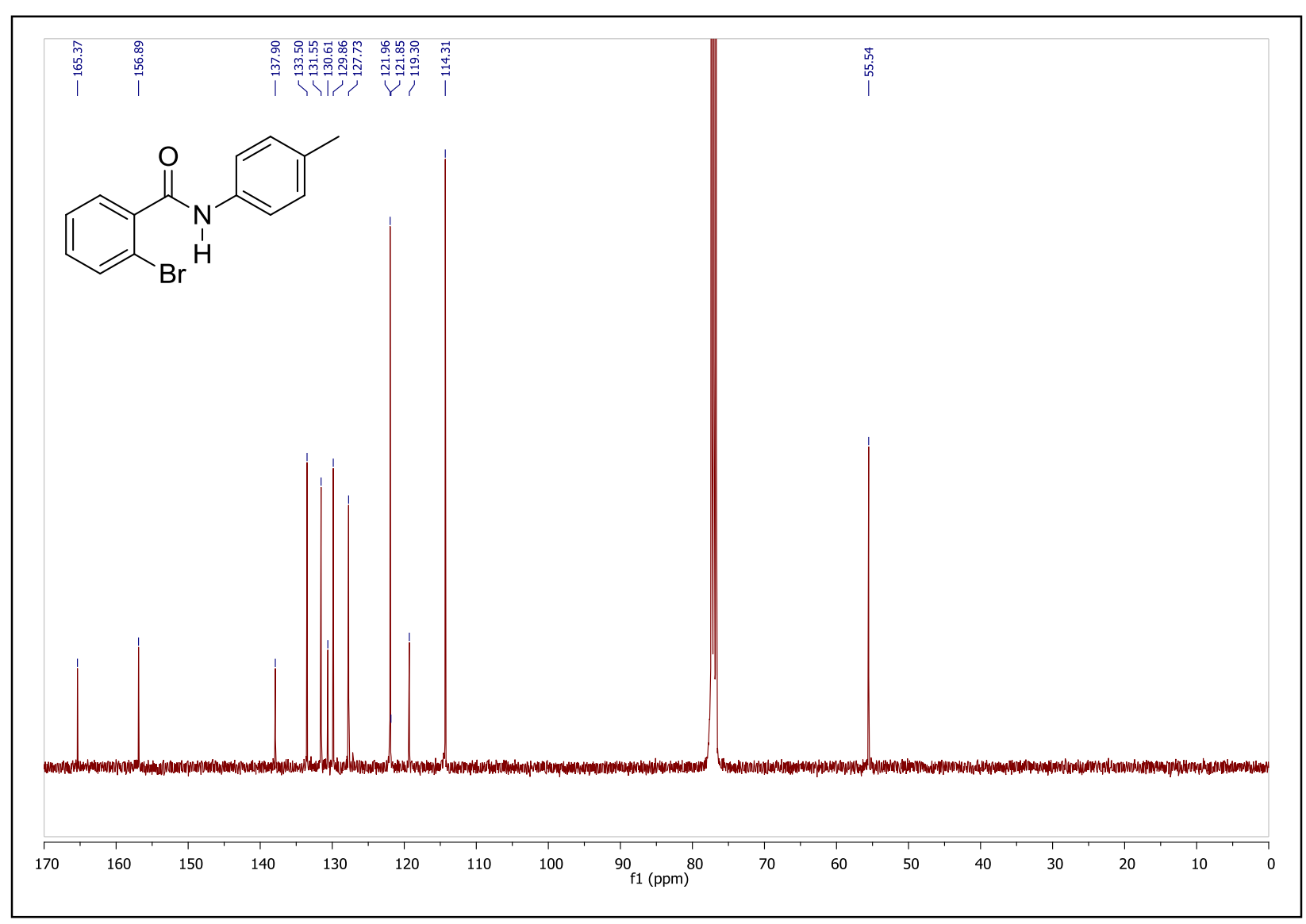


${ }^{1} \mathrm{H}-\mathrm{NMR}$ of 2-bromo- $N$-( $p$-tolyl)benzamide in $\left(\mathrm{CD}_{3}\right)_{2} \mathrm{SO}$ (aromatic expansion)

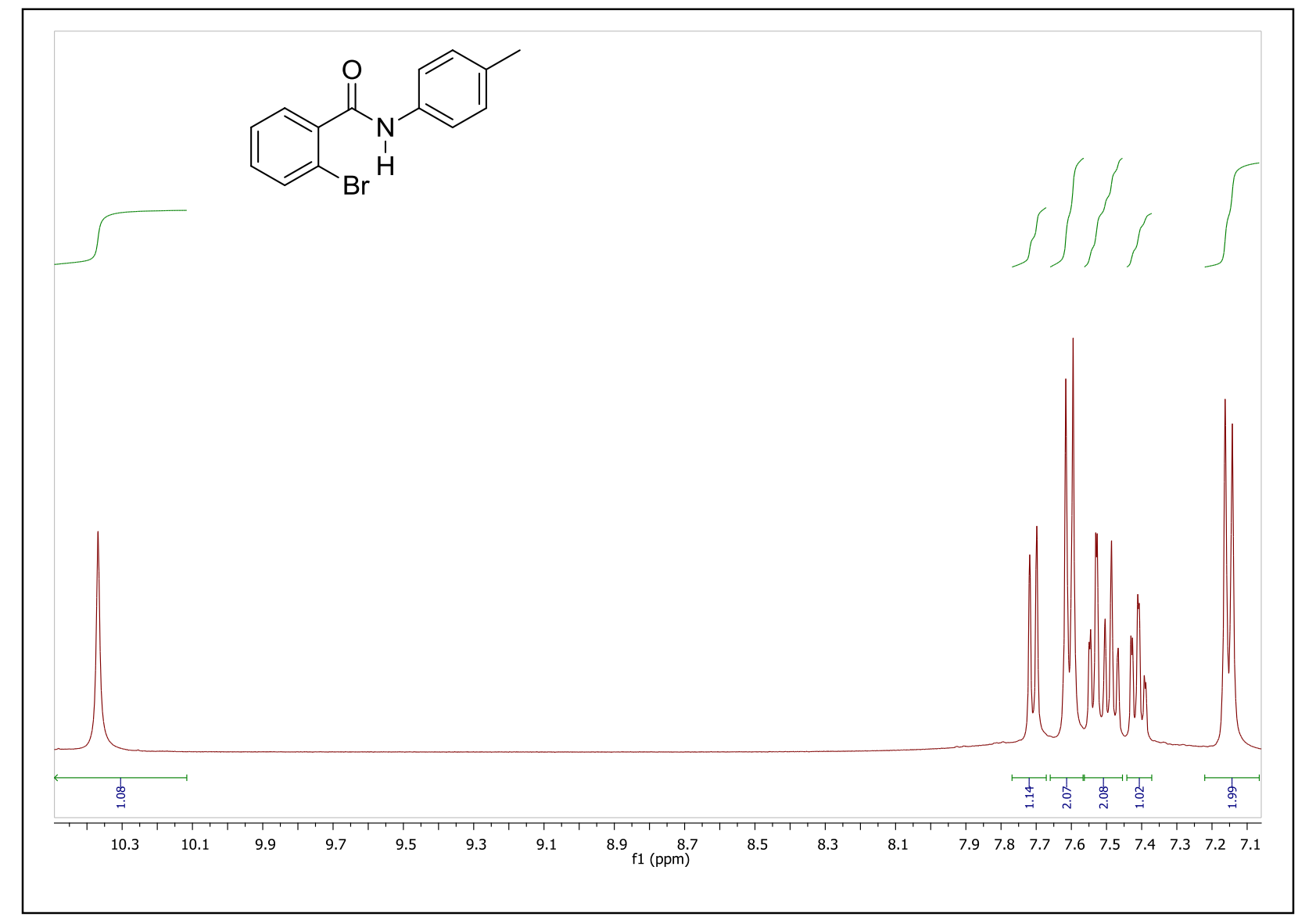


${ }^{1} \mathrm{H}-\mathrm{NMR}$ of $\mathrm{N}$-( $p$-tolyl)benzamide in d- $\left(\mathrm{CD}_{3}\right)_{2} \mathrm{CO}$

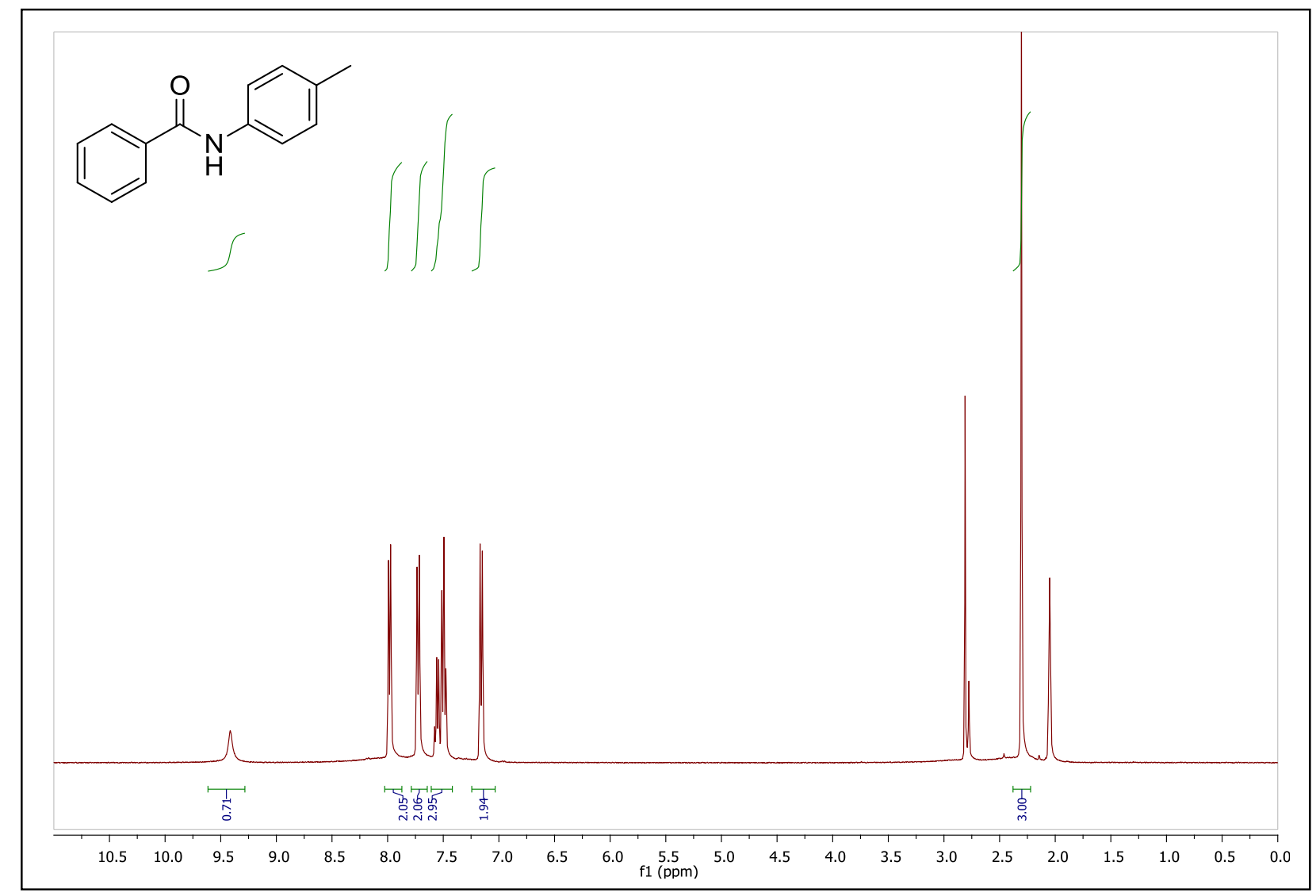


${ }^{13} \mathrm{C}$-NMR of $N$-(p-tolyl)benzamide in $\left(\mathrm{CD}_{3}\right)_{2} \mathrm{CO}$

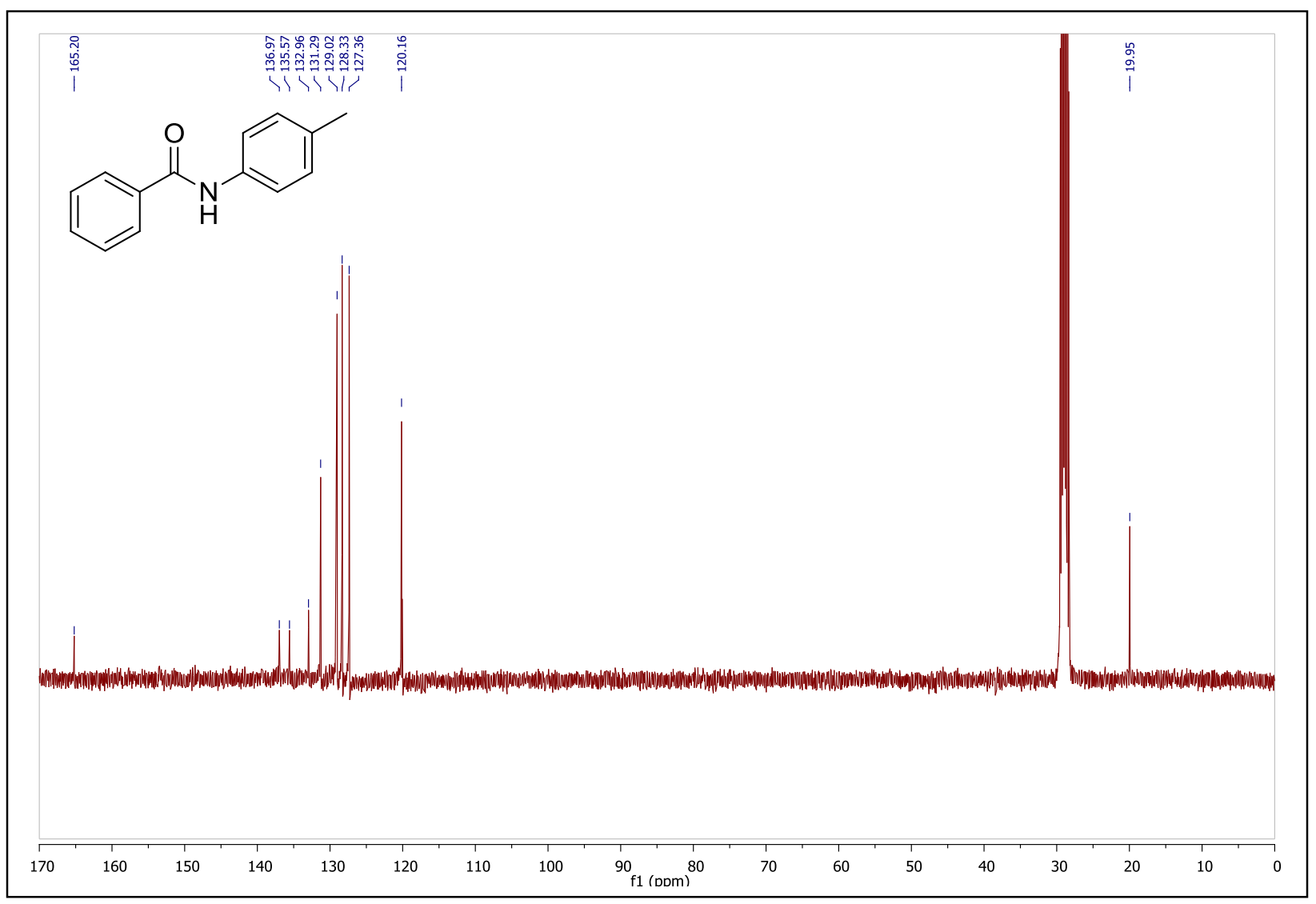


${ }^{1} \mathrm{H}-\mathrm{NMR}$ of $\mathrm{N}$-(p-tolyl)benzamide in $\left(\mathrm{CD}_{3}\right)_{2} \mathrm{CO}$ (aromatic expansion)

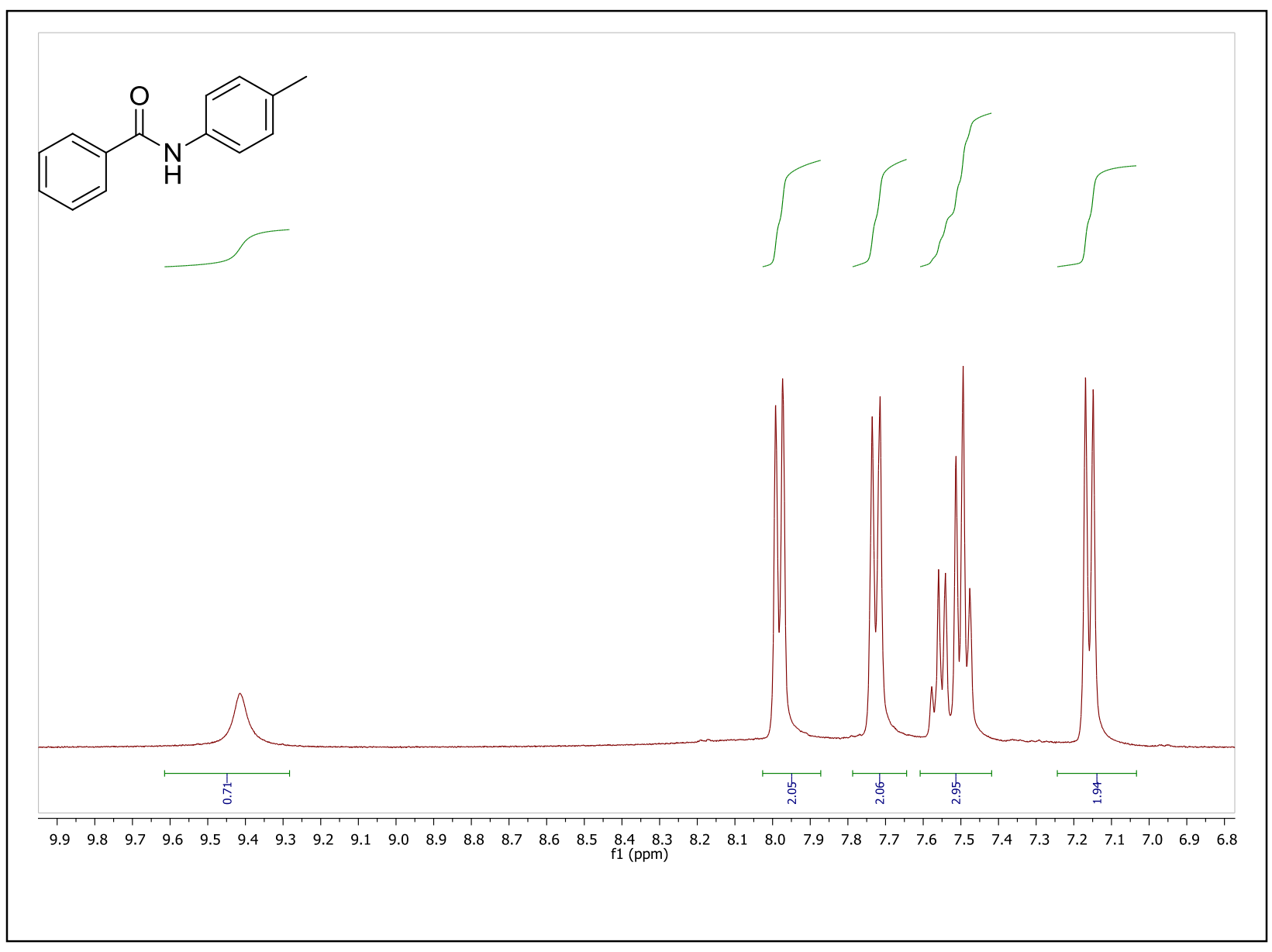


${ }^{1} \mathrm{H}-\mathrm{NMR}$ of 23 in $\mathrm{CDCl}_{3}$

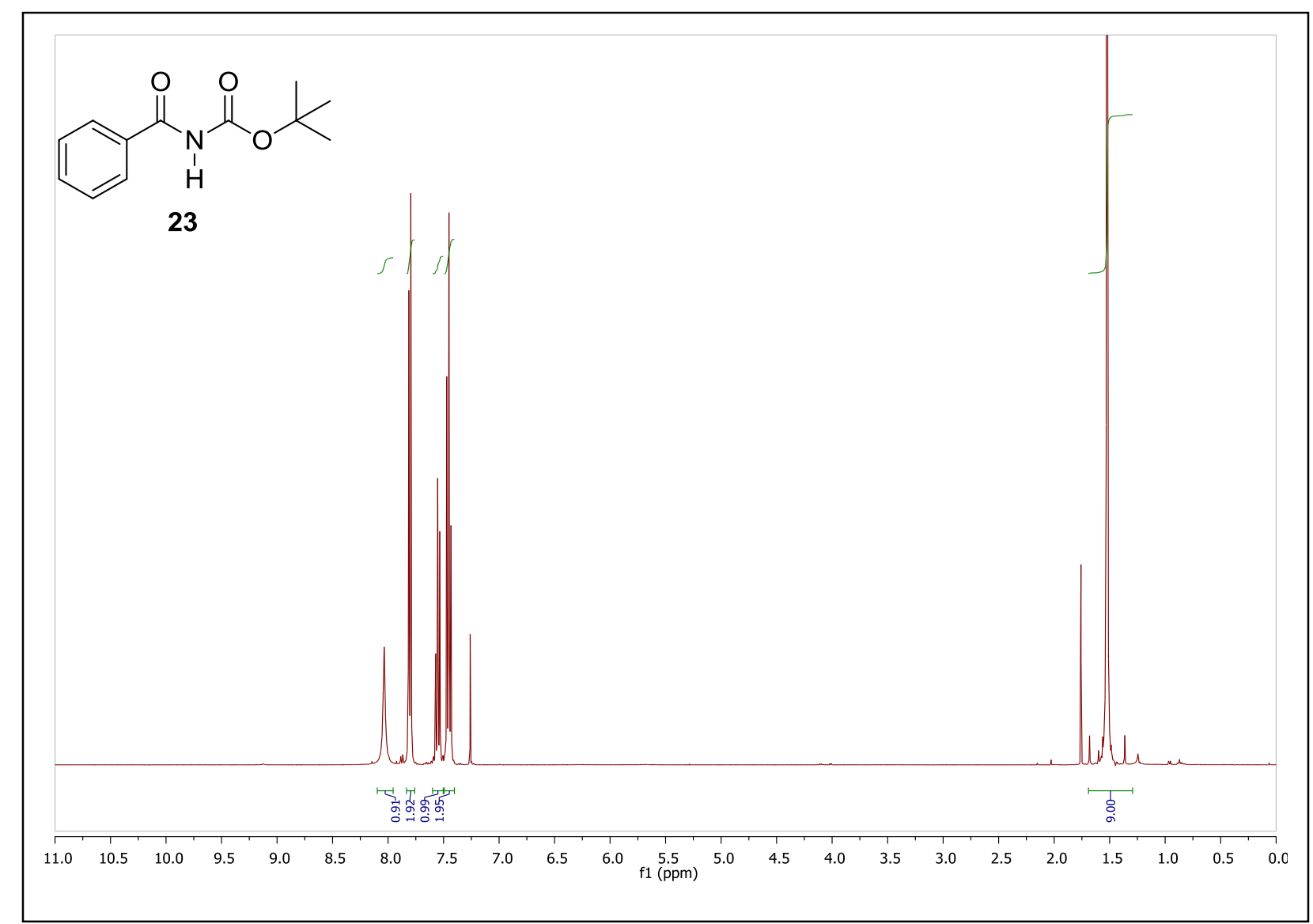


${ }^{13} \mathrm{C}$-NMR of 23 in $\mathrm{CDCl}_{3}$

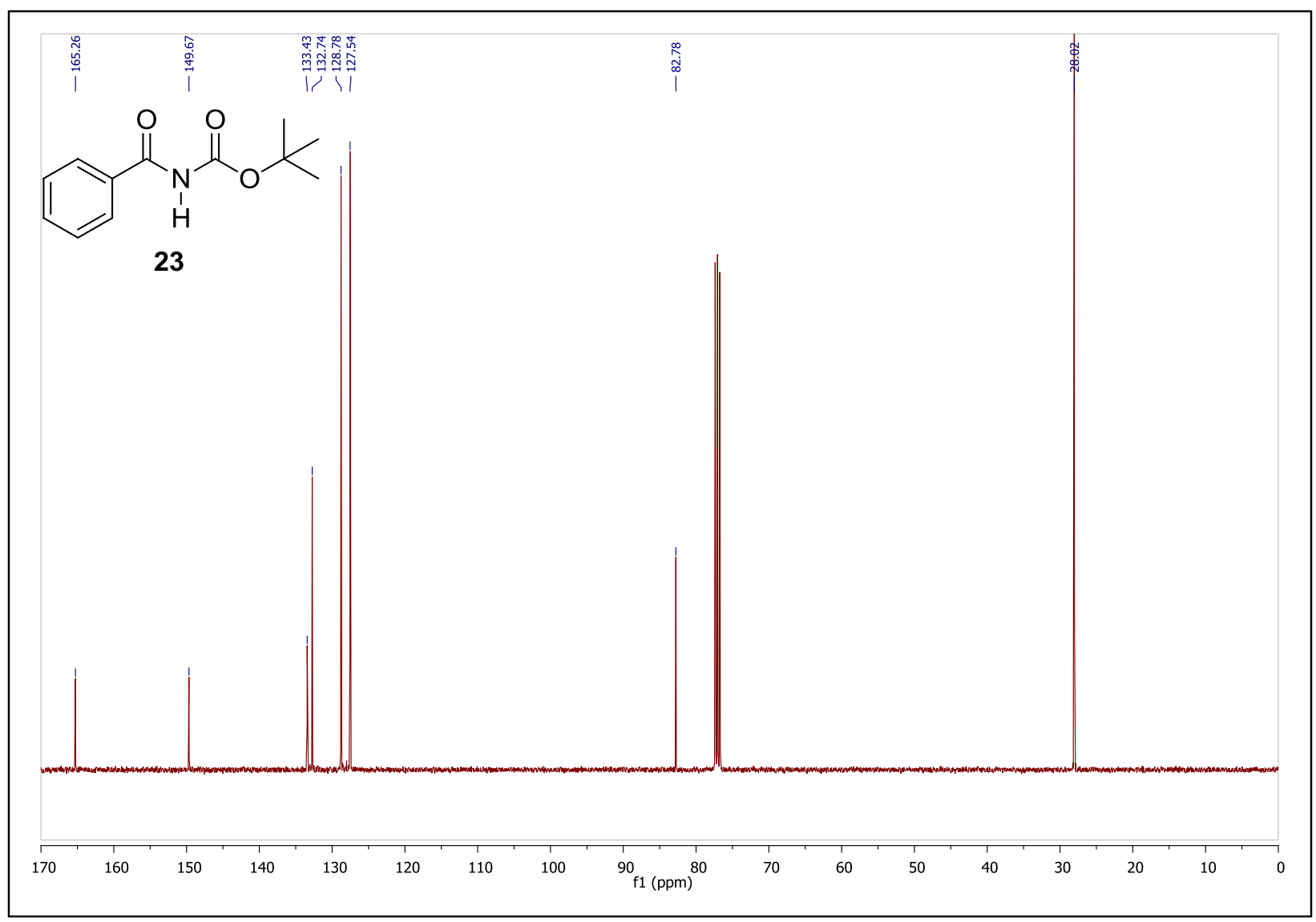


${ }^{1} \mathrm{H}-\mathrm{NMR}$ of 23 in $\mathrm{CDCl}_{3}$ (aromatic expansion)

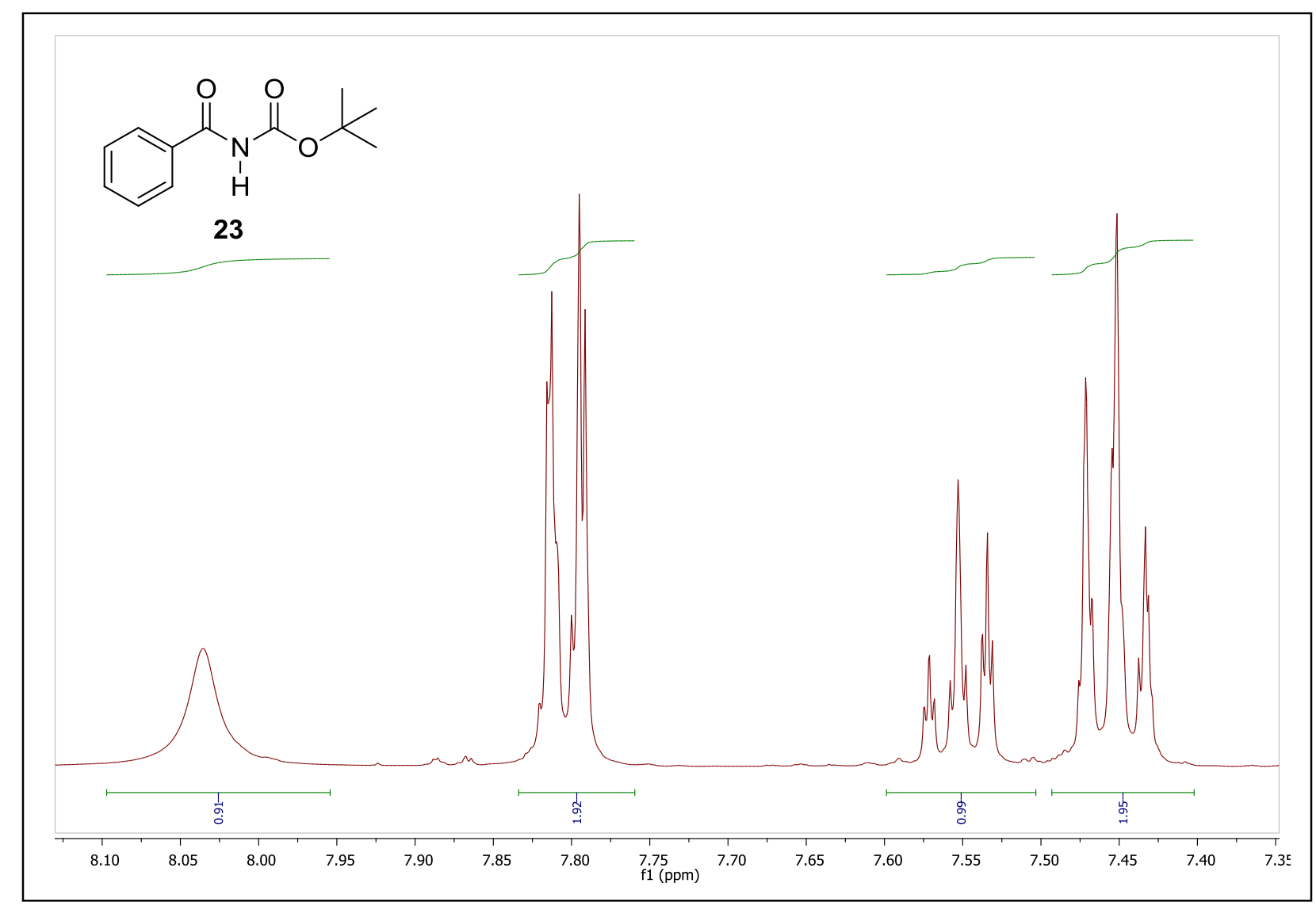


${ }^{1} \mathrm{H}-\mathrm{NMR}$ of 4 in $\left(\mathrm{CD}_{3}\right)_{2} \mathrm{SO}$

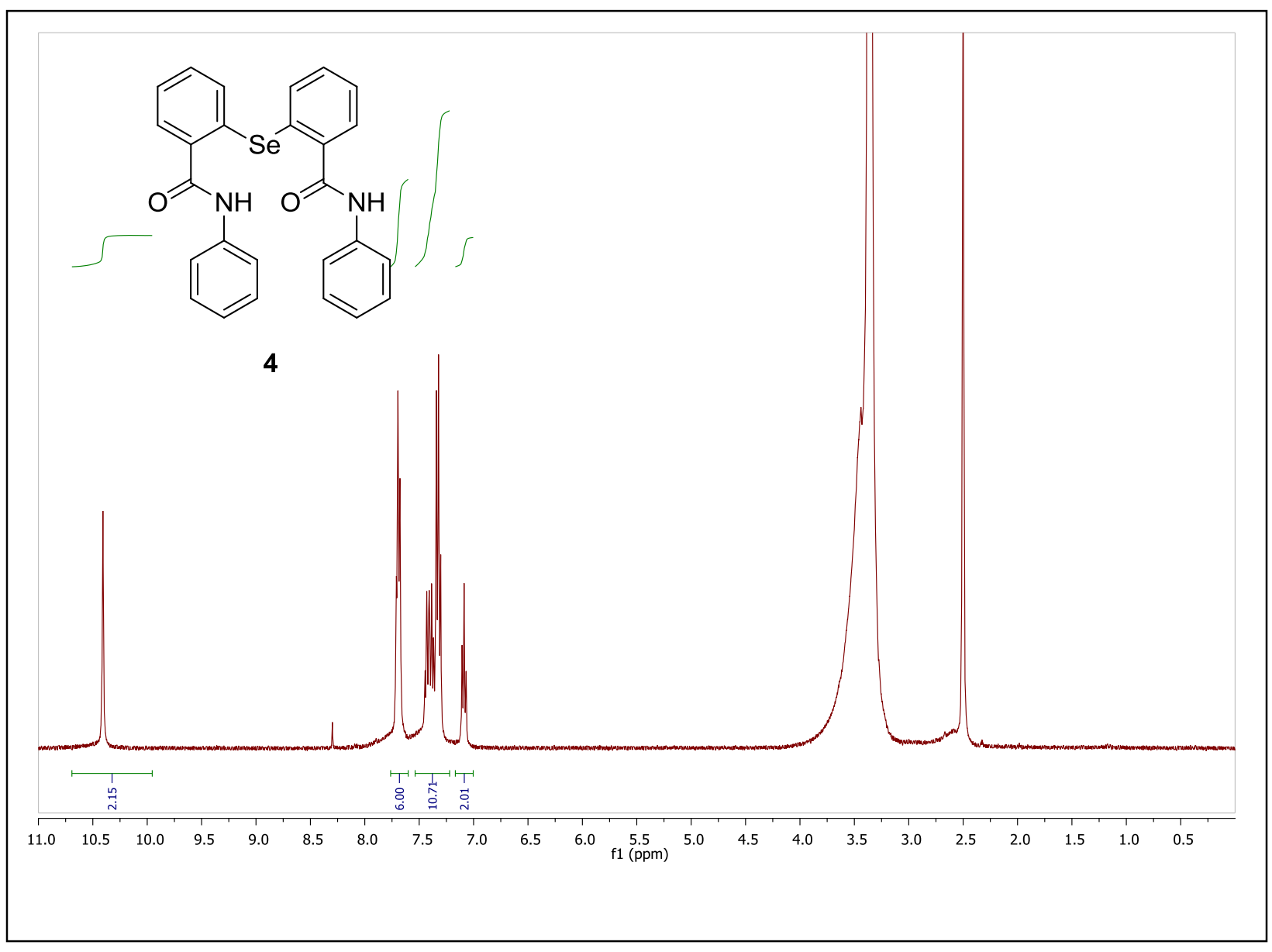


${ }^{13} \mathrm{C}-\mathrm{NMR}$ of 4 in $\left(\mathrm{CD}_{3}\right)_{2} \mathrm{SO}$

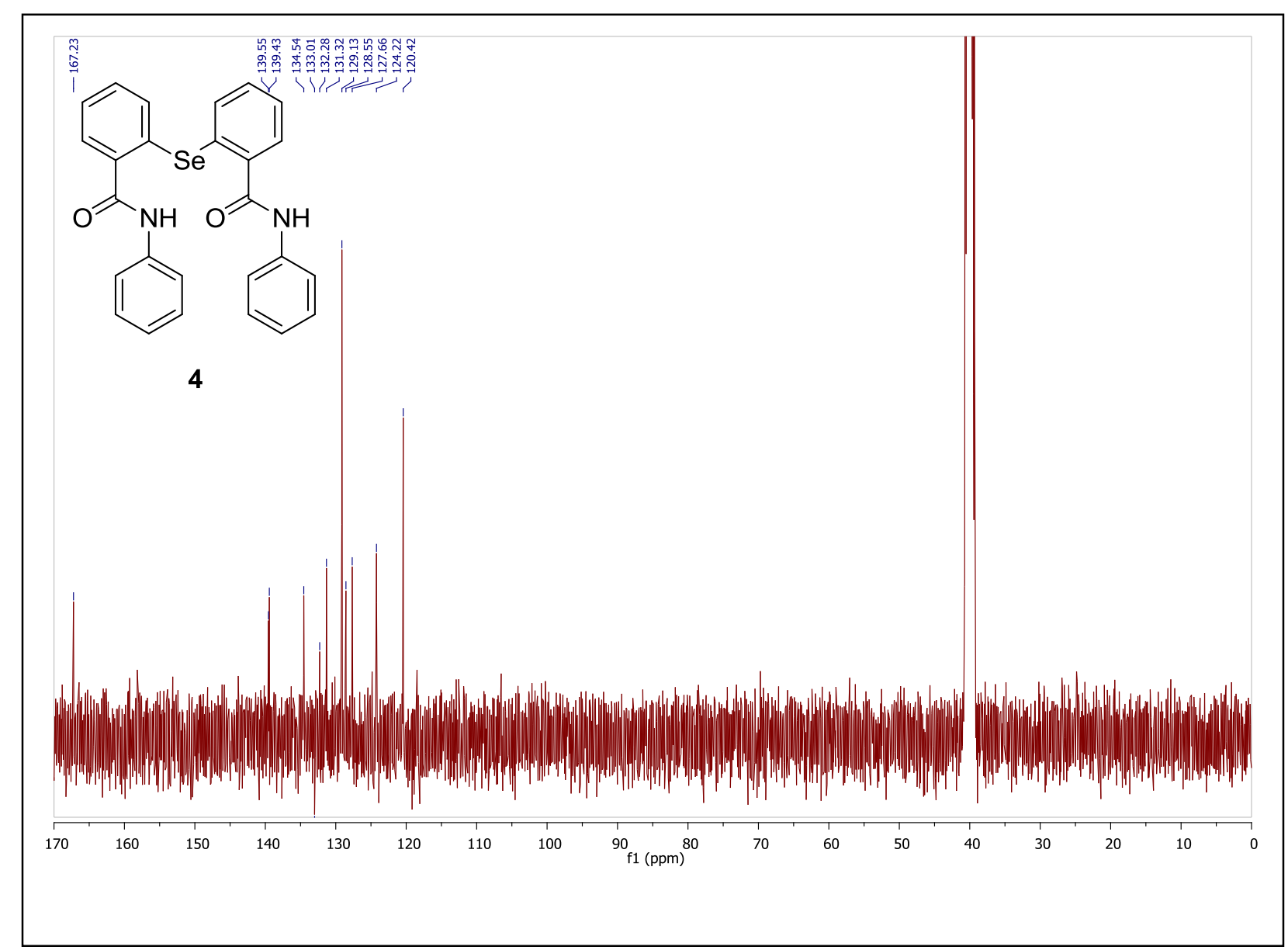


${ }^{1} \mathrm{H}-\mathrm{NMR}$ of 4 in $\left(\mathrm{CD}_{3}\right)_{2} \mathrm{SO}$ (aromatic expansion)

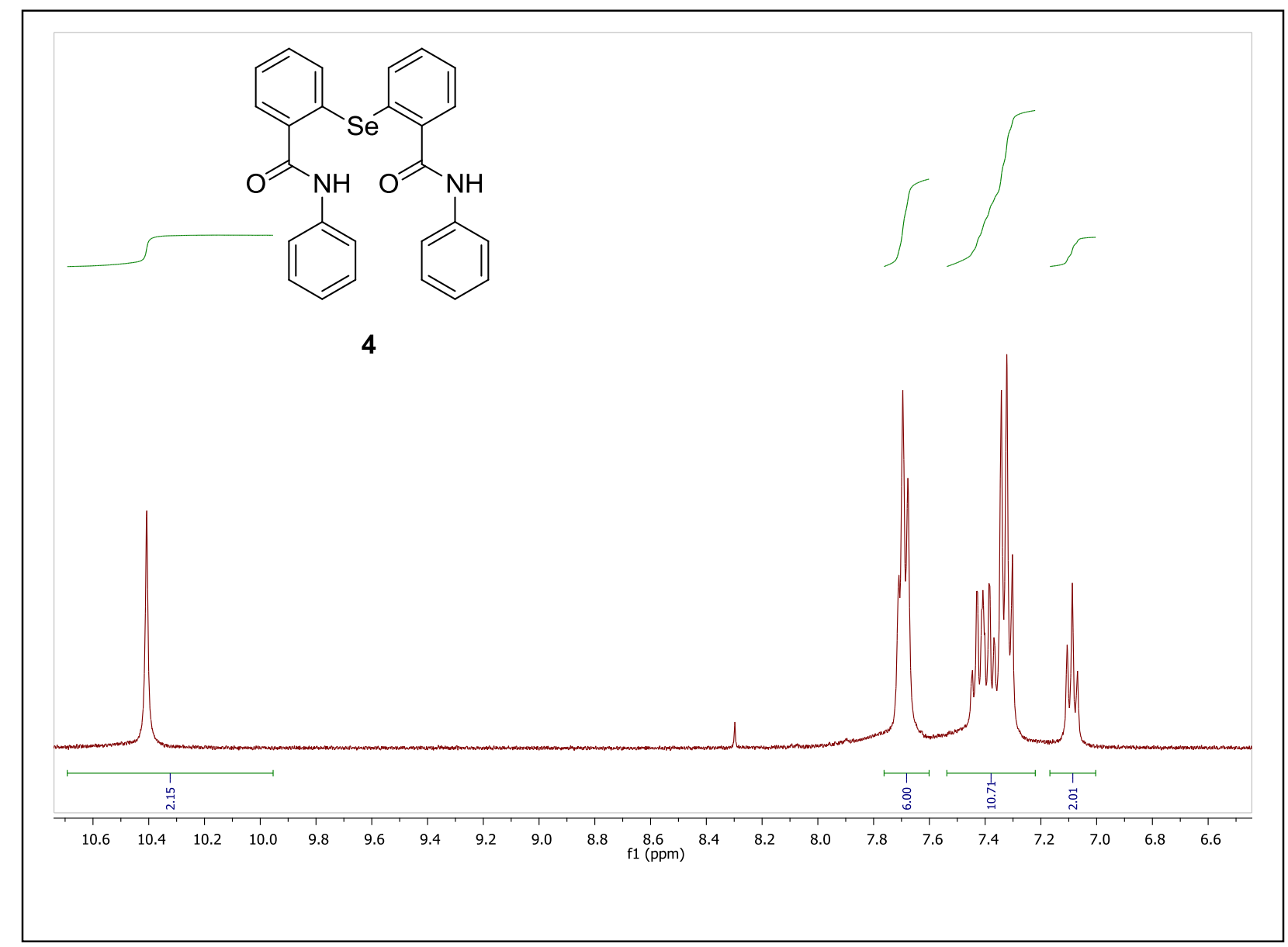


${ }^{1} \mathrm{H}-\mathrm{NMR}$ of $\mathbf{3 7}$ in $\left(\mathrm{CD}_{3}\right)_{2} \mathrm{CO}$

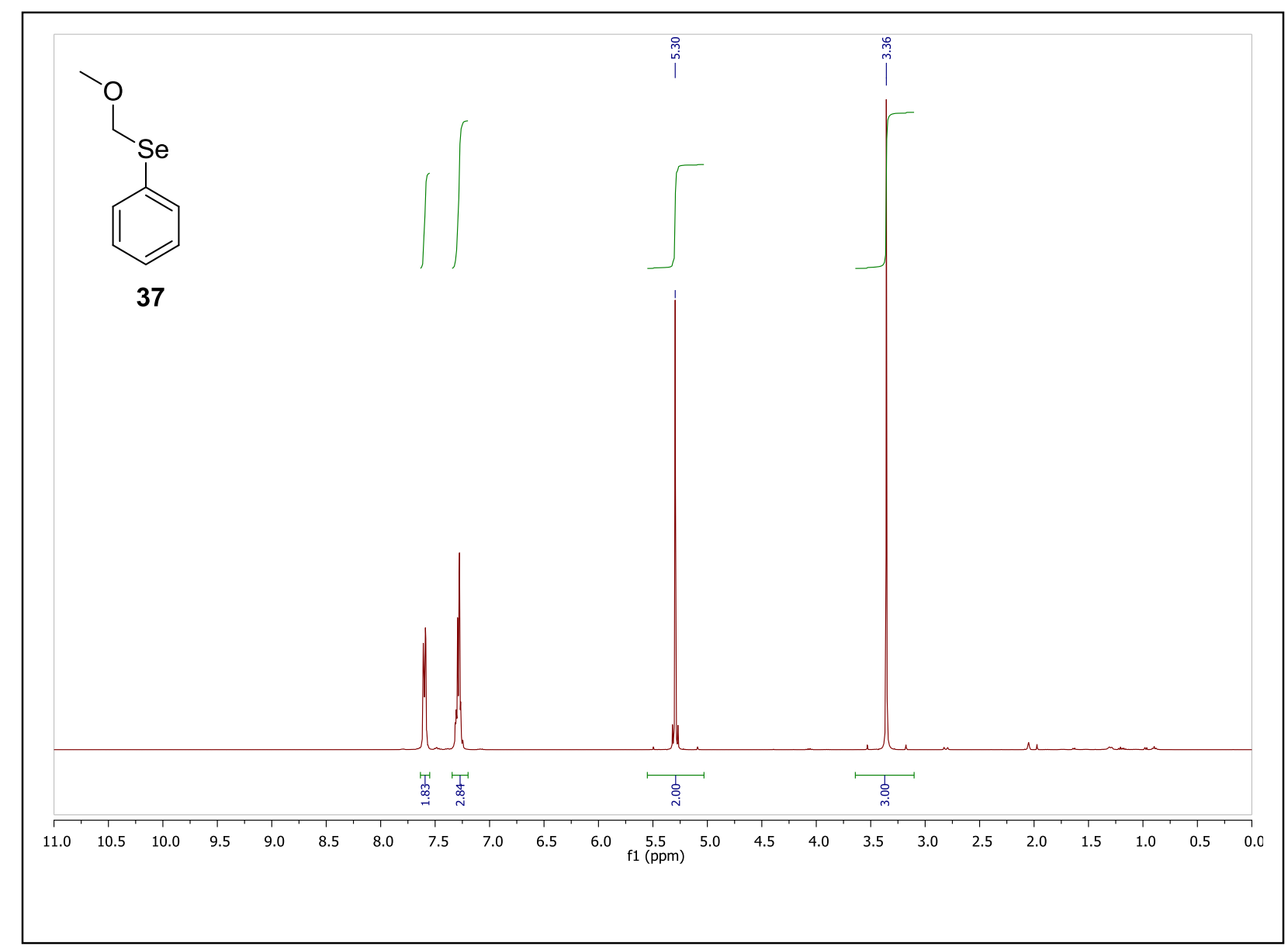


${ }^{13} \mathrm{C}-\mathrm{NMR}$ of $\mathbf{3 7}$ in $\left(\mathrm{CD}_{3}\right)_{2} \mathrm{CO}$

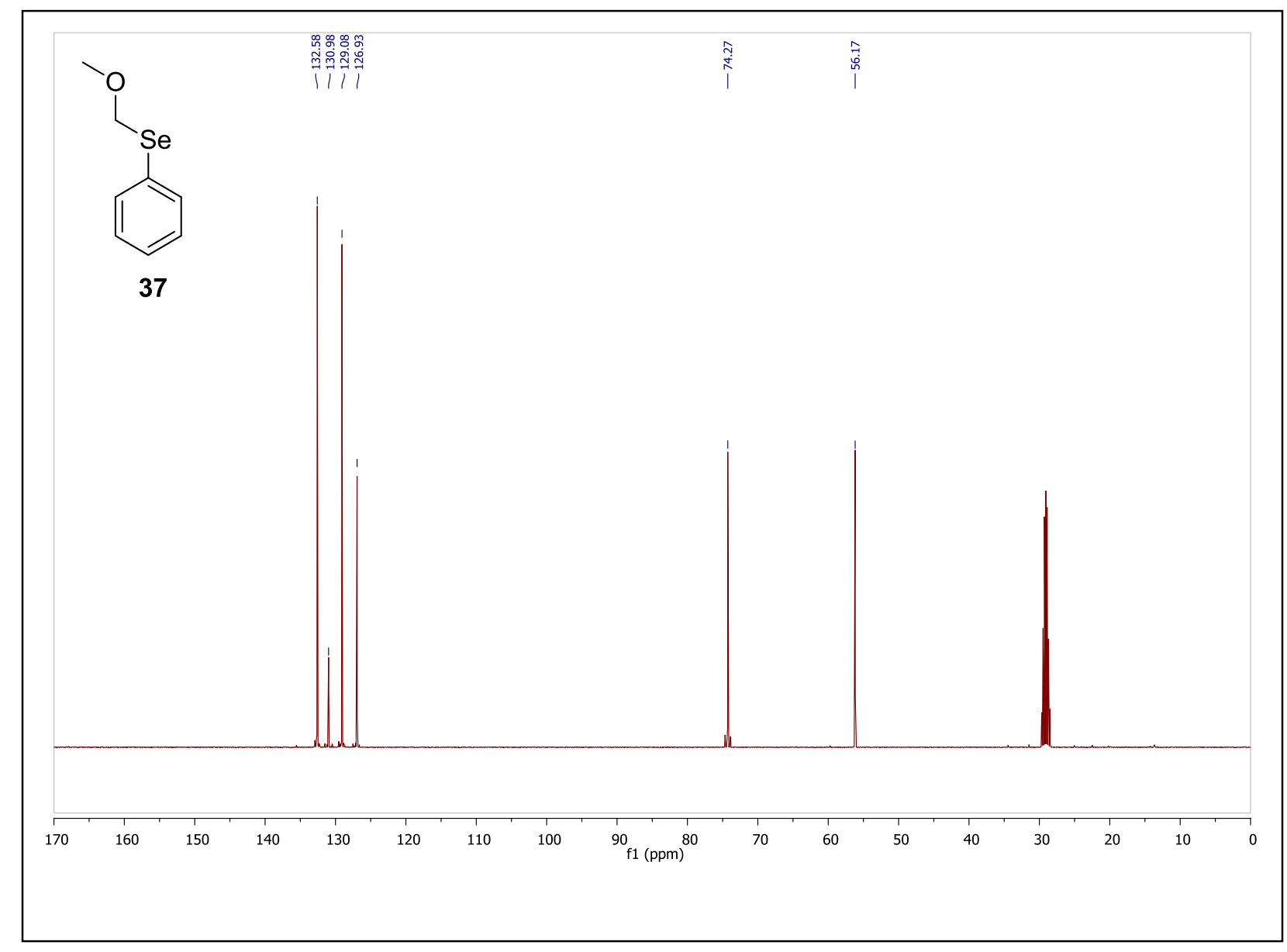


${ }^{1} \mathrm{H}-\mathrm{NMR}$ of 37 in $\left(\mathrm{CD}_{3}\right)_{2} \mathrm{CO}$ (aromatic expansion)

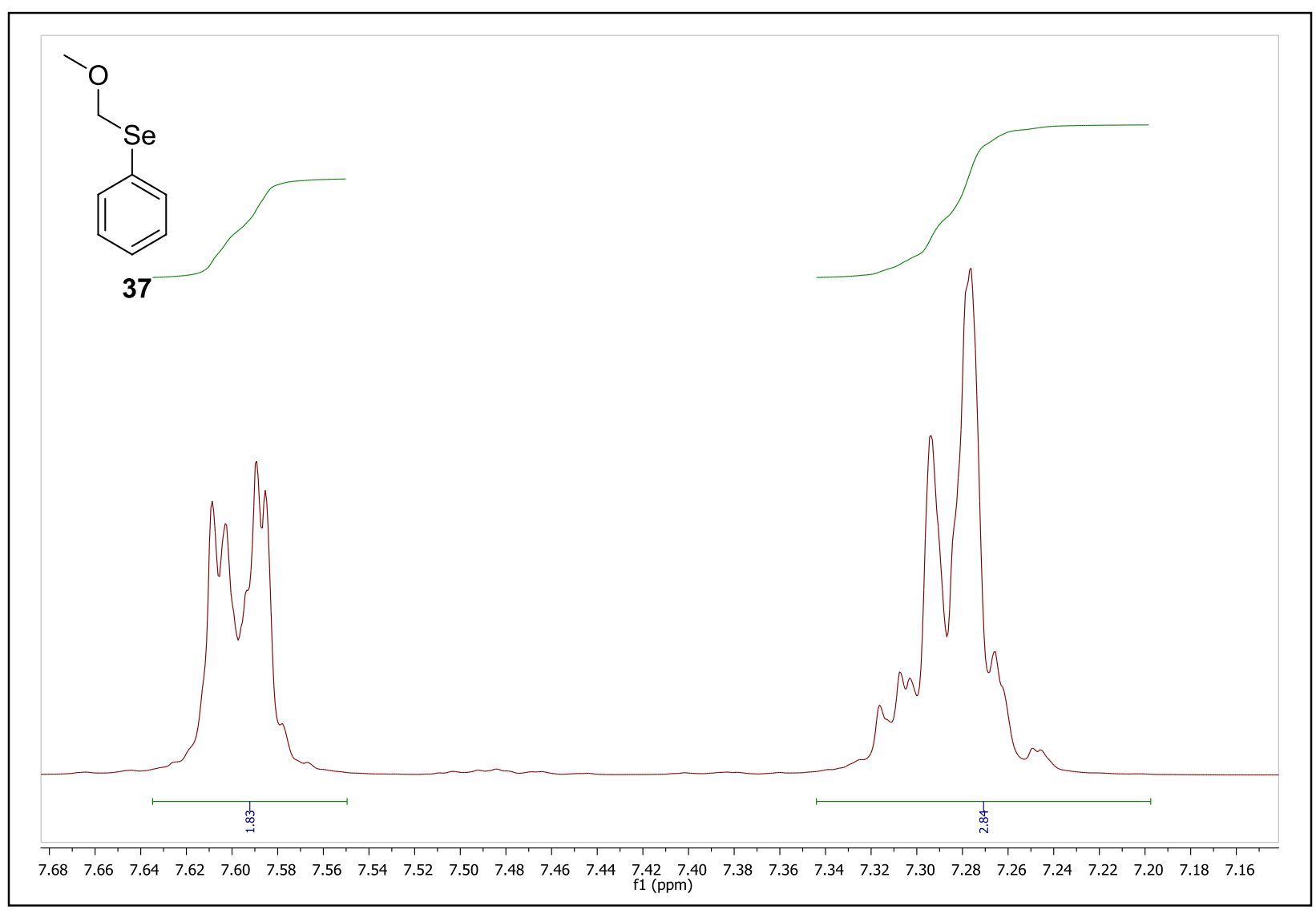


${ }^{1} \mathrm{H}-\mathrm{NMR}$ of 37 in $\left(\mathrm{CD}_{3}\right)_{2} \mathrm{CO}$ (alkyl expansion)

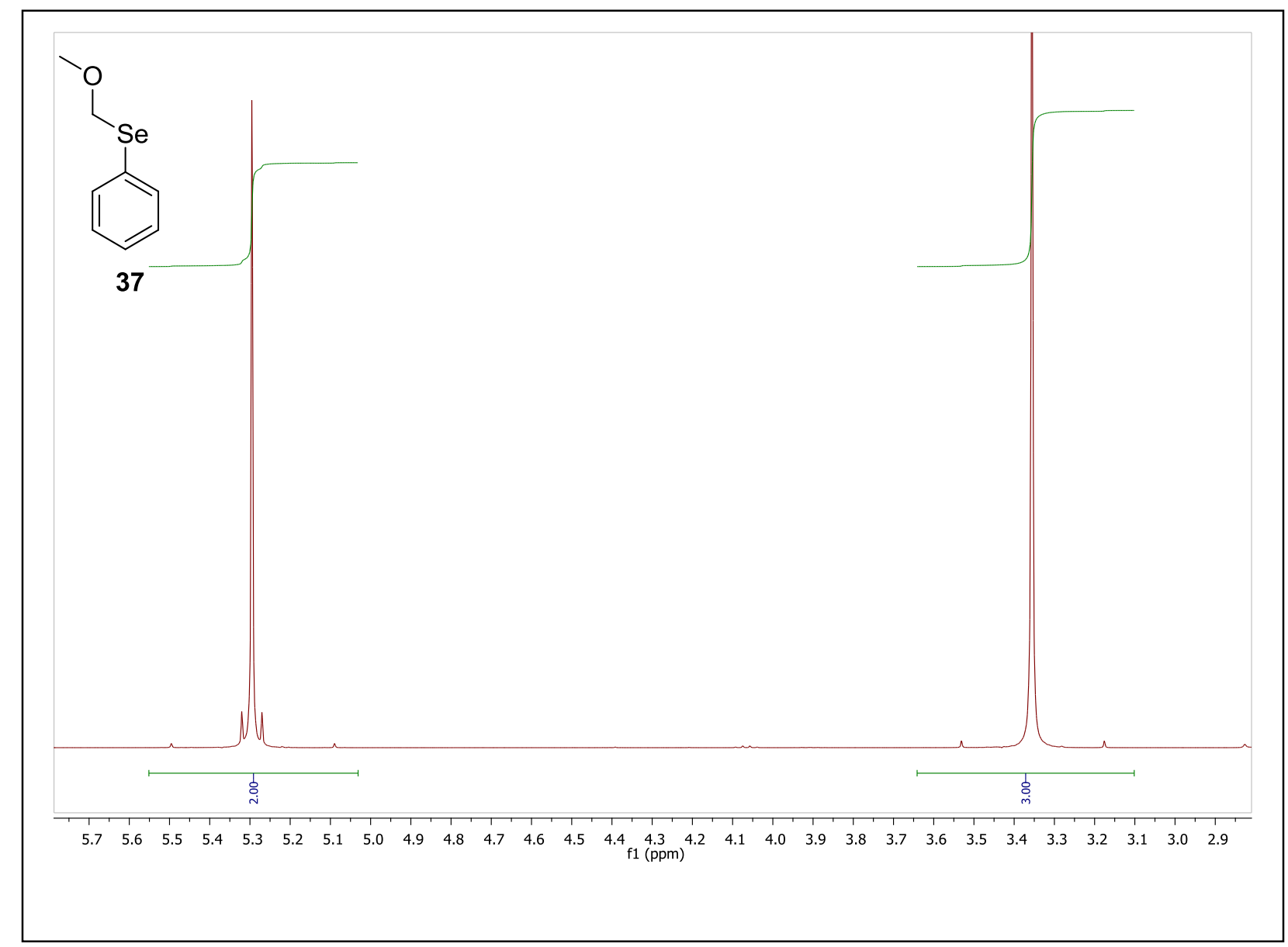


${ }^{1} \mathrm{H}-\mathrm{NMR}$ of 37 in $\mathrm{CDCl}_{3}$

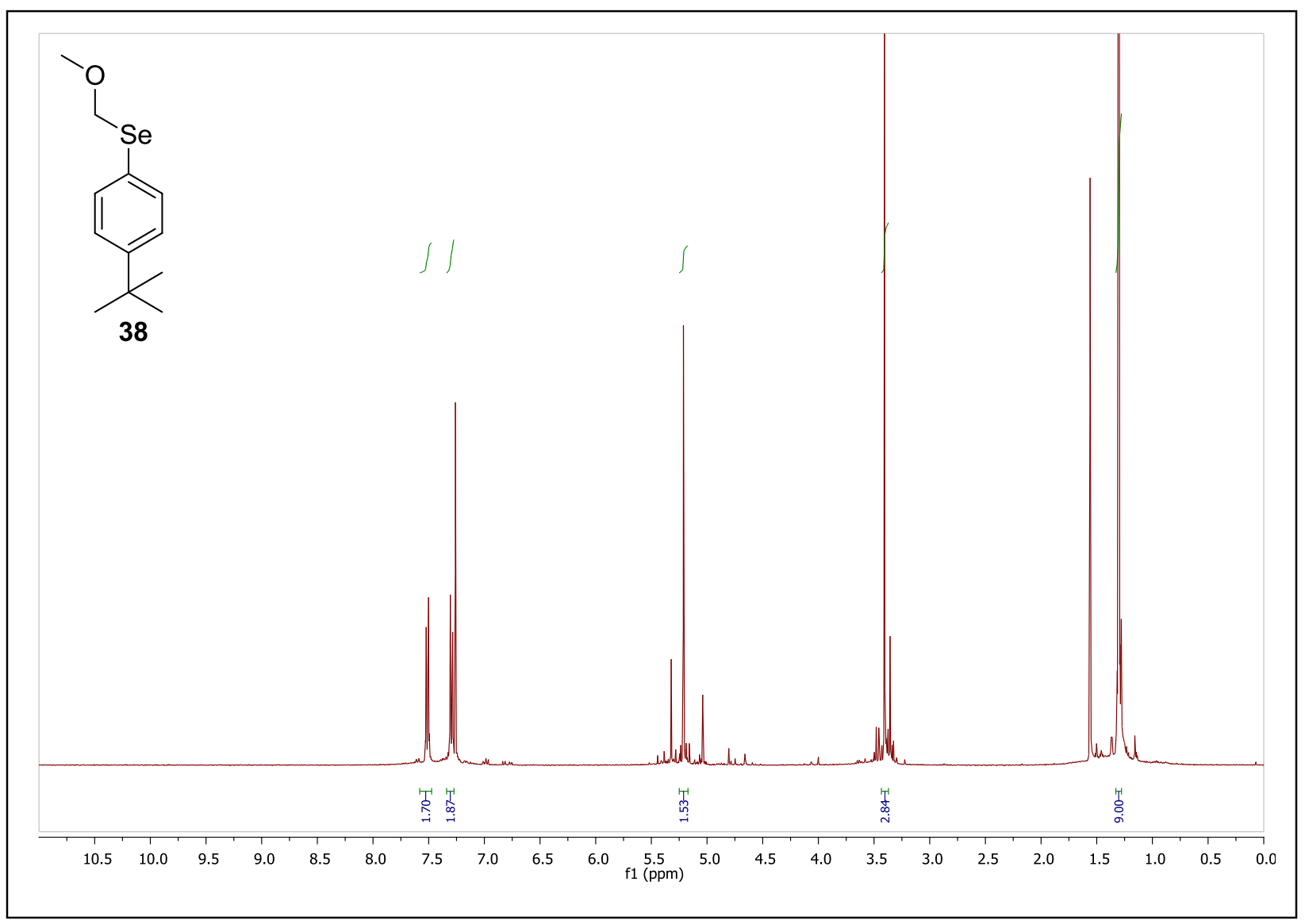


${ }^{13} \mathrm{C}-\mathrm{NMR}$ of $\mathbf{3 8}$ in $\mathrm{CDCl}_{3}$

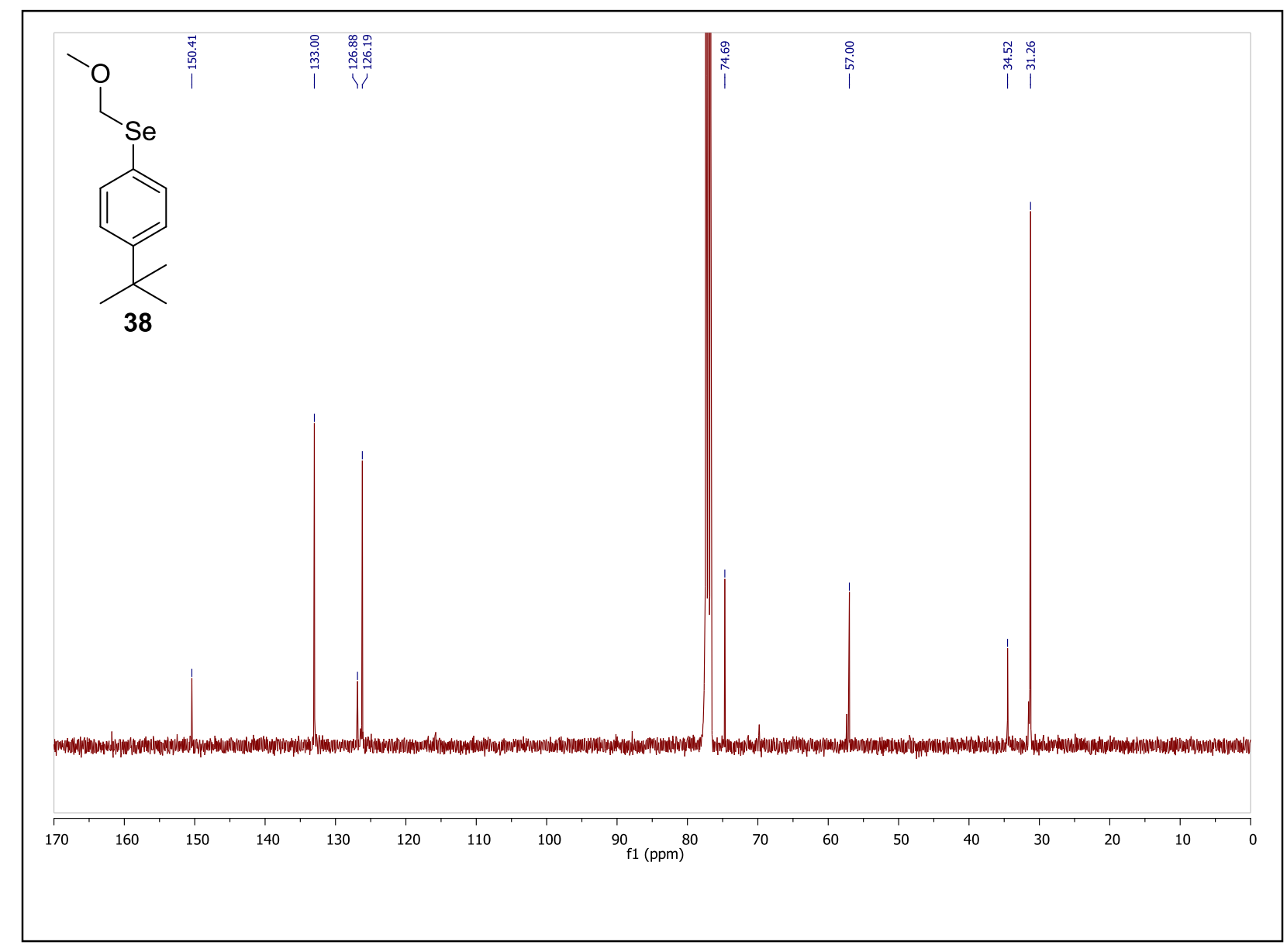


${ }^{1} \mathrm{H}-\mathrm{NMR}$ of $\mathbf{3 8}$ in $\mathrm{CDCl}_{3}$ (aromatic expansion)

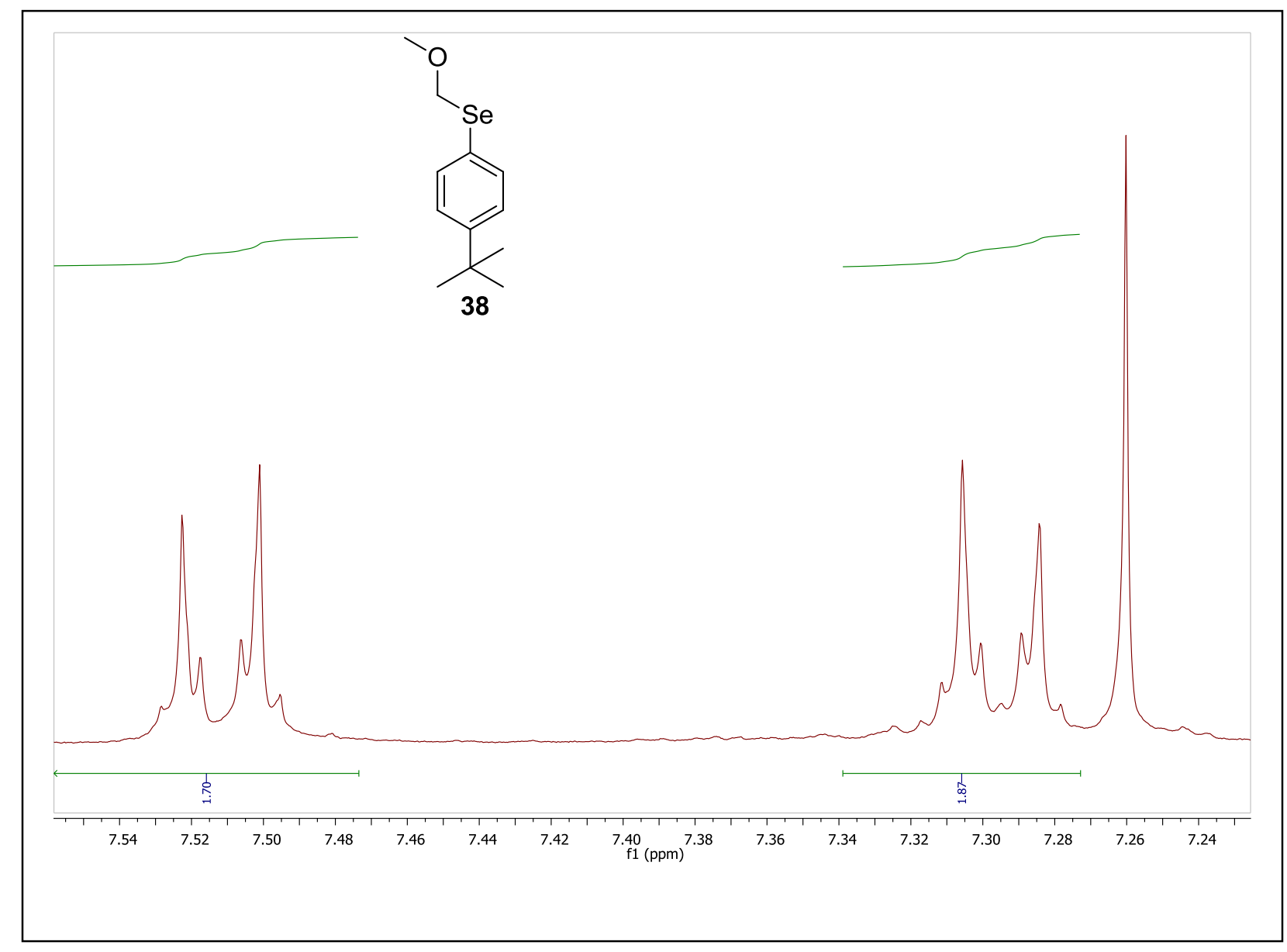


${ }^{1} \mathrm{H}-\mathrm{NMR}$ of 38 in $\mathrm{CDCl}_{3}$ (alkyl expansion)

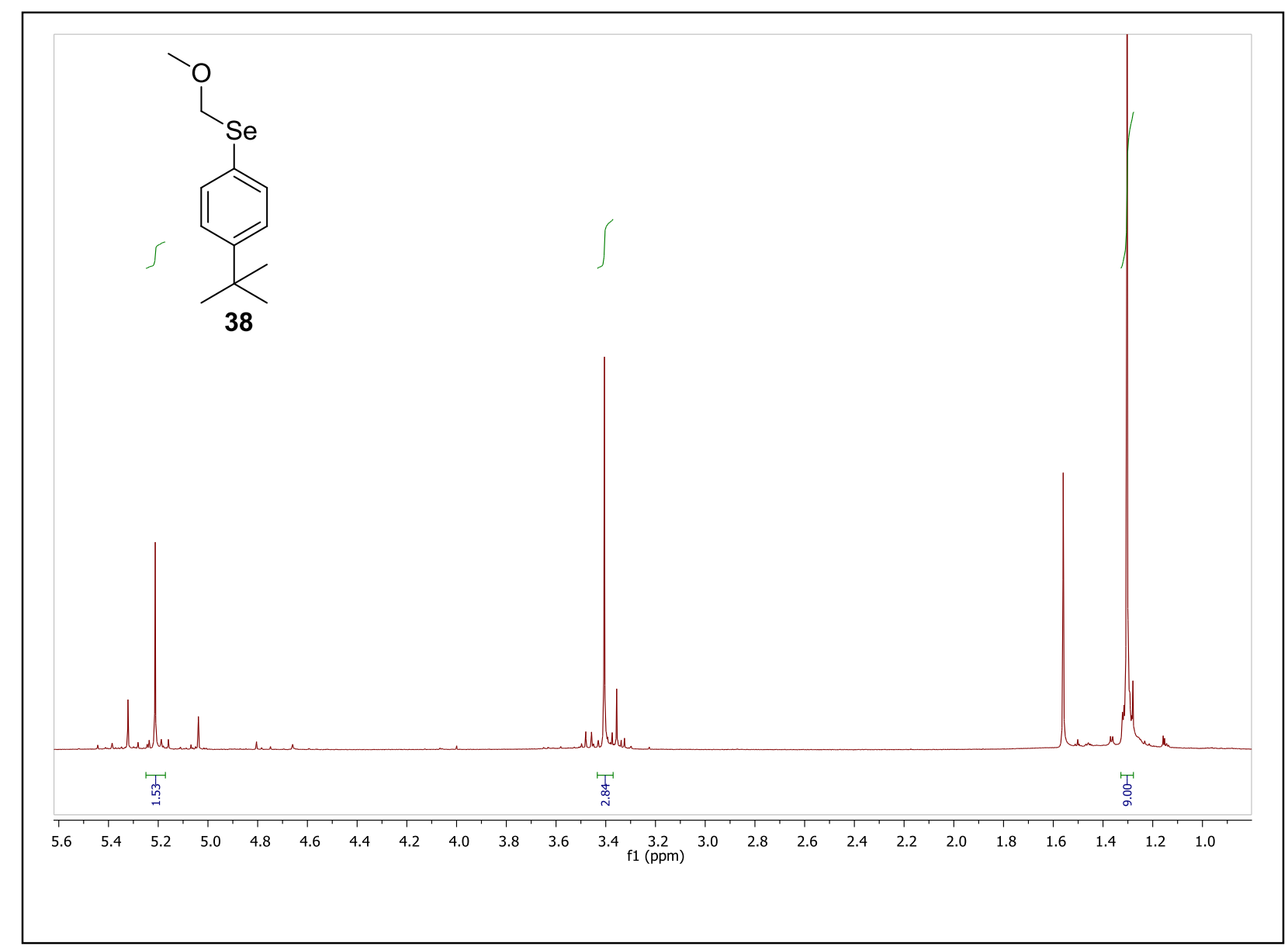


${ }^{1} \mathrm{H}-\mathrm{NMR}$ of $\mathbf{2 6}$ in $\left(\mathrm{CD}_{3}\right)_{2} \mathrm{SO}$

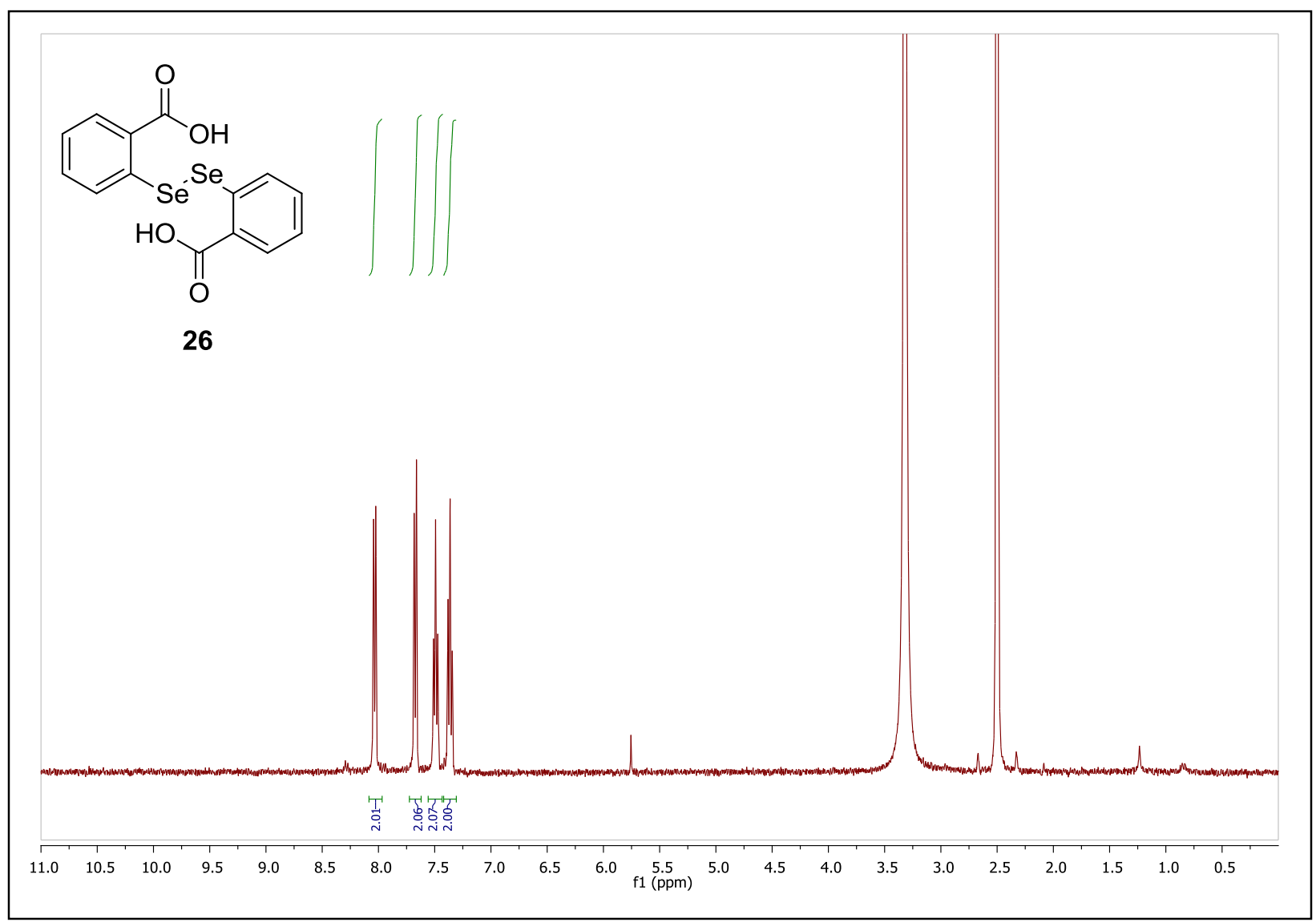


${ }^{1} \mathrm{H}-\mathrm{NMR}$ of 26 in $\left(\mathrm{CD}_{3}\right)_{2} \mathrm{SO}$ (alkyl expansion)

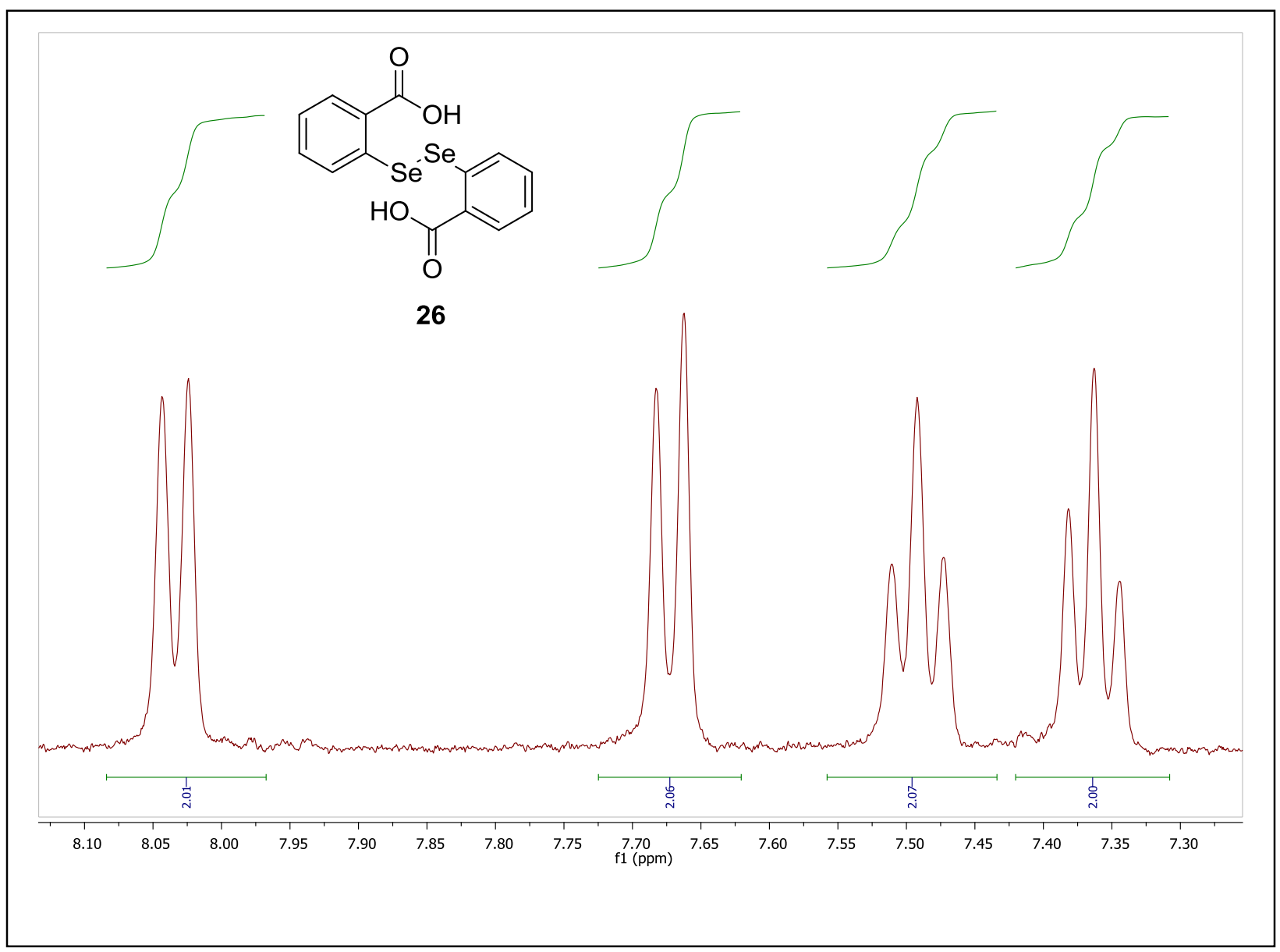


${ }^{1} \mathrm{H}-\mathrm{NMR}$ of $\mathbf{1 6}$ in $\left(\mathrm{CD}_{3}\right)_{2} \mathrm{CO}$

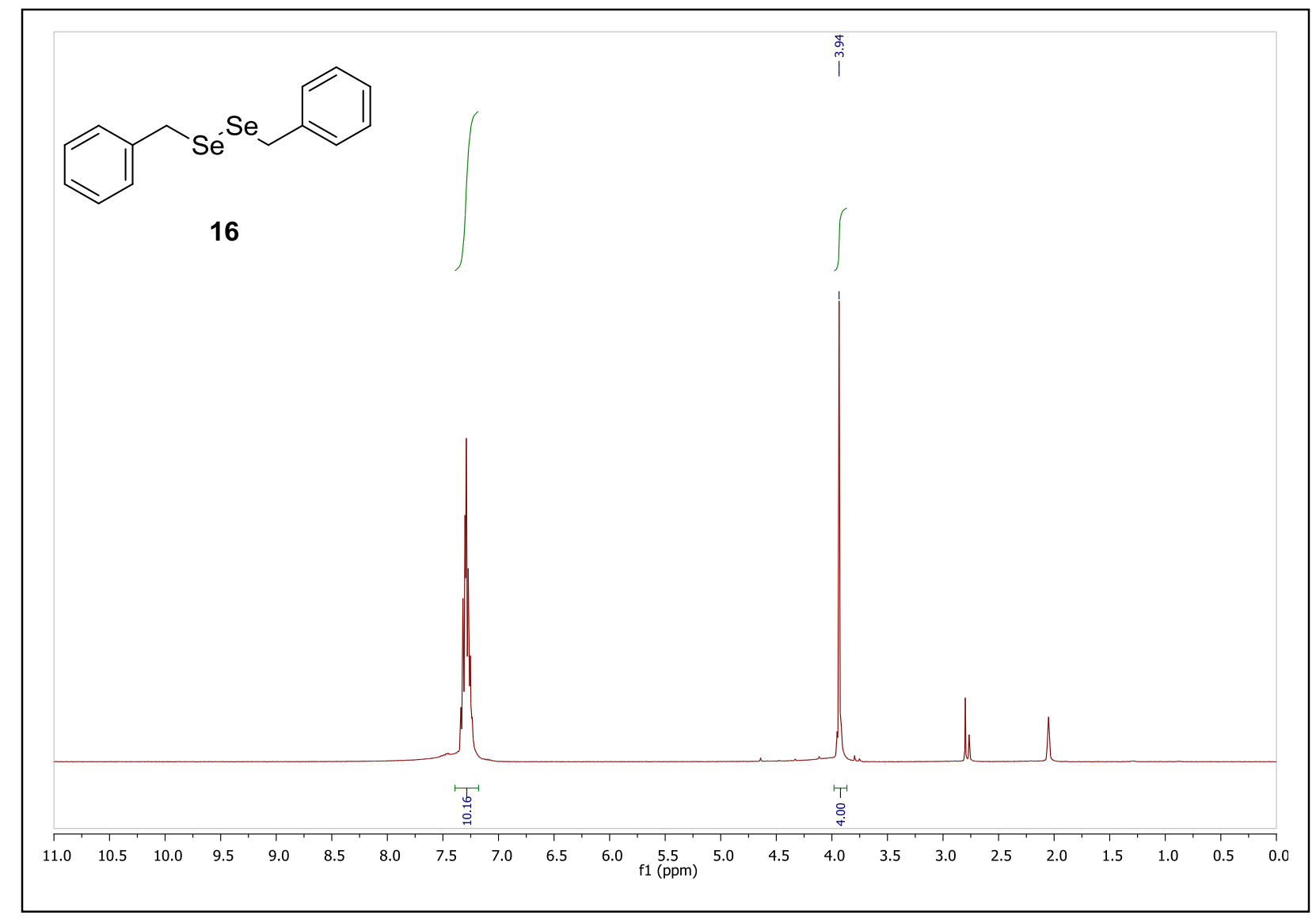


${ }^{13} \mathrm{C}-\mathrm{NMR}$ of $\mathbf{1 6}$ in $\left(\mathrm{CD}_{3}\right)_{2} \mathrm{CO}$

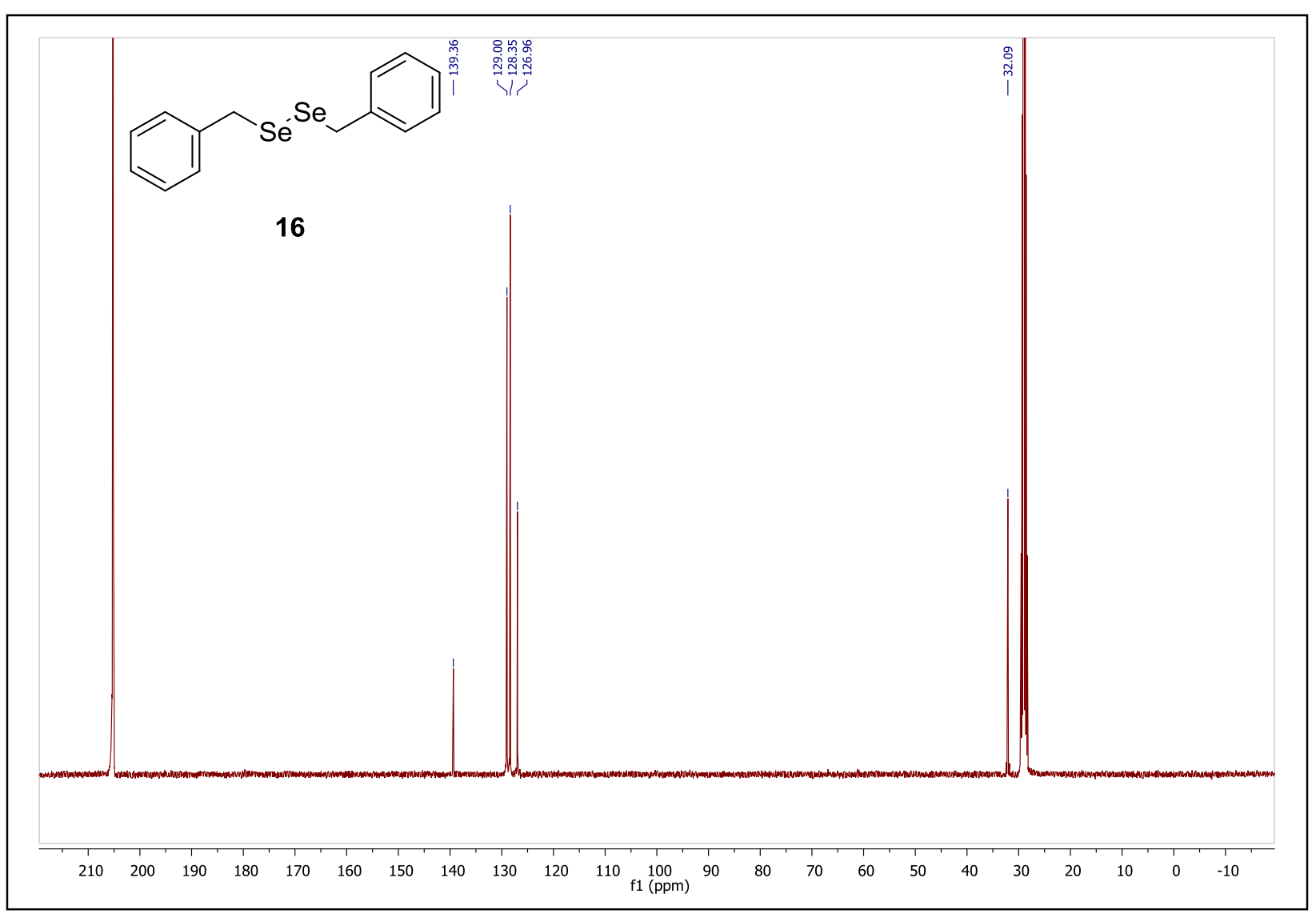


${ }^{1} \mathrm{H}-\mathrm{NMR}$ of $\mathbf{3}$ in $\mathrm{CDCl}_{3}$

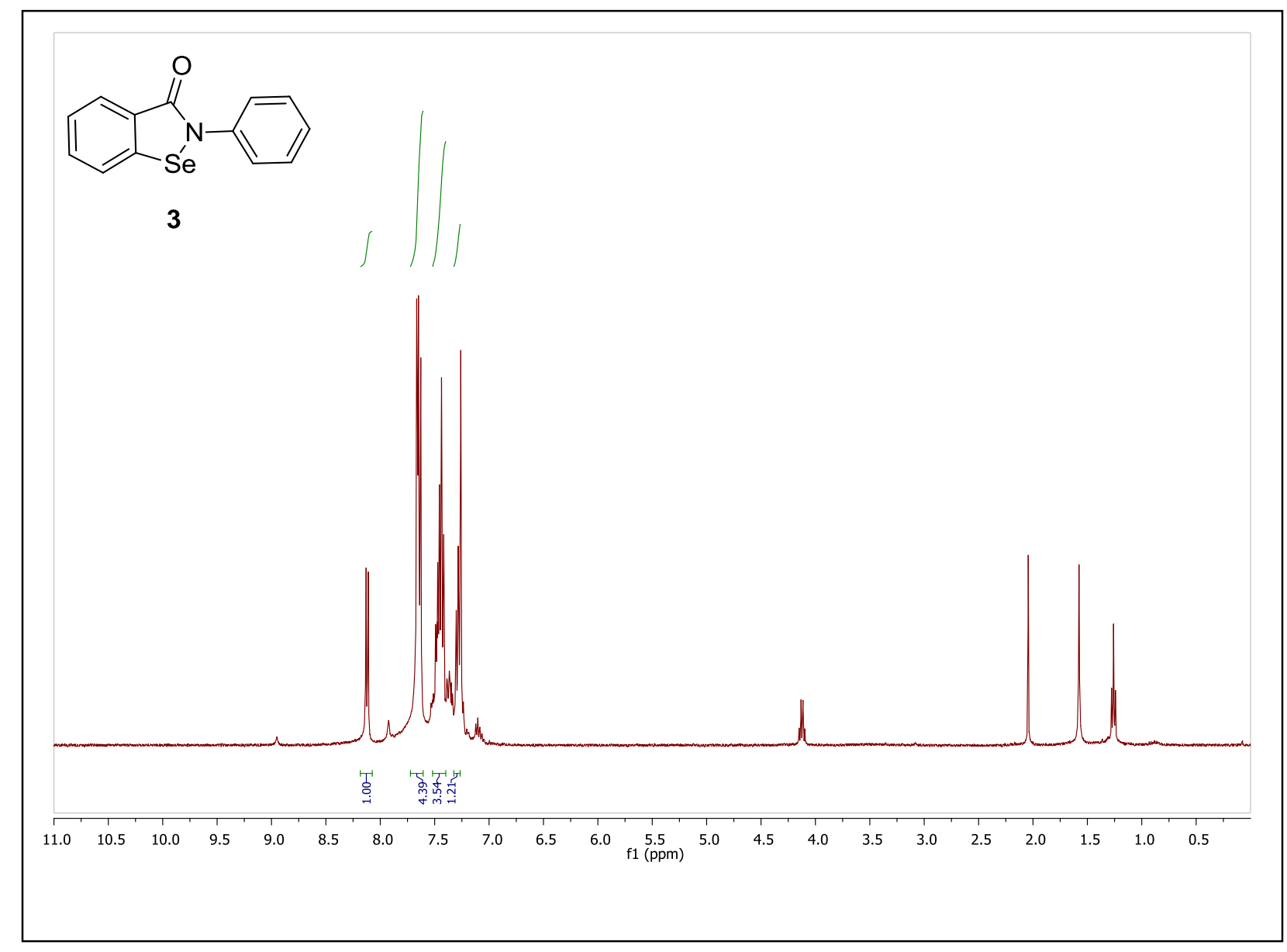


${ }^{13} \mathrm{C}-\mathrm{NMR}$ of $\mathbf{3}$ in $\mathrm{CDCl}_{3}$

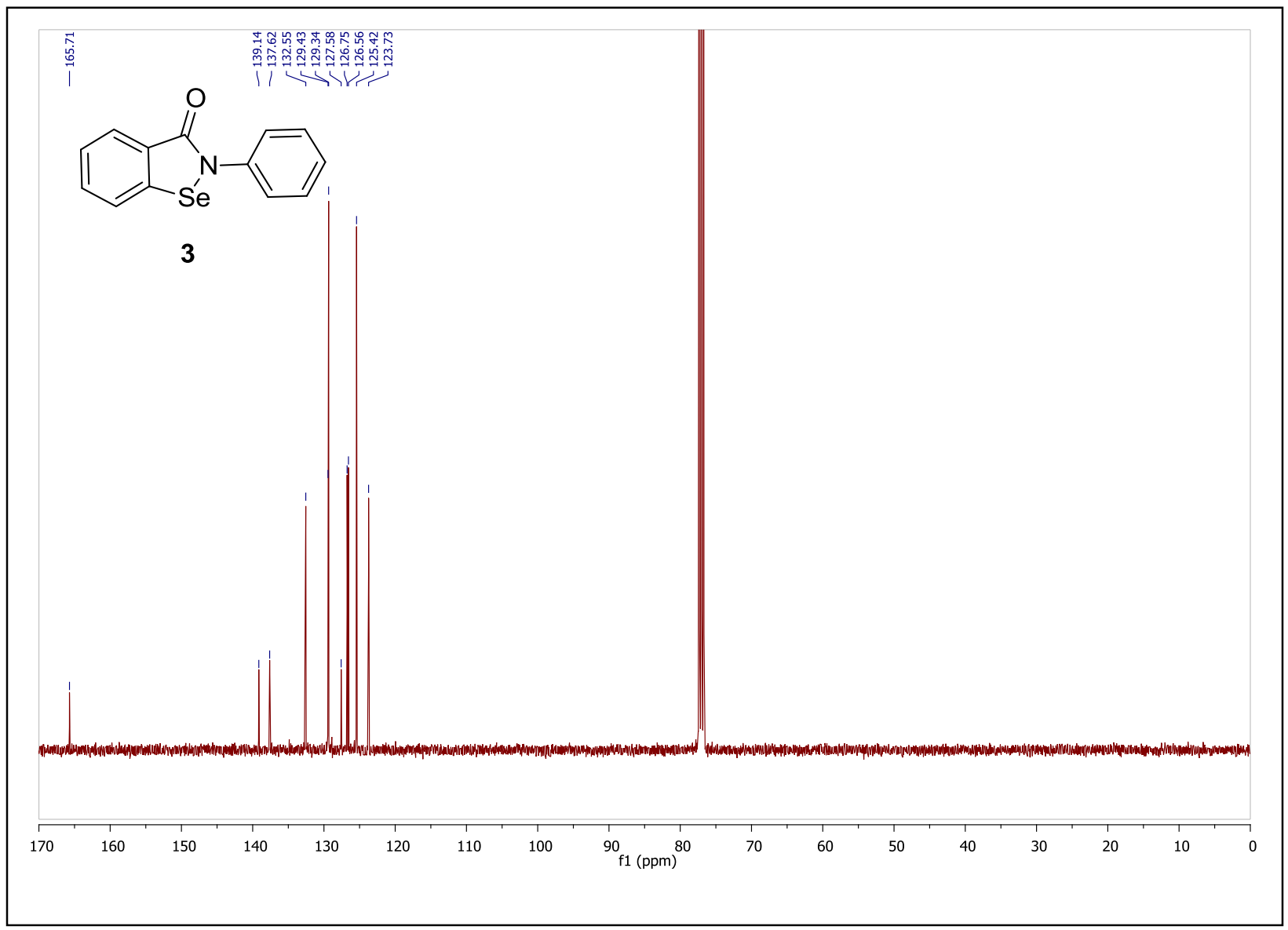


${ }^{1} \mathrm{H}-\mathrm{NMR}$ of $\mathbf{3}$ in $\mathrm{CDCl}_{3}$ (alkyl expansion)

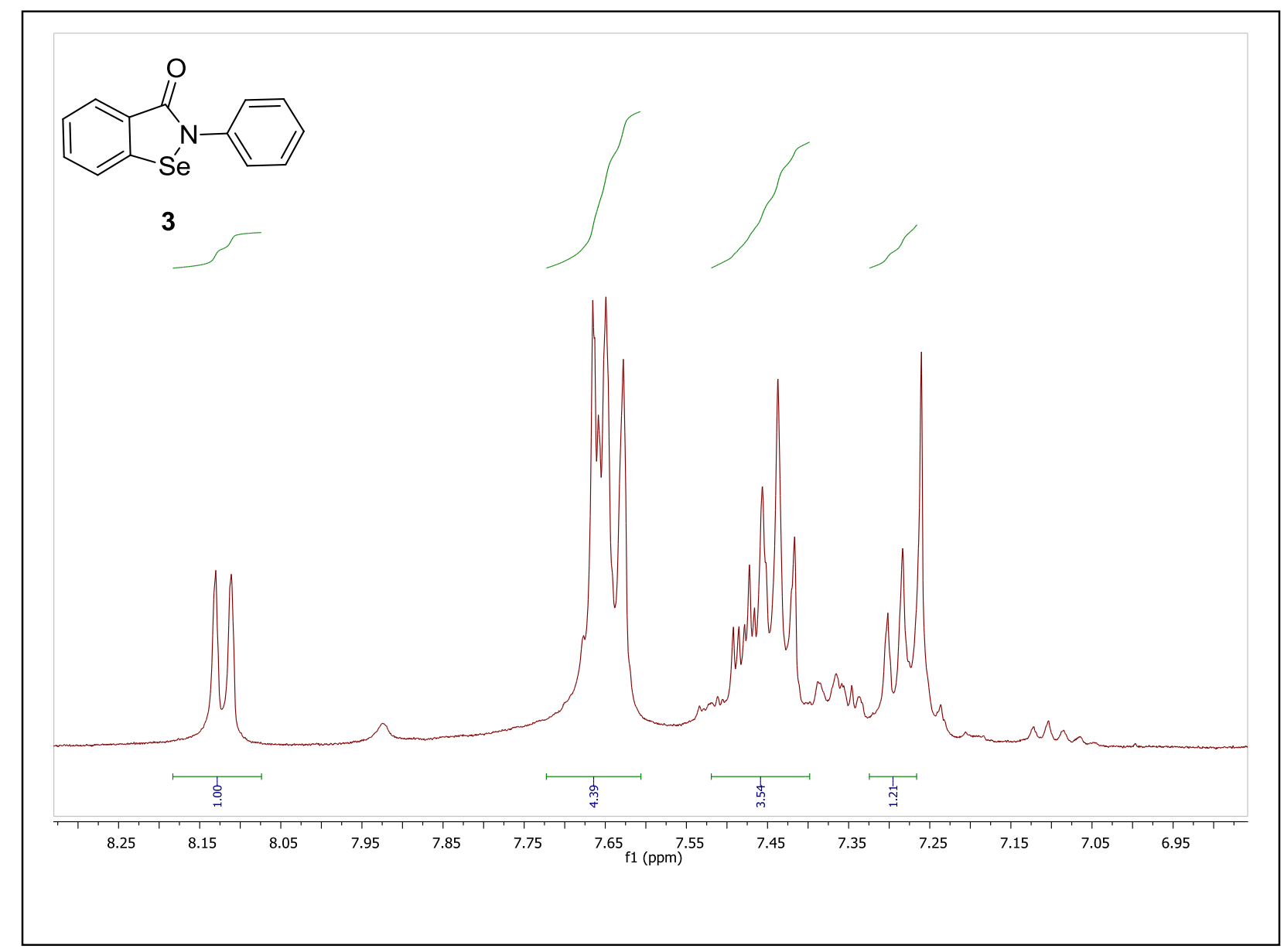


${ }^{1} \mathrm{H}-\mathrm{NMR}$ of 14 in $\left(\mathrm{CD}_{3}\right)_{2} \mathrm{SO}$

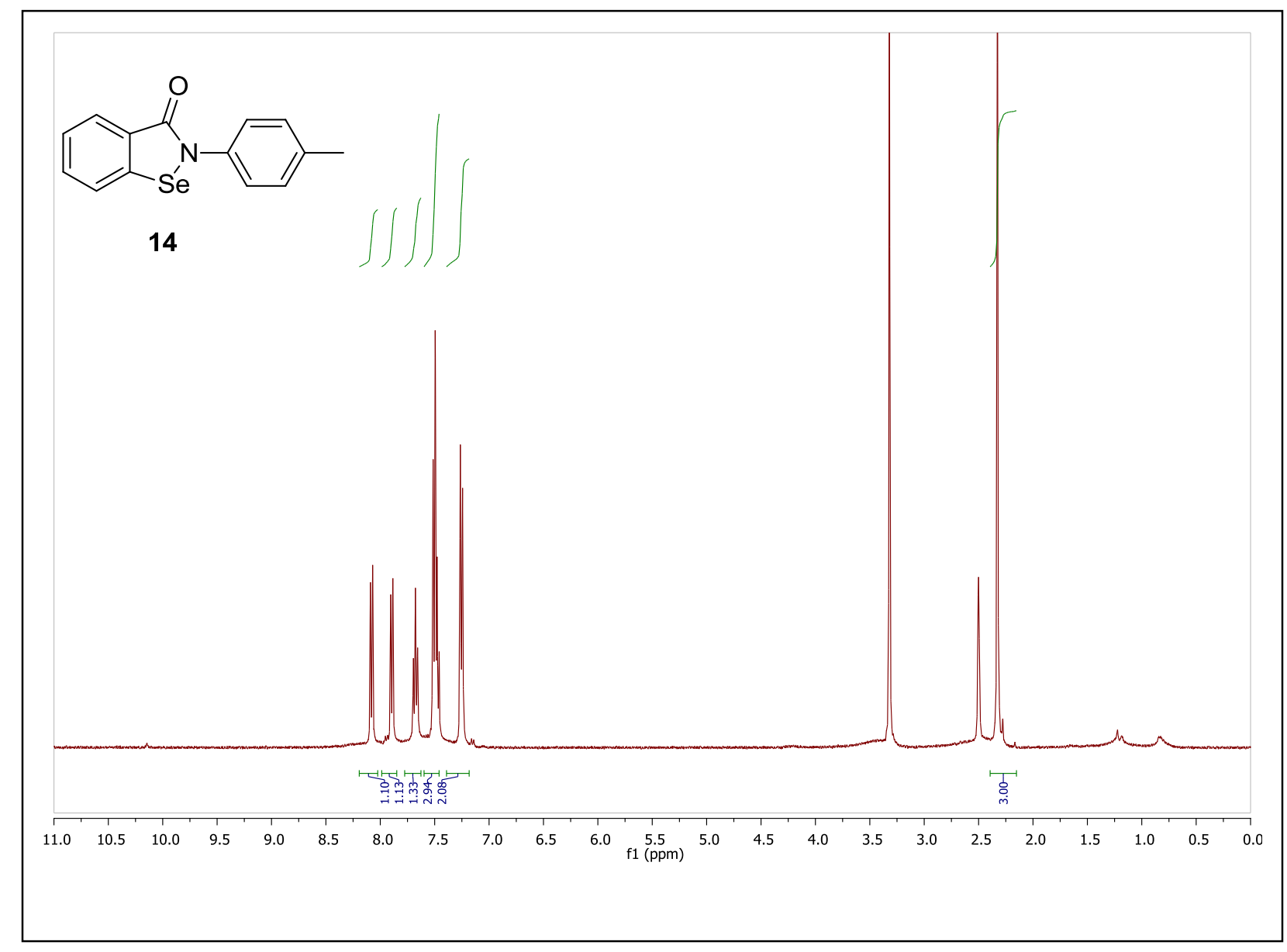


${ }^{13} \mathrm{C}-\mathrm{NMR}$ of $\mathbf{1 4}$ in $\left(\mathrm{CD}_{3}\right)_{2} \mathrm{SO}$

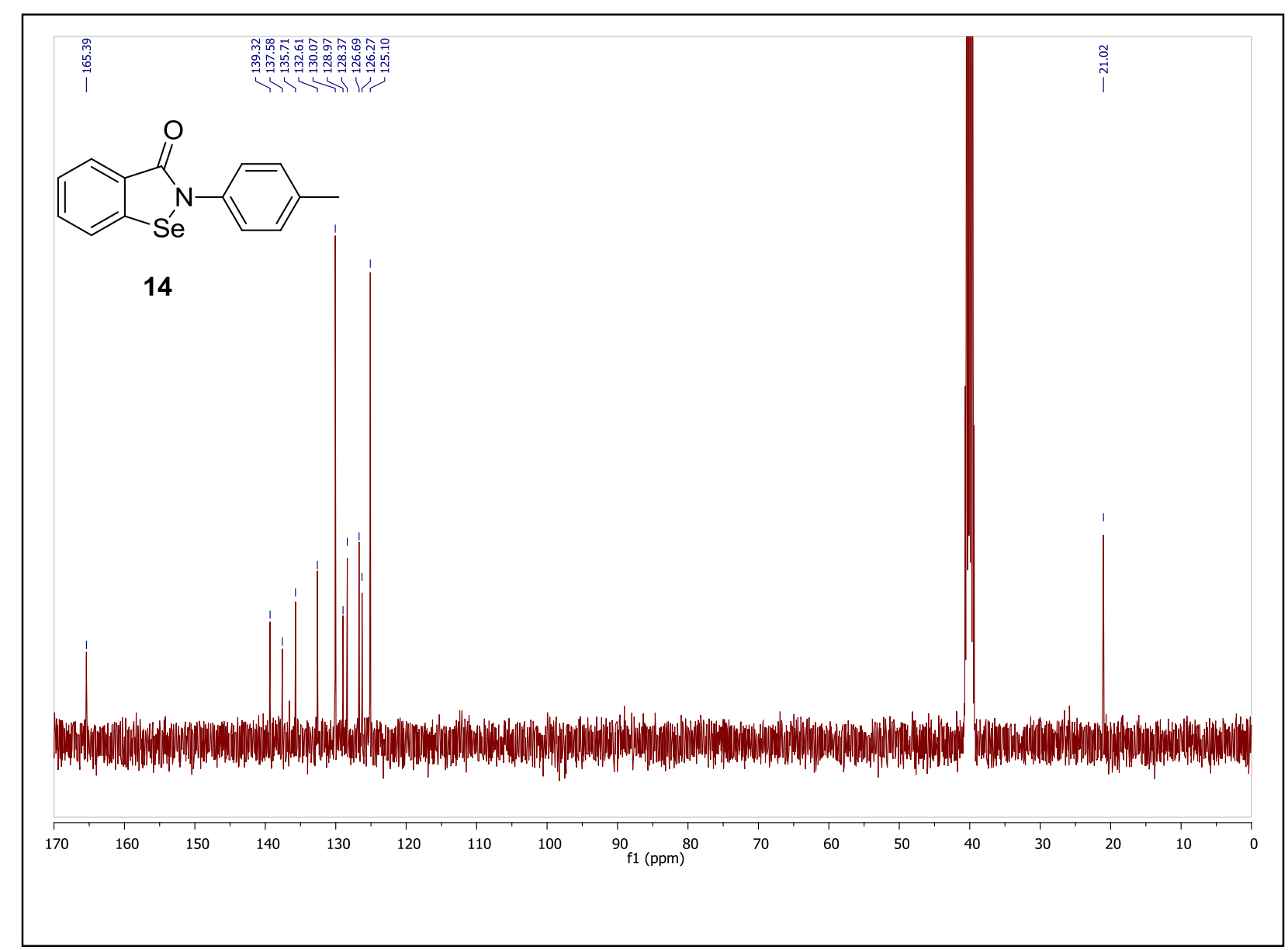


${ }^{1} \mathrm{H}-\mathrm{NMR}$ of 14 in $\left(\mathrm{CD}_{3}\right)_{2} \mathrm{SO}$ (aromatic expansion)

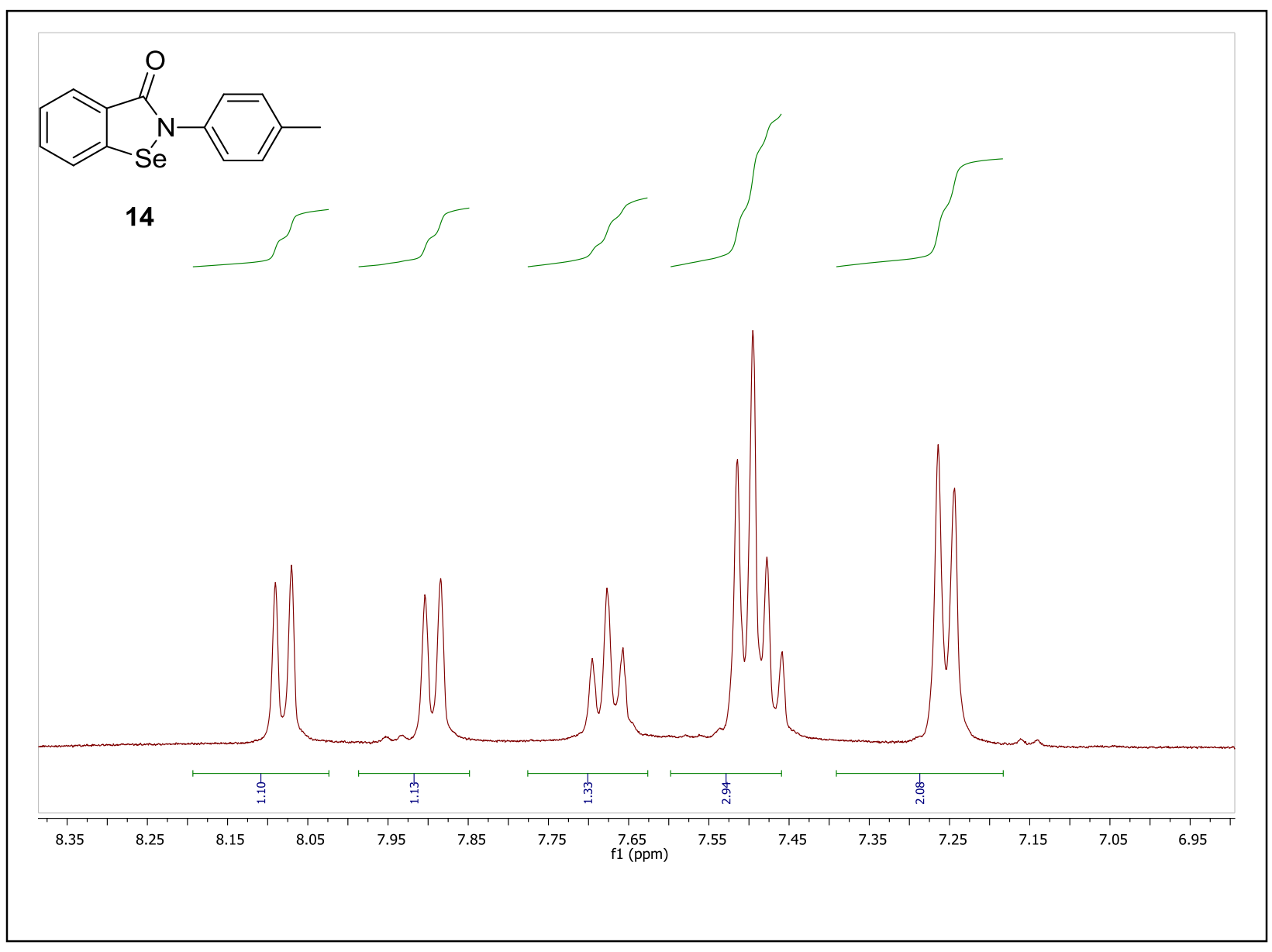




\section{References}

1) Glasauer, A.; Chandel, N. S. ROS. Curr. Biol. 2013, 23, 100-102.

2) Suzuki, K. Anti-Oxidants for Therapeutic Use: Why Are Only a Few Drugs in Clinical Use? Adv. Drug Deliv. Rev. 2009, 61, 287-289.

3) Sanz, A. Mitochondrial Reactive Oxygen Species: Do They Extend or Shorten Animal Lifespan? Biochim. Biophys. Acta 2016, xxx, xxx - xxx.

4) Callegari, A. J. Does Transcription-Associated DNA Damage Limit Lifespan? DNA Repair (Amst). 2016, 41, 1-7.

5) Sena, L. A.; Chandel, N. S. Physiological Roles of Mitochondrial Reactive Oxygen Species. Mol. Cell 2012, 48, 158-166.

6) Wirth, T. Small Organoselenium Compounds: More than Just Glutathione Peroxidase Mimics. Angew. Chem. Int. Ed. 2015, 54, 10074-10076.

7) Byun, B. J.; Kang, Y. K. Conformational Preferences and pKa Value of Selenocysteine Residue. Biopolymers 2011, 95, 345-353.

8) Soriano-Garcia, M. Organoselenium Compounds as Potential Therapeutic and Chemopreventive Agents: A Review. Curr. Med. Chem. 2004, 1657-1669.

9) Wolters, L. P.; Orian, L. Peroxidase Activity of Organic Selenides: Mechanistic Insights from Quantum Chemistry. Curr. Org. Chem. 2016, 20, 189-197.

10) Nordberg, J.; Arnér, E. S. J. Reactive Oxygen Species, Antioxidants, and the Mammalian Thioredoxin System. Free Radic. Biol. Med. 2001, 31, 1287-1312. 
11) Orian, L.; Toppo, S. Organochalcogen Peroxidase Mimetics as Potential Drugs: A Long Story of a Promise Still Unfulfilled. Free Radic. Biol. Med. 2014, 66, 65-74.

12) Arakawa, M.; Ito, Y. N-Acetylcysteine and Neurodegenerative Diseases: Basic and Clinical Pharmacology. The Cerebellum 2007, 6, 308-314.

13) Meotti, F. C.; Borges, V. C.; Zeni, G.; Rocha, J. B. T.; Nogueira, C. W. Potential Renal and Hepatic Toxicity of Diphenyl Diselenide, Diphenyl Ditelluride and Ebselen for Rats and Mice. Toxicol. Lett. 2003, 143, 9-16.

14) Parnham, M. J.; Sies, H. The Early Research and Development of Ebselen. Biochem. Pharmacol. 2013, 86, 1248-1253.

15) Sarma, B.; Mugesh, G. Glutathione Peroxidase (GPx)-like Antioxidant Activity of the Organoselenium Drug Ebselen: Unexpected Complications with Thiol Exchange Reactions. J. Am. Chem. Soc. 2005, 11477-11485.

16) Mugesh, G.; du Mont, W.; Sies, H. Chemistry of Biologically Important Synthetic Organoselenium Compounds. Chem. Rev. 2001, 2125-2179.

17) Luo, Z.; Sheng, J.; Sun, Y.; Lu, C.; Yan, J.; Liu, A.; Luo, H. Bin; Huang, L.; Li, X. Synthesis and Evaluation of Multi-Target-Directed Ligands against Alzheimer's Disease Based on the Fusion of Donepezil and Ebselen. J. Med. Chem. 2013, 56, 9089-9099.

18) Mao, F.; Chen, J.; Zhou, Q.; Luo, Z.; Huang, L.; Li, X. Novel Tacrine-Ebselen Hybrids with Improved Cholinesterase Inhibitory, Hydrogen Peroxide and Peroxynitrite Scavenging Activity. Bioorganic Med. Chem. Lett. 2013, 23, 6737-6742.

19) Lisiak, R.; Mlochowski, J.; Palus, J. Nucleophilic Cleavage of Selenaheterocyclic Ring in 
Benzisoselenazol-3(2 H)-Ones and 1,3,2-Benzodiselenazoles. Polish J. Chem 2007, 14031411.

20) Lesser, R.; R. Weiß. Uber Selenhaltige Aromatische Verbindungen. Chem. Ber. 1924, 1077-1082.

21) Engman, L. Expedient Synthesis of Ebselen and Related Compounds. J. Org. Chem. 1989, $54,2966-2968$.

22) Balkrishna, S. J.; Bhakuni, B. S.; Chopra, D.; Kumar, S. Cu-Catalyzed Efficient Synthetic Methodology for Ebselen and Related Se-N Heterocycles. Org. Lett. 2010, 12, 53945397.

23) Qiu, R.; Reddy, V. P. rakash; Iwasaki, T.; Kambe, N. The Palladium-Catalyzed Intermolecular C-H Chalcogenation of Arenes. J. Org. Chem. 2015, 80, 367-374.

24) Snieckus, V. Directed Ortho Metalation. Tertiary Amide and O-Carbamate Directors in Synthetic Strategies for Polysubstituted Aromatics. Chem. Rev. 1990, 90, 879-933.

25) Barbier, J.; Wegner, J.; Benson, S.; Gentzsch, J.; Pietschmann, T.; Kirschning, A. Total Synthesis of a Noricumazole A Library and Evaluation of HCV Inhibition. Chem. - A Eur. J. 2012, 18, 9083-9090.

26) Pietka-Ottlik, M.; Potaczek, P.; Piasecki, E.; Mlochowski, J. Crucial Role of Selenium in the Virucidal Activity of Benzisoselenazol-3(2H)-Ones and Related Diselenides. Molecules 2010, 15, 8214-8228.

27) Balkrishna, S. J.; Kumar, A.; Panini, P.; Kumar, S.; Kumar, S. Synthesis, Characterization and Crystal Structure of 2-((4-Bromophenyl) Carbamoyl) Phenylselenenyl Bromide 
Derived from Oxidative Addition of Bromine to 2-Phenyl-1,2-Benzoisoselenazol-3-(2H)One. Indian J. Chem. 2013, 52A, 1078-1085.

28) Wang, J.-X.; Cui, W.; Hu, Y. Convenient Synthesis of Dibenzyl Diselenides under Phase Transfer Conditions. J. Chem. Soc. Perkin Trans. 1 1994, 2341-2343.

29) Schröder, N.; Wencel-Delord, J.; Glorius, F. High-Yielding, Versatile, and Practical [Rh(III)Cp*]-Catalyzed Ortho Bromination and Iodination of Arenes. J. Am. Chem. Soc. 2012, 134, 8298-8301.

30) Kamigata, N.; Iizuka, H.; Izuoka, A.; Kobayashi, M. Photochemical Reaction of 2-Aryl1,2-Benzisoselenazol-3(2H)-Ones. Bull. Chemi. Soci. Jpn 1986, 59, 2179-2183.

31) Krief, A.; Derock, M. Synthesis of Diselenides and Selenides from Elemental Selenium. Tetrahedron Lett. 2002, 43, 3083-3086.

32) He, J.; Li, D.; Xiong, K.; Ge, Y.; Jin, H.; Zhang, G.; Hong, M.; Tian, Y.; Yin, J.; Zeng, H. Inhibition of Thioredoxin Reductase by a Novel Series of Bis-1,2-Benzisoselenazol3(2H)-Ones: Organoselenium Compounds for Cancer Therapy. Bioorganic Med. Chem. 2012, 20, 3816-3827.

33) Barral, K.; Moorhouse, A. D.; Moses, J. E. Efficient Conversion of Aromatic Amines into Azides: A One-Pot Synthesis of Triazole Linkages Efficient Conversion of Aromatic Amines into Azides: A One-Pot Synthesis of Triazole Linkages. Drug Discov. Today 2007, 11-14.

34) Fahrenwaldt, T.; Fischer, C.; Matin, A.; Iqbal, J. Synthesis and Antiproliferative Activity of Selenoindirubins and Selenoindirubin-N-Glycosides. Biomol. Chem. 2013, 11, 3963- 
3978.

35) Sathyamurthy, R.; Brumaghim, J.; Vanderveer, D. Structure of "bis(methoxymagnesium) Diselenide": A Reagent for the Introduction of Selenium into Organic Molecules. J. Chem. Crystallogr. 2007, 37, 109-117.

36) Foster, D. G. Selenophenol. Org. Synth. 1944, 24, 89.

37) Anciaux, A.; Eman, A.; Dumont, W.; Krief, A. Reactivity of Mixed Sulfo-Seleno Acetals And Oxo-Seleno Acetals With N-Butyllithium: A New Route To Substituted Epoxides. Tettrahedron Lett. 1975, 19, 1617-1620.

38) Balkrishna, S. J.; Kumar, S.; Azad, G. K.; Bhakuni, B. S.; Panini, P.; Ahalawat, N.; Tomar, R. S.; Detty, M. R.; Kumar, S. An Ebselen like Catalyst with Enhanced GPx Activity via a Selenol Intermediate. Org. Biomol. Chem. 2014, 12, 1215-1219.

39) Pacuła, A. J.; Ścianowski, J.; Aleksandrzak, K. B. Highly Efficient Synthesis and Antioxidant Capacity of $N$-Substituted Benzisoselenazol-3(2H)-Ones. $R S C A d v$. 2014, 4, 48959-48962. 